Florida International University

FIU Digital Commons

FIU Electronic Theses and Dissertations

University Graduate School

$11-23-1992$

\title{
The development and validation of a preschool screening instrument for the identification of language impaired and educable mentally handicapped Head Start children
}

Samuel Corrado

Florida International University

DOI: $10.25148 /$ etd.FI14061520

Follow this and additional works at: https://digitalcommons.fiu.edu/etd

Part of the Special Education and Teaching Commons

\section{Recommended Citation}

Corrado, Samuel, "The development and validation of a preschool screening instrument for the identification of language impaired and educable mentally handicapped Head Start children" (1992). FIU Electronic Theses and Dissertations. 2588.

https://digitalcommons.fiu.edu/etd/2588 


\title{
ABSTRACT OF THE DISSERTATION
}

The Development and Validation of a Preschool Screening Instrument for

The Identification of Language Impaired and Educable Mentally

Handicapped Head Start Children

by

\author{
Samuel Corrado
}

Florida International University, 1992

\author{
Miami, Florida
}

Professor Stephen S. Strichart, Major Professor

This study developed and validated a preschool screening instrument designed to identify children, enrolled in the Dade county Head start program, who would be found eligible for placement in a language impaired or educable mentally handicapped program in the Dade county Public schools (DCPS) system. Previously used commercial screening instruments were demonstrated to have unsatisfactory predictive validity. The new screening instrument was developed by utilizing already existing test items from a developmental skills assessment instrument, the Learning Accomplishment Profile-Diagnostic. These items were selected on the basis of their sensitivity and specificity hit rate scores. The reliability of the new screening instrument was established by using the test-retest and interrater methods. Predictive validity was established by using a double sample technique of 600 Head start children for each sample and the classification or hit rate method following a comprehensive evaluation process. The new screening instrument was found to be a more accurate predictor of the need for exceptional student education services than the commercial screening instruments. The results showed that predictions could be made with confidence when a preschool screening instrument is developed which clearly defines: a) the population to be screened; b) the population to be identified; c) the criteria to determine who will be referred for comprehensive assessment; and, d) the criteria for determining who is eligible for intervention services. 


\title{
FLORIDA INTERNATIONAL UNIVERSITY
}

\author{
Miami, Florida
}

The Development and Validation of a Preschool Screening Instrument for The Identification of Language Impaired and Educable Mentally Handicapped Head Start Children

A dissertation submitted in partial satisfaction of the requirements for the degree of Doctor of Education in Special Education

by

Samuel Corrado

1992 
To Professors Barry Greenberg, Philip Lazarus, and Stephen S. Strichart, Major Professor:

This dissertation, having been approved in respect to form and mechanical execution, is referred to you for judgement upon its substantial merit.

Dean I. Ira Goldenberg

College of Education

The dissertation of Samuel Corrado is approved.

Barry Greenberg

Philip Lazarus

Stephen S. Strichart, Major Professor

Date of Examination: November 23, 1992

Dean Richard L. Campbell

Division of Graduate Studies

Florida International University, 1992

(ii) 



\section{DEDICATION}

This work is dedicated to my parents,

Samuel G. and Anna Mae Corrado 


\section{ACKNOWLEDGMENTS}

The completion of this doctoral project was made possible by the many contributions of committee members, colleagues, and friends. First and foremost I would like to extend my most sincere expression of appreciation to Dr. Stephen Strichart, committee chairperson, for his guidance and assistance throughout the study. Dr. Strichart gave me the direction and helped me to remain focused during this long project and for this I will always be grateful. I would also like to extend my appreciation to Dr. Philip Lazarus and Dr. Barry Greenberg for their willingness to serve as committee members and for their encouragement and guidance throughout these years.

A special expression of appreciation is extended to Dr. Carole Abbott, for her scholarly assistance, critical insights, and inspiration.

Special mention is due to many people for their assistance with this project such as: Grace Laskis, Special Needs Coordinator for the Dade County Head Start program, who helped in scheduling and organizing the many mass screenings; Drs. Keith and Marcia Scott and Dr. Susan Gold, University of Miami Mailman Center for Child Development, who provided support in terms of personnel and equipment for the mass screenings; 
Dr. Eleanor Levine, Project Director of FDLRS/South, who as my supervisor provided much support for the project; Dr. Eydie Sloan, Enabling Technology Specialist at FDLRS/South, for her assistance with technology; Linda Bicky, Speech and Language Pathologist at the Hearing and Speech Center of Florida, who coordinated all of the language evaluations for the study; and finally all of the graduate assistants from the University of Miami and the School Psychology Interns from Florida International University whose work was invaluable for the completion of the project. 
1972

B.A., Social

Psychology, Florida

Atlantic University

Boca Raton, Florida

1974

B.A., Elementary

Education, Florida

Atlantic University

Boca Raton, Florida

1978

M.S., School Psychology

Florida International

University

Miami, Florida

1974-1977

Counselor and Teacher of the Severely Emotionally

Disturbed, Bertha Abess

Children's Center

Miami, Florida

1977-1978

Teacher for the Learning

Disabled, Bannatyne

Learning Resources Center

Miami, Florida

1978-1992

School Psychologist, Florida

Diagnostic and Learning

Resources Center-South

Miami, Florida 


\begin{tabular}{|c|c|}
\hline DEDICATION & iii \\
\hline ACKNOWLEDGMENTS & \\
\hline VITA & \\
\hline TABLE OF CONTENTS & vii \\
\hline LIST OF TABLES & ix \\
\hline LIST OF FIGURES & xvii \\
\hline CHAPTER I INTRODUCTION & \\
\hline PROBLEM & \\
\hline SCREENING MEASURES & 21 \\
\hline SCREENING TEST CONSTRUCTION & 21 \\
\hline PURPOSE & 25 \\
\hline NULL HYPOTHESES & 26 \\
\hline CHAPTER II METHOD & 27 \\
\hline SUBJECTS & 27 \\
\hline PROCEDURE & 30 \\
\hline DECISION RULES & 36 \\
\hline MATERIALS & 51 \\
\hline CHAPTER III RESULTS & 53 \\
\hline HIT RATE VALIDITY DATA & 53 \\
\hline
\end{tabular}


$\begin{array}{ll}\text { CHAPTER IV DISCUSSION } & 76\end{array}$

$\begin{array}{ll}\text { SUMMARY } & 76\end{array}$

IMPLICATIONS FOR PRACTICE

AREAS FOR FUTURE RESEARCH 80

LIMITATIONS $\quad 82$

CONCLUSIONS AND RECOMMENDATIONS 84

APPENDICES

A DEFINITION OF TERMS

B HIT RATE DATA FOR THE DENVER 93 DEVELOPMENTAL SCREENING TEST-R, THE DEVELOPMENTAL INDICATORS FOR THE ASSESSMENT OF LEARNING-R, THE DALLAS PRESCHOOL SCREENING TEST, AND THE BRIGANCE EARLY SCREEN

C DADE COUNTY PUBLIC SCHOOL'S PROCEDURAL GUIDELINES FOR LANGUAGE IMPAIRED AND EDUCABLE MENTALLY HANDICAPPED PRESCHOOLERS

D COMMERCIAL INSTRUMENTS EXAMINED 115 FOR ITEM PREDICTABILITY

E RESULTS OF CROSSTABULATION OF LEARNING ACCOMPLISHMENT PROFILEDIAGNOSTIC ITEMS

F CROSSTABULATION FOR DECISION RULES

G DESCRIPTIONS OF TESTS USED DURING 161 THE COMPREHENSIVE EVALUATION

REFERENCES 


\section{LIST OF TABLES}

Table

Page

1 Types of Handicapping conditions Served by Head Start

2 Types of Handicapping Conditions in Dade

County Head start Served by Dade County Public Schools

3 Characteristics of The Dade County Head

start Program

4 Characteristics of Sample one $(n=500)$ Used to Identify Items

5 Characteristics of Sample Two Used for Hit Rate Validity

6 Characteristics of Sample Three Used for Hit Rate validity

7 Crosstabulation of combinations of Items With Age and Final Diagnosis of Language Impaired and EMH For Decision Rules Age Recoded into Six Categories

8 Crosstabulation of Test Items, LN6, LN7,

LN9, and LN11 with Qualification for DCPS Programs for Language Impaired and EMH With Use of Decision Rule for Age Category 3-0 to $3-5$

9 Crosstabulation of Test Items, LN6, LN7,

LN9, and LN11 with Qualification for DCPS Programs for Language Impaired and EMH With Use of Decision Rule for Age Category 3-6 to $3-11$

10 Crosstabulation of Test Items, LN6, LN7, LN9, and LN11 with Qualification for DCPS Programs for Language Impaired and EMH With Use of Decision Rule for Age Category 4-0 to $4-5$

11 Crosstabulation of Test Items, LN6, LN7, LN9, and LN11 With Qualification for DCPS Programs for Language Impaired and EMH With Use of Decision Rule for Age Category 4-6 to $4-11$ 
List of Table's (cont'd)

Table

Page

12 Crosstabulation of Test Items, LN6, LN7, LN9, and LN11 With Qualification for DCPS Programs for Language Impaired and EMH With Use of Decision Rule for Age Category 5-0 to 5-5

13 Crosstabulation of Test Items, LN6, LN7,

LN9, and LN11 With Qualification for DCPS Programs for Language Impaired and EMH With Use of Decision Rule for Age Category 5-6 to $5-11$

14 Hit Rate for New Screening Test If Decision Rules Were Used With The Sample of 500 Head start Children

15 Test-retest and Inter-rater Reliability Results for New Screening Test $(n=40)$

16 Hit Rate Data for New Screening Instrument With Sample one

17 Characteristics of True Positives for Sample one

18 Characteristics of False Positives for Sample one

19 Characteristics of Children Categorized as Positive (Refer for Testing) for Sample One

20 Hit Rate Data for New Screening Instrument With Sample Two

21 Characteristics of True Positives for Sample Two

22 Characteristics of False Positives for Sample Two

23 Characteristics of Children Categorized as Positive (Refer for Testing) for Sample Two 
List of Table's (cont'd)

Table

Page

24 Percentage of Children Categorized as True Positives for Each Age Group for Sample one

25 Percentage of Children Categorized as

True Positives for Each Age Group for Sample Two

26 Chi square for New Test and DDST-R with Sample one for Sensitivity

27 Chi square for New Test and DDST-R with Sample Two for Sensitivity

28 Chi square for New Test and DIAL-R with Sample one for Sensitivity

29 Chi square for New Test and DIAL-R with Sample Two for Sensitivity

30 Chi square for New Test and DIAL-R with Sample one for specificity

31 Chi square for New Test and DIAL-R with Sample Two for specificity

32 Chi square for New Test and Dallas with Sample one for Sensitivity

33 Chi square for New Test and Dallas with Sample Two for Sensitivity

34 Chi square for New Test and Brigance with Sample one for Sensitivity

35 Chi square for New Test and Brigance with Sample Two for Sensitivity

36 Chi square for New Test and Brigance with Sample one for Specificity

37 Chi square for New Test and Brigance with Sample Two for Specificity

B-1 Characteristics of Sample for Hit Rate Validity of DDST-R 
List of Table's (cont'd)

Table

Page

B-2 Hit Rate for DDST-R with Dade county Head 96 start Program

B-3 Characteristics of Sample for Hit Rate Validity of DIAL-R

B-4 Hit Rate for DIAL-R with Dade county Head Start Program

B-5 Characteristics of Sample for Hit Rate Validity of DALIAS

B-6 Hit Rate for DALLAS with Dade county Head start Program

B-7 Characteristics of Sample for Hit Rate validity of Brigance

B-8 Hit Rate for Brigance with Dade County Head start Program

E-1 Crosstabulation of Test Item LN6 With Qualification for DCPS Programs for Language Impaired and EMH for Children Age 3

E-2 Crosstabulation of Test Item LN6 With Qualification for DCPS Programs for Language Impaired and EMH for Children Age 4

E-3 Crosstabulation of Test Item LN6 With Qualification for DCPS Programs for Language Impaired and EMH for Children Age 5

E-4 Crosstabulation of Test Item LN7 with Qualification for DCPS Programs for Language Impaired and EMH for Children Age 3

E-5 Crosstabulation of Test Item LN7 With Qualification for DCPS Programs for Language Impaired and EMH for Children Age 4 
List of Table's (cont'd)

Table

Page

E-6 Crosstabulation of Test Item LN7 with

Qualification for DCPS Programs for

Language Impaired and EMH for Children Age 5

E-7 Crosstabulation of Test Item LN9 With

Qualification for DCPS Programs for

Language Impaired and EMH for Children Age 3

E-8 Crosstabulation of Test Item LN9 With

Qualification for DCPS Programs for

Language Impaired and EMH for Children Age 4

E-9 Crosstabulation of Test Item LN9 With

Qualification for DCPS Programs for

Language Impaired and EMH for Children Age 5

E-10 Crosstabulation of Test Item LN11 With Qualification for DCPS Programs for Language Impaired and EMH for Children Age 3

E-11 Crosstabulation of Test Item LN11 with Qualification for DCPS Programs for Language Impaired and EMH for Children Age 4

E-12 Crosstabulation of Test Item LN11 With Qualification for DCPS Programs for Language Impaired and EMH for Children Age 5

F-1 Crosstabulation of Test Item LN6 With Qualification for DCPS Programs for Language Impaired and EMH for Age Category 3-0 to 3-5

F-2 Crosstabulation of Test Item LN6 with Qualification for DCPS Programs for Language Impaired and EMH for Age Category $3-6$ to $3-11$ 
List of Table's (cont'd)

Table

Page

F-3 Crosstabulation of Test Item LN6 With Qualification for DCPS Programs for Language Impaired and EMH for Age Category 4-0 to 4-5

F-4 Crosstabulation of Test Item LN6 With Qualification for DCPS Programs for Language Impaired and EMH for Age Category $4-6$ to $4-11$

F-5 Crosstabulation of Test Item LN6 With Qualification for DCPS Programs for Language Impaired and EMH for Age Category 5-0 to 5-5

F-6 Crosstabulation of Test Item LN6 With Qualification for DCPS Programs for Language Impaired and EMH for Age Category 5-6 to 5-11

F-7 Crosstabulation of Test Item LN7 With Qualification for DCPS Programs for Language Impaired and EMH for Age Category 3-0 to 3-5

F-8 Crosstabulation of Test Item LN7 With Qualification for DCPS Programs for Language Impaired and EMH for Age Category 3-6 to 3-11

F-9 Crosstabulation of Test Item LN7 With Qualification for DCPS Programs for Language Impaired and EMH for Age Category 4-0 to 4-5

F-10 Crosstabulation of Test Item LN7 With Qualification for DCPS Programs for Language Impaired and EMH for Age Category 4-6 to 4-11

F-11 Crosstabulation of Test Item LN7 With Qualification for DCPS Programs for Language Impaired and EMH for Age Category 5-0 to 5-5 
List of Table's (cont'd)

Table

Page

F-12 Crosstabulation of Test Item LN7 With Qualification for DCPS Programs for Language Impaired and EMH for Age Category 5-6 to 5-11

F-13 Crosstabulation of Test Item LN9 With Qualification for DCPS Programs for Language Impaired and EMH for Age Category 3-0 to 3-5

F-14 Crosstabulation of Test Item LN9 With Qualification for DCPS Programs for Language Impaired and EMH for Age Category $3-6$ to $3-11$

F-15 Crosstabulation of Test Item LN9 With Qualification for DCPS Programs for Language Impaired and EMH for Age Category 4-0 to 4-5

F-16 Crosstabulation of Test Item LN9 With Qualification for DCPS Programs for Language Impaired and EMH for Age Category 4-6 to 4-11

F-17 Crosstabulation of Test Item LN9 With Qualification for DCPS Programs for Language Impaired and EMH for Age Category 5-0 to 5-5

F-18 Crosstabulation of Test Item LN9 With Qualification for DCPS Programs for Language Impaired and EMH for Age Category $5-6$ to 5-11

F-19 Crosstabulation of Test Item LN11 With Qualification for DCPS Programs for Language Impaired and EMH for Age Category 3-0 to 3-5

F-20 Crosstabulation of Test Item LN11 With Qualification for DCPS Programs for Language Impaired and EMH for Age Category $3-6$ to $3-11$ 
List of Table's (cont'd)

Table

Page

F-21 crosstabulation of Test Item LN11 With Qualification for DCPS Programs for Language Impaired and EMH for Age Category 4-0 to 4-5

F-22 Crosstabulation of Test Item LN11 With Qualification for DCPS Programs for Language Impaired and EMH for Age Category $4-6$ to $4-11$

F-23 Crosstabulation of Test Item LN11 with Qualification for DCPS Programs for Language Impaired and EMH for Age Category $5-0$ to 5-5

F-24 Crosstabulation of Test Item LN11 With Qualification for DCPS Programs for Language Impaired and EMH for Age Category $5-6$ to 5-11 
1 The Hit Rate Model for Evaluating Screening Decisions Based on a Particular Screening Instrument

2 Dade County Public School Screening and Evaluation Procedure for Dade County Head start Program

3 Example of Crosstabulation Procedure Used to Identify A Test Item for The New Screening Test

4 Crosstabulation Results for The Four LAP-D Items with Significant Sensitivity and specificity scores

5 Evaluation Procedure for Validation of Screening Decisions 


\section{CHAPTER I}

\section{Introduction}

The nation has been expressing concern about the large number of children who are not satisfactorily progressing in school. An estimated 12 percent of the school age population, in the United States, have physical, mental, or emotional difficulties that hinder their chances of having a positive school experience (Lichtenstein \& Ireton, 1991). Another segment of the school age population, who do not achieve their potential because of mild learning problems or disadvantaged environments, could also be included in the estimation of the students who are not meeting with success in school. Frequently, these children continue to fall further and further behind in their academics with each successive school year (McNulty, Smith \& Soper, 1983). Many of these children reveal early indications of a need for some type of special assistance in school (Adelman, 1982). Most local and state education departments have implemented preschool screening programs to assist in the early identification process (Ysseldyke \& O'Sullivan, 1987). Preschool screening is a brief, inexpensive procedure that aims "to identify those children in the general population who may be at-risk for a specific disability, or who may otherwise need special services or 
programs in order to develop to their maximum potential" (Barnes, 1982, p. 11).

Early intervention literature indicates that identifying children at-risk, through a preschool screening program, is a positive policy to practice (Castro \& Mastropieri, 1986). Edmiaston and Mowder (1985) reviewed a series of reports on preschool intervention projects for "at risk" children which included diverse handicapping conditions and children with all degrees of impairments. They concluded that early intervention was effective, and that the earlier it began, the greater was the long term financial savings. Fewell \& Oelwein (1991), using data from 14 sites which utilize a Model Preschool Program for Children with Down Syndrome and Other Developmental Delays, reported evidence for the effectiveness of early intervention. Lazar and Darlington (1982), who reported on pooled data from 12 studies, concluded that there were immediate and long term educational and attitudinal benefits from early intervention programs. "Prevention and intervention in the earliest stages of a problem are seen as having the potential for being more effective and economical than later remediation" (Adelman, 1982, p. 256). The importance of early identification and intervention is the reason for the increase in preschool 
screening programs. Meisels, Harbin, \& Modigliani (1988) conducted a survey and found that to be in compliance with P.L. 94-142 more than half of the 50 states mandate screening for children between the ages of three and six.

To "screen" is defined as a transitive verb meaning: To separate from a group those individuals showing indications of, or tendencies toward, mental or physical incapacity for specified activities. (Funk \& Wagnall, 1965). Preschool screening is the "process of early detection, usually involving observation and measurement procedures, of all preschool children (children between the ages of 3 and 5 years), who, for a variety of reasons (social, emotional, intellectual, biological, physical, linguistic, environmental or any combination of such), will be unable to attain optimum growth and/or normal development" (Barnes, 1982, p. 7).

Screening is the first step in the evaluation process. At this first step, "a large group is assessed with brief, simple, low-cost procedures to sort out those individuals who might have a problem (i.e., who are at risk) from those individuals who apparently do not need a follow-up evaluation at the time" (Lichtestein \& Ireton, 1984, p. 9). Individuals who are sorted out or identified as a result of the screening proceed to the next step, evaluation for 
the purpose of placement or diagnosis. This involves more extensive and definitive procedures utilizing standardized preschool psychoeducational assessment instruments to determine whether the indicated problem or problems in question are actually present. As a result, this diagnosticevaluation process is more costly and time-consuming than screening. Only those children identified at the screening step continue on to a more comprehensive evaluation. When the results of the evaluation support the hypothesis that a problem is present, a diagnosis is then made and intervention strategies are recommended and implemented.

\section{Problem}

The problem considered in this study is that too many children enrolled in the Dade County Head Start Program are incorrectly identified by commercial screening tests as at-risk or not at-risk for language impaired or educable mentally handicapped programs. The incompatibility of commercial standardized preschool screening measures with the local Head Start population and the quantitative criteria used for placement in the Dade County Public Schools Preschool Programs have contributed heavily to these screening inefficiencies (see p. 16 thru 18 and Appendix B). Consequently, too many Head Start students are unnecessarily being administered complete 
psychological evaluations while other children are being overlooked and are not receiving the services they need.

Head Start is a nationally important program for early intervention. It is a federally funded program that serves low income young children ages three thru five years. The Dade County Head Start Program, which serves approximately 4,000 children, works jointly with the University of Miami and the Dade County Public School System (DCPS) in providing services to the youngsters enrolled. These services include screening, evaluation, and intervention for children who are identified as impaired or delayed. Table 1 shows the handicapping conditions served by Head Start and their rate of prevalence on a national level based on the Head Start criteria.

As Table 1 indicates, an overwhelming percentage of the Head Start children identified as handicapped are those identified as having a speech impairment. The category of speech impairment, as defined nationally by Head Start, also includes language impairment 
Table 1

Types of Handicapping Conditions Served by Head Start

Nationally

Handicapping Condition

$\mathrm{N}$

$\%$

Speech Impairment

Health Impairment

Physical/Orthopedic

Learning Disability

Mental Retardation

Emotional Disturbance

Hearing Impairment

Visual Impairment

Total
36,199

61.0

7,178

12.1

3,475

5.9

3,391

5.7

3,053

5.1

2,746

4.6

1,863

3.1

1,430

$\underline{2.4}$

59,335 100.0

Note: From U.S. Department of Health and Human Services (1985)

Table 2 displays the number of Dade County Head Start children who were provided service by DCPS based on P.L. 94-142, P.L. 99-457, and the School District Procedural Guidelines. For the purpose of this study, the local Head Start data for speech impairment and language impairment (see Appendix A for definitions) has been separated into two distinct categories 
since the focus of this study will be the language impaired only. Also for the purpose of this study, the category of mental retardation will be referred to as educable mentally handicapped $(\mathrm{EMH})$ since this is the terminology that DCPS uses for this handicapping condition.

Table 2

Types of Handicapping Conditions in Dade County Head start Served by DCPS

Handicapping Condition

$\mathrm{N}$

$\%$

Speech Impairment 56

$29 \%$

Language Impaired

80

$41.5 \%$

Learning Disability

10

$5 \%$

Educable Mentally Handicapped

24

$13 \%$

Emotional Disturbance

20

$10 \%$

Hearing Impairment

1

$.5 \%$

Visual Impairment

$\underline{2}$

$1 \%$

Total

193

$100 \%$

Note: From Florida Diagnostic and Learning Resources system/South (FDLRS/South)

These two categories (language impaired and educable mentally handicapped) will be the concern of this study for two reasons. First, they 
are similar developmental areas or constructs. Lichtenstein and Ireton (1984) state that "... language is difficult to distinguish from the cognitive area, since a major part of cognitive functioning involves processing of verbal material and relies upon comprehension of language." (p. 52). Also, most young children with mild mental retardation exhibit problems in language development (Thurman \& Widerstrom, 1985). Second, these two categories generate the highest number of children for exceptional education from preschool screenings except for speech impairment (29\%). The category of language impaired accounts for $41.5 \%$ of the total DCPS preschool exceptional student population while the category of educable mentally handicapped accounts for $13 \%$ (see Table 2). The category of speech impairment will not be a concern of this study because "... it is essentially a disorder of speech articulation ... and other nonlinguistic and linguistic areas of functioning are generally within normal limits." (Cantwell \& Baker, 1987, p. 76).

The potential for preschool screening programs to improve the provision of early identification services is enormous. However, results of screening programs often fall short of expectations. One of the factors which contributes to these short falls has to do with accuracy of the screening 
instruments.

Inaccurate screening instruments may lead to identification or classification errors. There are two types of identification or classification errors: a) when a child is referred for further testing when it is not necessary (false positive) and b) when a child with a problem is not identified and is thus not provided services (false negative). These classification errors most frequently occur because of the incompatibility of the commercial screening instruments with both the actual population being screened and with the local procedural criteria for diagnosis.

Scott and Hogan (1982) identified criteria to be considered when selecting a screening instrument:

1) Conditions for which screening is performed should be well defined.

2) Instruments should have demonstrated reliability and predictive validity.

3) Administration should be accomplished easily, quickly, and economically.

4) Data on the number of false positives and false negatives should be available and at an acceptable ratio for sensitivity and 
human cost. (see page 15 for definitions of false positive and false negative)

5) Procedures should be acceptable to both the professional and lay community.

Most screening processes rely upon a multidimensional screening test, e.g., Developmental Indicators for the Assessment of Learning-Revised (DIAL-R), Denver Developmental Screening Test-Revised (DDST-R), Dallas Preschool Screening Test, or the Brigance Preschool Screen. Screening is essentially a matter of translating the results of a child's performance on a screening instrument into a screening recommendation. The screening recommendation is based upon the decision rule (e.g., cutoff score) that is supplied by the publisher of the screening instrument. The user makes no decisions regarding an appropriate referral rate, but simply accepts what the instrument offers. The problem with this approach is that a given decision rule cannot be optimal for all situations and settings, and the user may or may not find the results appropriate when applied to local criteria for obtaining early intervention services.

When choosing a screening instrument to be used for a particular population it is important to consider the percentage of the normative sample referred by the decision rule and the composition of the screening 
instrument's normative sample (e.g., ethnicity, and social economic status).

Standardized screening instruments typically provide normative data indicating what percentage of the instrument's normative sample is referred by recommended decision rules or cutoff scores. However, normative data are of limited value to the user if the nature of the normative sample and the local population differ. For this reason it is preferable to select a measure developed with a sample similar to the population which will be screened. The population with which this study is concerned is the children enrolled in the Dade County Head Start Program.

The normative samples used for commercial screening instruments are not comparable to the population that is enrolled in Head Start in the Dade County area. This can be seen by comparing Table 3 , which illustrates the ethnic make up of Head Start's population in Dade County, with the normative information for commercial instruments. These instruments are described in Appendix B. The Head Start Program in Dade County has 52 school sites and serves approximately 4,000 children. These Head Start sites are in disadvantaged areas of Dade County and serve both the rural and urban sections of the county forming an extremely diverse population. 
Table 3

Characteristics of The Dade County Head Start Program

\begin{tabular}{lr|cc}
\hline Ethnicity & Percent & Age & Percent \\
\hline African American & $58 \%$ & 3 & $29 \%$ \\
Hispanic & $23 \%$ & 4 & $67 \%$ \\
Haitian & $18 \%$ & 5 & $4 \%$ \\
White & $1 \%$ & & \\
\hline
\end{tabular}

Note: From Dade County Head start Program 1991

Suen, Czudnowski, and Majumder (1989) state that the generalizability theory of measurement recognizes there is more than one aspect to the question of reliability and validity of instruments. The most important reliability-validity issue is that of decision consistency or classification, i.e., whether the screening test selects children as intended. Test validity information should include the validity of particular interpretations or types of decisions (Standards for Educational and Psychological Tests, 1985). Further, errors of prediction should be estimated and reported. Salvia and Ysseldyke (1977) and Lichtenstein (1979 \& 1981) among others advocate the classification or hit-rate model as the method to report validity. The 
classification or hit rate model summarizes the relationship between outcomes of a screening instrument and the "actual status" of children in a given population. The actual status is arrived at through an in-depth psychoeducational evaluation. Terminology used with this model are:

1) Hit Rate - This is the proportion of accurate screening decisions out of the total number of screening decisions. Originally proposed by Meehl $\&$ Rosen (1955), it has influenced the work of a number of researchers (Barnes, 1982; Lichtenstein, 1981; and Satz \& Fletcher, 1979). Hit rate is expressed as a percentage that provides an index of the accuracy of a screening instrument. (Lichtenstein \& Ireton, 1984)

2) Base Rate - This is the prevalence of the problem to be identified. It provides an estimate of the existing problem that the screening instrument seeks to identify. (Lichtenstein \& Ireton, 1984)

3) Referral Rate - This is the total number of children referred for testing by a particular screening instrument. It is expressed as a percentage that should be higher than the base rate and that will thus index the possibility that all of the target group children would have been identified. (Lichtenstein \& Ireton, 1984) 
4) Sensitivity - This refers to the capacity of a screening measure to identify those children with special problems. It is expressed as a percentage that indexes the true positives. This percentage should be as close to $100 \%$ as possible. (Lichtenstein \& Ireton, 1984)

5) Specificity - This is the accuracy of a screening procedure accuracy in selecting out those children who do not have special needs. It is expressed as a percentage which indexes the true negatives. It should be as close to one or $100 \%$ as possible. (Lichtenstein \& Ireton, 1984)

6) Efficiency of screening result (refer) - This has to do with accurate screening outcomes. It is expressed as a percentage which indicates the probability that a decision to "refer" for further evaluation will be accurate in identifying a target group child. It should be as close to $100 \%$ as possible. (Lichtenstein \& Ireton, 1984)

7) Efficiency of screening result (do not refer) - This has to do with accurate screening outcomes. It is expressed as a percentage which indicates the probability that a decision of "do not refer" for further evaluation will be accurate in correctly identifying a child who is not within the target group. This figure should be as close to $100 \%$ as possible. (Lichtenstein \& Ireton, 1984) 
8) True negative - This is a hit rate category. It represents the case when a child is not referred for testing and not in need of service.(Lichtenstein \& Ireton, 1984)

9) True positive - This is a second hit rate category. It represents the case when a child is referred by the screening procedure for testing and is in need of service. (Lichtenstein \& Ireton, 1984)

10) False negative or under-referral - This is a third hit rate category. It represents the case when a child is not referred by the screening procedure for testing but is in need of service. (Lichtenstein \& Ireton, 1984)

11) False positive or over-referral - This is a fourth hit rate category. It represents the case when a child is referred by the screening procedure for testing but is not in need of services. (Lichtenstein \& Ireton, 1984)

The most important concepts in the hit rate model are base rate, sensitivity, specificity, and efficiency of screening result (refer). These concepts provide the means of measuring a screening instrument's strengths and liabilities. Glaros and Kline (1988) point out that sensitivity and specificity when used with the target population's base rate can provide a level of confidence in the predictive power of an instrument. The base rate provides an indication of the amount of children in the target population 
while the sensitivity and specificity scores indicate how accurate the instrument is in identifying the target population. The efficiency of screening result (refer) provides an estimate of the possibility that a screening referral will prove accurate.

The concepts of hit rate, referral rate, and efficiency of screening outcome (do not refer) are considered to be problematic in that they are easily influenced by the size of the base rate and are not as reliable in the establishment of confidence in an instrument as are sensitivity, specificity, base rate, and efficiency of screening (refer) (Lichtenstein \& Ireton, 1991). Figure 1 illustrates the possible outcomes of a screening. A child can either be categorized as a screening positive or a screening negative. The psychoeducational evaluation further divides the screening population into the two categories of requiring special services or not requiring special services.

Bracken (1987) and Ittenbach, Harrison, and Deck (1989) have cited difficulties that affect standardized screening instruments such as low reliability, and standardized samples which do not reflect the population of children who are to be assessed. Appendix B lists and describes the screening tests that have been used with Dade County Head Start children 
Figure 1

The Hit Rate Model for Evaluating Screening Decisions Based on a Particular screening Instrument

\section{Evaluation Result}

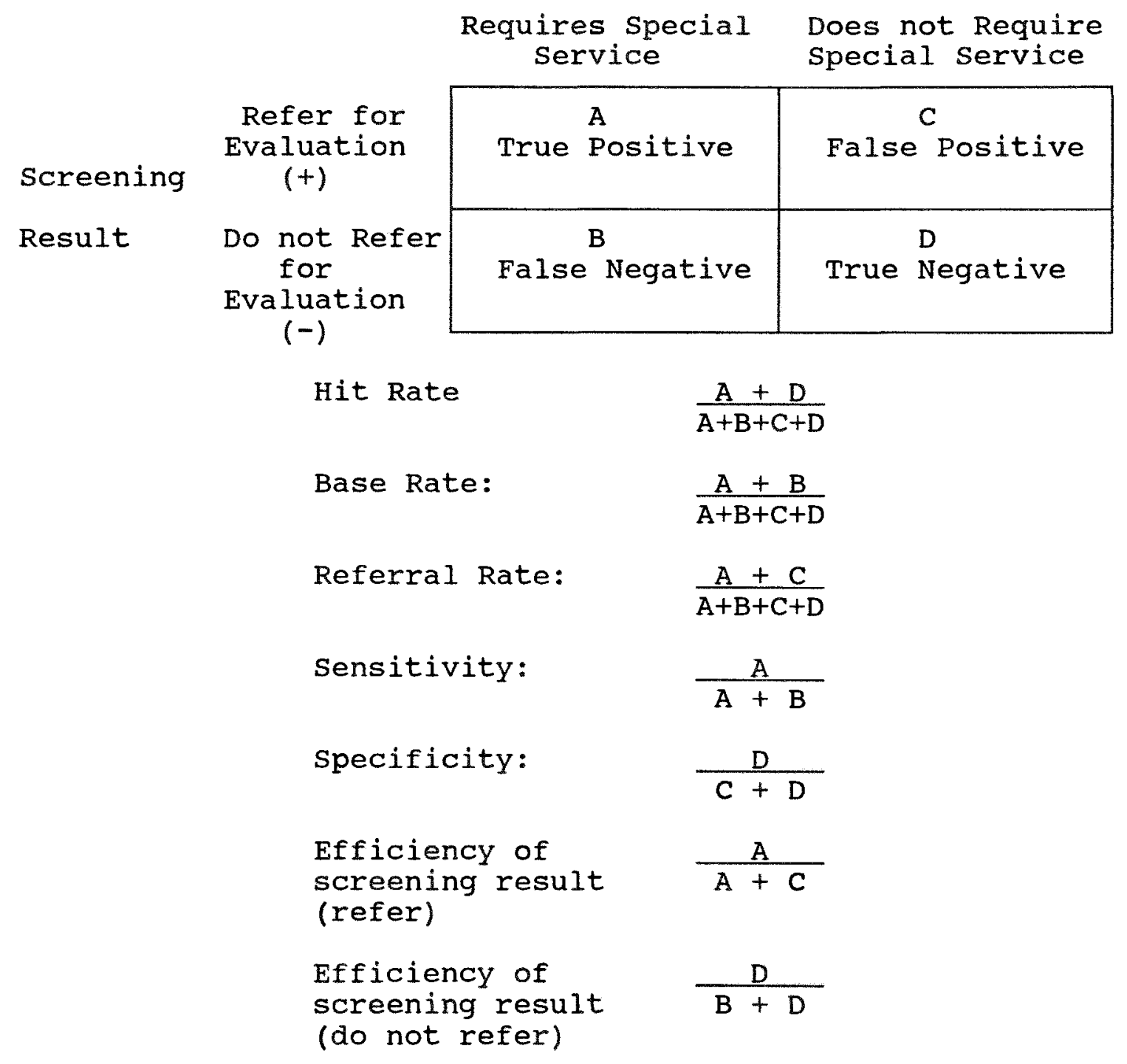


by DCPS. Descriptions of each test's norms, validity, and reliability information are included along with the hit rate data for Dade County Head Start. The difficulties that the incompatibility of the commercial screening tests have presented when used with the Dade County Head Start population is documented in Appendix B. Low hit rates, large amounts of false positives, and some false negatives have occurred.

Another factor which leads to classification errors concerns the local procedural guidelines or criteria that are used by various agencies such as DCPS (see Appendix C for DCPS criteria). Harrison (1992) writes that "...agencies utilize numerous types of criteria to determine children who are eligible for intervention services as a result of comprehensive assessment..." (p. 10). Consequently, limitations occur when trying to utilize commercial screening instruments. The commercial screening instruments are not based upon the criteria of specific agencies. The primary characteristics of a screening program are who is to be identified and for what purpose. Wilson and Reichmuth (1985), in a review of the literature on predictive effectiveness of identification of at-risk learners, suggest that the most important factor in this regard is to "...specify the state we are attempting to predict". (p. 184) The purpose of the DCPS Preschool Screening Program 
is to identify children to be evaluated for the Exceptional Student Programs that exist at the various local elementary schools. DCPS has a delineated sequence of steps that must be followed during the psychoeducational evaluation process. This sequence is illustrated in Figure 2.

A procedures manual is supplied by the county which has established criteria for each handicapping condition. These criteria set guidelines for decision making when a child, following a psychoeducational assessment, is being considered placement into one of the existing special education classes. This placement criteria set by the county places parameters for screening instruments and thus for screening decisions based on these screening instruments.

The two classification categories primarily affected by this decision making process are language impaired and educable mentally handicapped. The following are reasons why these two categories are the most affected:

1) The categories of language impaired and educable mentally handicapped have criteria which are clearly defined by quantitative cutoff points. Decisions for qualification are objective not subjective. 
Figure 2

DCPS Screening and Evaluation Procedure for Dade County Head start Program

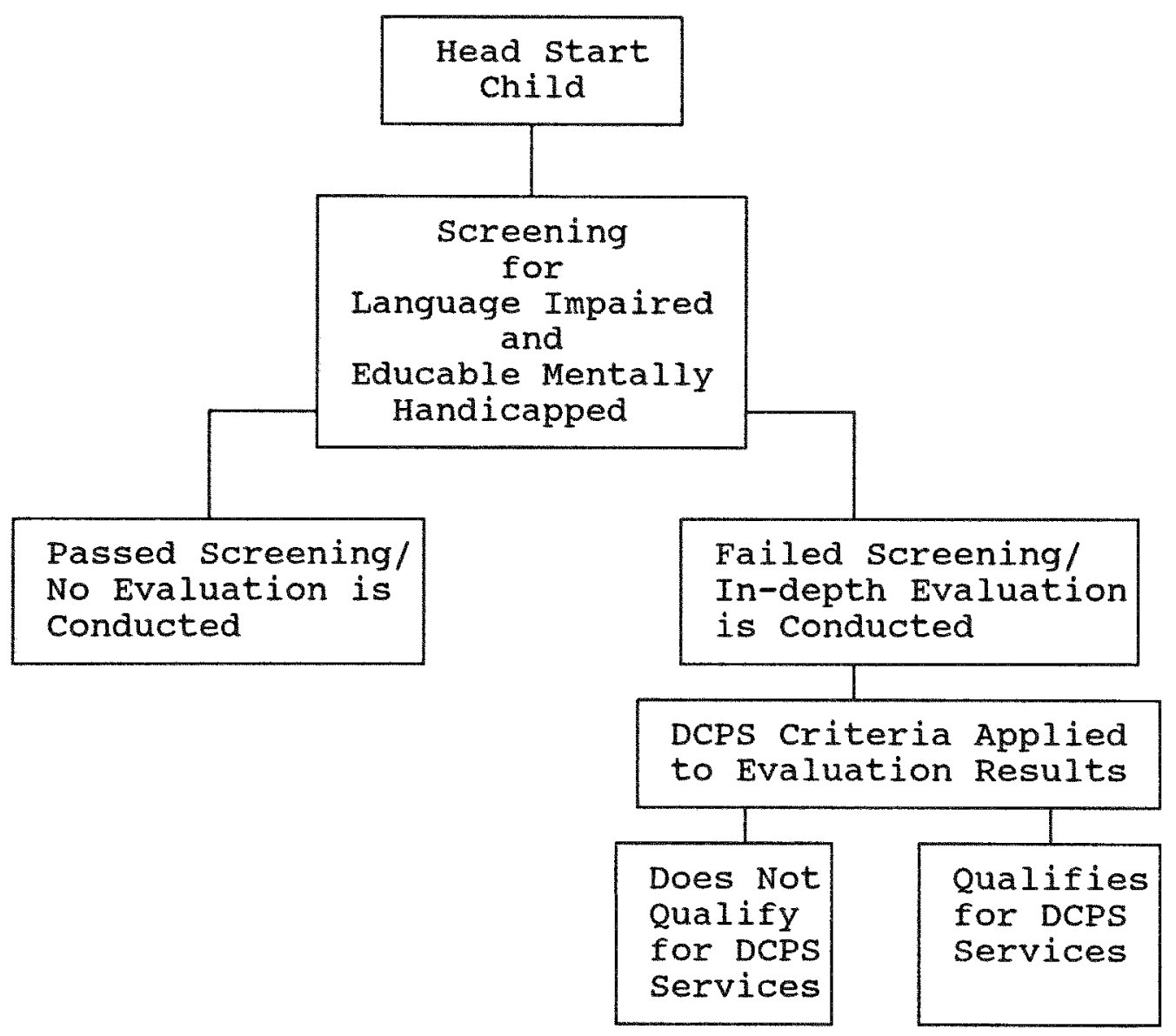

2) Hit Rate data for these two categories using commercial screening instruments is unsatisfactory (see Appendix B). The data in Appendix B show that the hit rates, sensitivity and/or specificity rates, etc., scores are insufficient. This means that confidence is lacking in the ability of these 
screening instruments to accurately predict positives and negatives.

\section{Screening Measures}

The effectiveness of screening measures can be evaluated in two ways: a) how well they have been constructed and standardized and b) how accurately their scores predict to certain outcome measures (Barnes, 1982). In addition, a screening measure must possess high acceptability to the professionals providing the diagnostic follow-ups, and the children taking the test must be able to relate to the items. Barnes (1982) states that "The screening test should be simple in design. To be maximally effective for the large-scale screenings it should require little or no equipment, be simple to administer and score, be relatively short duration in time and capable of being given in a wide variety of settings". (p. 27)

\section{Screening Test Construction}

Since currently available screening instruments are not providing adequate validity data for the target population being considered in this study, the development of a new screening instrument is warranted.

Item selection and analysis are important concepts in the construction of a new screening test. The actual items selected, for a screening test, depend on the content specifications established and the target population. In this 
study language and cognitive skills are the focus; therefore item content will emphasize these areas.

One of the methods by which items are selected is to draw from other measures which are presently used to assess the target population. This type of item selection technique aids in item validity. Items for screening tests should meet the following criteria (Barnes, 1982):

1) Fair and appropriate

2) Free from ambiguity

3) Free from cultural/response bias

4) Should not be too easy or too difficult.

A screening test should also have uniformity of test materials and their presentation. These uniformities are ensured by precise instructions as to how the instrument is to be administered, scored, and interpreted. The standardization process of screening test construction is a two-fold problem. The first problem concerns the standardization of test procedures and materials, including establishing the reliability and validity of the test. The second problem concerns the selection of a sample population. By choosing appropriate items from already existing tests and using samples of children from the population that the screening test will be serving, these problems 
can be minimized.

The reliability of a screening instrument is a major factor. It is important to demonstrate that the measure will be consistent from one administration to another. If a test is not reliable, than the judgement or decision of the screener will be tentative. Reliability or consistency is usually estimated by the test-retest method. This method is accomplished by the technique of repeated measurement (two measures of a child in the same representative group). A coefficient of correlation between the two sets of scores is then calculated.

Another type of reliability measure which is essential is inter-rater reliability. This type of reliability coefficient estimates the ability of different examiners to judge accurately and consistently the performance of a child on each item. Inter-rater reliability is established by having examiners observe and evaluate a number of children at the same time. The scores reported by each examiner are then correlated and the resulting coefficient yields an estimate of inter-rater reliability.

The validity of a screening instrument is concerned with the soundness of all the interpretations or decisions (refer or do not refer) the examiner makes based on the test results (pass or fail). Content and predictive validity 
are a concern of all tests.

Content validity estimates how well the items actually contain the subject matter on which the test focuses. Content validity centers on the test materials and the item domain. In this study the domain is language and cognitive skills and materials and items will require demonstration of skills in these areas.

Construct validity has to do with the measurement of the trait, skill, or ability the test is trying to measure. In this study the abilities are cognitive/language abilities. The literature on these abilities states that they are closely related and overlap. The use of already existing items from tests that measure these two areas will fulfill the construct validity concept.

Predictive validity will be the main focus of this study. In predictive validity there is always an external criterion involved which establishes the standard or direct measure of the characteristics or behavior in question. In this study predictive validity will be concerned with the new screening instrument's ability to predict to the criteria for qualification into a Dade County Public School Program for language impaired or educable mentally handicapped children. This validity is estimated mainly through the use of the classification or hit rate model previously discussed on 
pages 12 thru 17 .

Purpose

The purpose of this study is to develop a more accurate preschool screening instrument for identifying Dade County Head Start children who are language impaired or educable mentally handicapped children (EMH) according to the (DCPS) criteria. The new screening instrument will be considered more accurate only if both the sensitivity and the specificity scores of the new test are significantly higher than the sensitivity and specificity scores of the previously used commercial screening tests. 


\section{Null Hypotheses}

Null Hypothesis 1: There is no significant difference between the sensitivity scores of the new screening instrument and the sensitivity scores of the previously used commercial screening instruments when used to identify Dade County Head Start children for placement into a Dade County Public School program for the language impaired or the educable mentally handicapped.

Null Hypothesis 2: There is no significant difference between the specificity scores of the new screening instrument and the specificity scores of the previously used commercial screening instruments when used to identify Dade County Head Start children for placement into a Dade County Public School program for the language impaired or the educable mentally handicapped. 


\section{CHAPTER II}

Method

\section{Subjects}

The subjects used to form the new screening instrument were all children enrolled in the Dade County Head Start Program. A total of 1,700 children were involved in the test construction procedure.

Of these 1,700 children, three separate samples were used. The first sample consisted of 500 children $(n=500)$. This group of children was used to select items that would potentially be used to construct the screening instrument. Test protocols from these subjects, who had previously been referred and administered a comprehensive evaluation for possible placement into a Dade County Public School program for the language impaired or the educable mentally handicapped, were examined by using a crosstabulation technique. The outcome (pass or fail) of each response to an item, made by each child and recorded on the test protocols, was stored on a computer file. Also stored on the computer file was the following: age in years, age in months, sex, ethnicity, qualification for a Dade County Public School program (yes or no), and diagnosis (no service recommended, language impaired, or EMH). 
The second and third randomly selected samples consisted of 600 children $(n=600)$ each. These groups of children were used to determine the effectiveness of the new screening instrument (i.e. Hit Rate). The results of this validation procedure were recorded in a computer file and consisted of the following data: age, age in months, sex, ethnicity, performance on each item (pass or fail), total screening test result (pass or fail), qualification for a Dade County Public School program (yes or no), and diagnosis (regular education, language impaired, or EMH).

The children in each sample were within the age range of 3 to 5 years, were of a low socioeconomic level, and displayed ethnic diversity. Tables 4,5 , and 6 describe the characteristics of each sample. Each of these samples were similar in ethnic composition to the total Dade County Head Start population as depicted in Table 3 on page 12. There was a majority of African Americans, a smaller number of Hispanics and Haitians, and a still smaller number of Whites. 
Table 4

Characteristics of Sample one $(n=500)$ Used to Identify Items

\begin{tabular}{ll|lc|lc}
\hline Ethnicity & $\%$ & Age & $\%$ & Sex & $\%$ \\
\hline African American & 37.4 & 3 & 41.2 & Male & 55.6 \\
Hispanic & 28.8 & 4 & 43.6 & Female 44.4 \\
Haitian & 19.2 & 5 & 15.2 & & \\
White & 14.6 & & & & \\
\hline
\end{tabular}

Table 5

Characteristics of Sample two Used for Hit Rate Validity

\begin{tabular}{lc|cc|cc}
\hline Ethnicity & $\%$ & Age & $\%$ & Sex & $\%$ \\
\hline African American & $42.4 \%$ & 3 & $33.3 \%$ & Male & $52 \%$ \\
Hispanic & $27 \%$ & 4 & $33.3 \%$ & Female $48 \%$ \\
Haitian & $25.3 \%$ & 5 & $33.3 \%$ & & \\
White & $5.3 \%$ & & & \\
\hline
\end{tabular}


Table 6

Characteristics of Sample Three Used for Hit Rate Validity

\begin{tabular}{|c|c|c|c|c|c|}
\hline Ethnicity & $\%$ & Age & $\%$ & Sex & $\%$ \\
\hline African American & $39.5 \%$ & 3 & $33.3 \%$ & Male & $51.2 \%$ \\
\hline Hispanic & $28.2 \%$ & 4 & $33.3 \%$ & Female & $48.8 \%$ \\
\hline Haitian & $26.7 \%$ & 5 & $33.3 \%$ & & \\
\hline White & $5.6 \%$ & & & & \\
\hline
\end{tabular}

\section{Procedure}

Each item on the commercial standardized or criterion referenced instruments utilized during the in-depth psychoeducational evaluation previously conducted on the children in Sample One was examined for predictability as to whether or not a child qualified for Dade County Public School programs for language impaired or educable mentally handicapped. The result of each child's performance on an individual item (pass or fail) was crosstabulated with the final diagnosis (qualify or not qualify for language impaired or educable mentally handicapped). Figure 3 illustrates an example of the crosstabulation procedure. The sensitivity and specificity score for each item was computed to provide an indication of the 
effectiveness of the item for predicting qualification for language impaired or EMH placement.

Figure 3

Example of Crosstabulation Procedure Used To Identify A Test Item for The New Screening Test

\begin{tabular}{|c|c|c|c|}
\hline & & & \\
\hline & & Yes & No \\
\hline & Fail & 20 & 25 \\
\hline & Pass & 25 & 20 \\
\hline & & Sensi & $45 \%$ \\
\hline & & Speci & $45 \%$ \\
\hline
\end{tabular}

This example item (Figure 3) would have been rejected from further consideration for the screening instrument because of its low sensitivity and specificity score. When an item produced acceptable sensitivity and/or specificity scores (between $70 \%$ to $100 \%$ ), it was placed into a pool of items which were further examined.

This further examination step was taken to identify items that, when 
combined into a screening test would meet the following criteria:

1)Ease of Administration - Items that trained personnel could readily administer.

2)Ease of scoring - Items that trained personnel would find easy to score and interpret as a pass or fail.

3)Items that require only readily available materials.

4)Items that together could be administered by trained personnel in a very limited amount of time appropriate for mass screenings of children (five to ten minutes per child).

All the items from the following instruments (see Appendix D for a description of each test), which were previously utilized during the in-depth psychoeducational evaluations, were examined in the crosstabulation procedure:

1)Expressive One Word Picture Vocabulary Test (EOWPVT)

2)Learning Accomplishment Profile - Diagnostic (LAP-D)

3)Leiter International Performance Scale - Arthur Adaptation (LIPS)

4)Merrill-Palmer Test Of Mental Scales

5)Peabody Picture Vocabulary Test - Revised (PPVT-R)

6)Zimmerman Preschool Language Scale (PLS) 
The items that best predicted the final diagnosis of language impaired or $\mathrm{EMH}$, either alone or in combination, were four items from the Learning Accomplishment Profile - Diagnostic (LAP-D) subtest of Language/Cognitive Naming (LN). Figure 4 lists the crosstabulation tables for each of these four items with their sensitivity and specificity scores (also see Appendix E for crosstabulation tables for each item in each of the age ranges 3,4 , and 5 years of age). None of the other instruments that were examined yielded items that were significant predictors of qualification for a Dade County Public School program for language impairment or educable mentally handicapped.

The four items from the Learning Accomplishment Profile - Diagnostic that were selected to compile the new screening instrument were the following:

1)Item LN6 - "Names use of three common objects" (spoon, cup, pencil, book, scissors). The child must be able to correctly state the use of at least three of the five items in order to pass. For example, when shown the spoon and asked, "What do we do with this?" the child responds, "eat". Any reasonable response can be accepted by the examiner (e.g. for book a child may say "look at pictures" or "read" or "turn pages"). This item is 
Figure 4

Crosstabulation Results for The Four LAP-D Items With Significant sensitivity and specificity scores

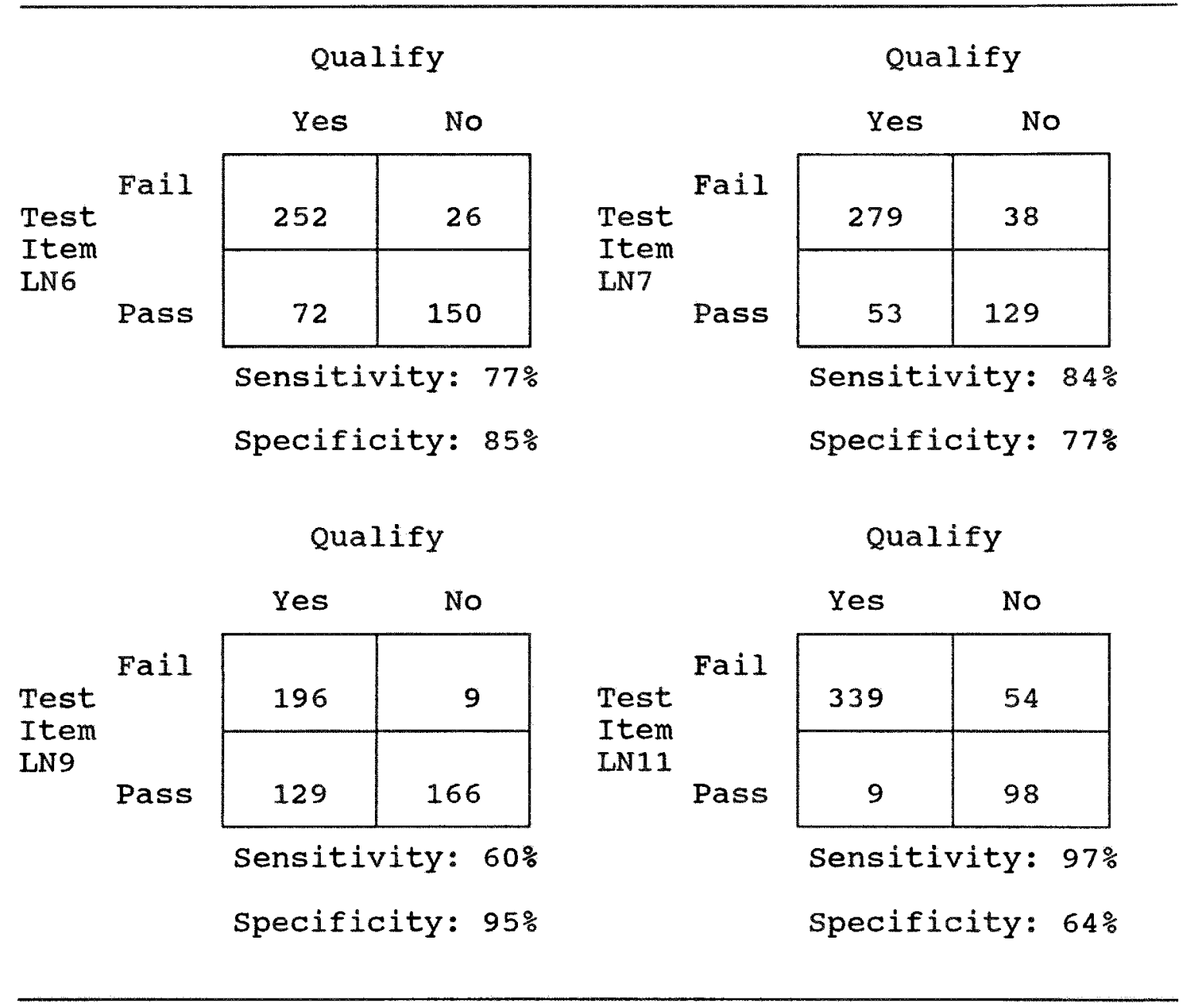

reported by the LAP-D manual to be at the 33 month level and attributed to Gesell, 1940.

2)Item LN7 - "Names three common objects by use". The child must be able to respond correctly to three out of these five questions: 

A - What do we sit on?
B - What do we ride in?
C - What do we sleep in?
D - What do we cook on?
E - What do we wear on our head?

Any reasonable response to these questions can be accepted, e.g. for question "A" a correct answer would be "chair", "sofa", "seat", etc.

This item is reported in the LAP-D manual to be at the 36 month level and attributed to Griffin, 1975.

3)Item LN9 - "Names ten pictures of common objects" (dog, ball, car, house, snake, wagon, fish, bed, shoe, light, flowers, fire, tree, banana, airplane, candy, turtle, rabbit). There is a total of eighteen pictures. This item is reported in the LAP-D manual to be at the 42 month level and attributed to Cattell, 1950.

4)Item LN11- "Names eight actions in pictures" (swimming, running, writing, eating, riding, jumping, sleeping, throwing, climbing, and reading). There is a total of ten pictures and the child must be able to name the action in at least eight pictures. This item is reported in the LAP-D manual to be at the 48 month level and attributed to Gesell, 1940. 


\section{Decision Rules}

Decision rules for the new screening instrument, (i.e. to determine whether a child passed the screening and did not need to be referred for further testing or failed the screening and should be referred for an in-depth psychoeducational evaluation) were arrived at by using the crosstabulation data that produced the items for the test. The data for the four items from the LAP-D (LN6, LN7, LN9, and LN11) and their level of predictability were crosstabulated with age in half year intervals (i.e. 3-0 to 3-5, 3-6 to 3$11,4-0$ to $4-6,4-6$ to $4-11,5-0$ to $5-6,5-6$ to 5-11) (see Appendix F for tables). This step consisted of combining the significant items and then crosstabulating with age and final diagnosis of language impaired or EMH. This procedure is illustrated in Table 7.

Table 7 illustrates the crosstabulation of the sampled children who passed items LN6, 7, and 9 but failed item LN11 and either qualified (yes) or did not qualify (no) for language impaired or EMH programs. Item LN11 seems to be very effective with children in the age categories 5-0 to 5-5 (5) and 56 to 5-11 (6). However, in the other age categories (1 thru 4) it does not have any predictability power. Therefore from this crosstabulation example item LN11 would not be used alone in the decision rule for children in the 
age categories of 3-0 to $3-5,3-6$ to $3-11,4-0$ to $4-5$, or $4-6$ to $4-11$.

Table 7

Crosstabulation of Combinations of Items With Age and Final

Diagnosis of Lanquage Impaired and EMH For Decision Rules and Age Recoded into six categories: \#1 (3-0 to 3-5), \#2 (3-6 to 3-11. \#3 (4-0 to 4-5), \#4 (4-6 to 4-11), \#5 (5-0 to 5-5), \#6 $(5-6$ to $5-11)$

Test Items: LN6 (pass); LN7 (pass); LN9 (pass); LN11 (fail): Age Category

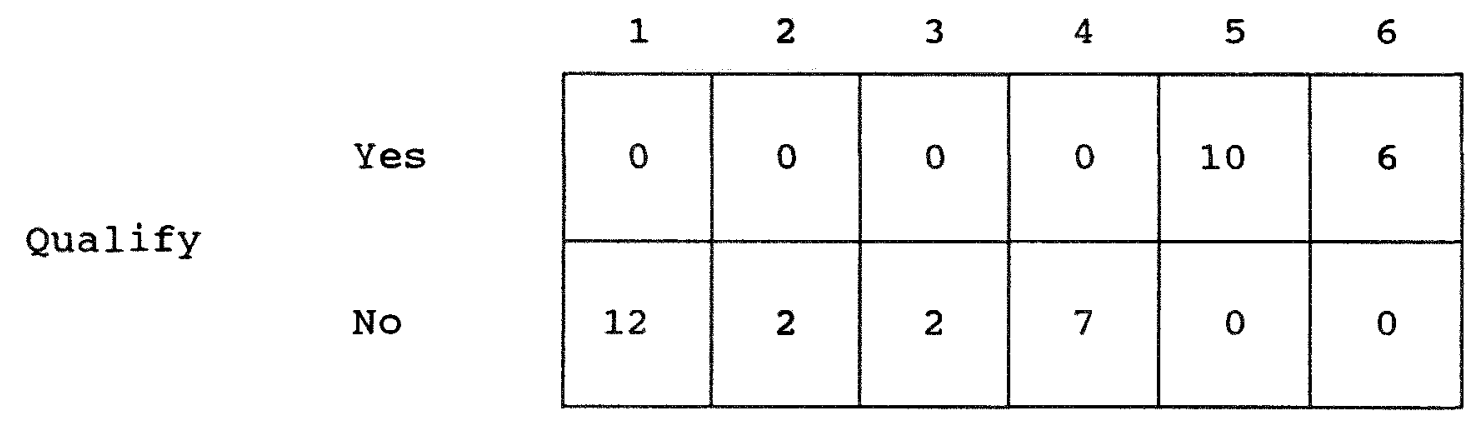


The following decision rules were formulated by using the technique shown in Table 7.

Decision Rule for age range 3-0 to 3-5: Refer child if fails two or more items not including item LN11.

Table 8

Crosstabulation of Test Items LN6, LN7, LN9, and LN11 with Qualification for DCPS Programs for Language Impaired and EMH With Use of The Decision Rule

Age: $3-0$ to 3-5

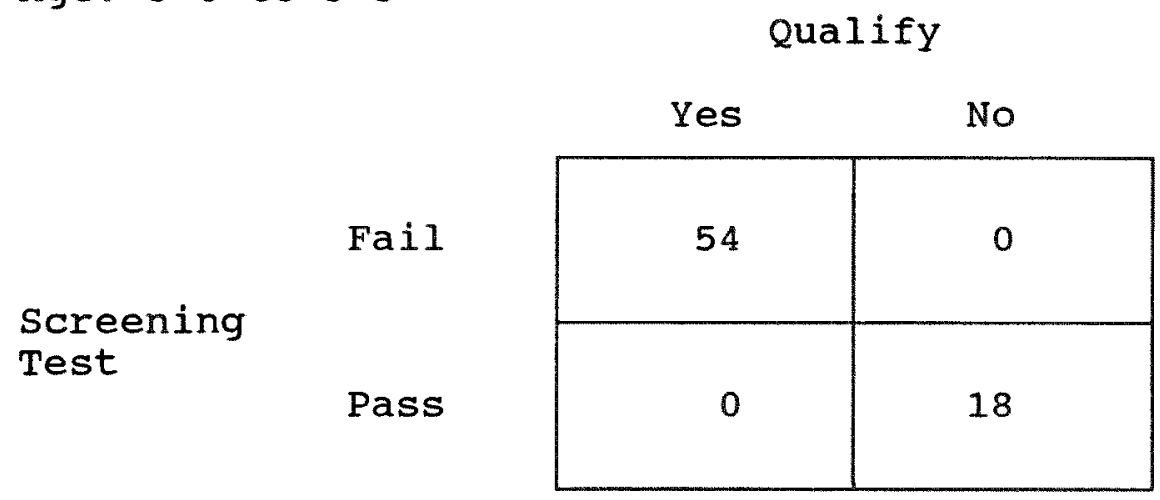

Sensitivity: $100 \%$

Specificity: $100 \%$ 
Decision Rule for age range 3-6 to 3-11: Refer child if fails two or more items not including item LN11.

Table 9

Crosstabulation of Test Items LN6, LN7, LN9, and LN11 with Qualification for DCPS Programs for Language Impaired and EMH With Use of The Decision Rule

Age: $3-6$ to $3-11$

$$
\text { Qualify }
$$

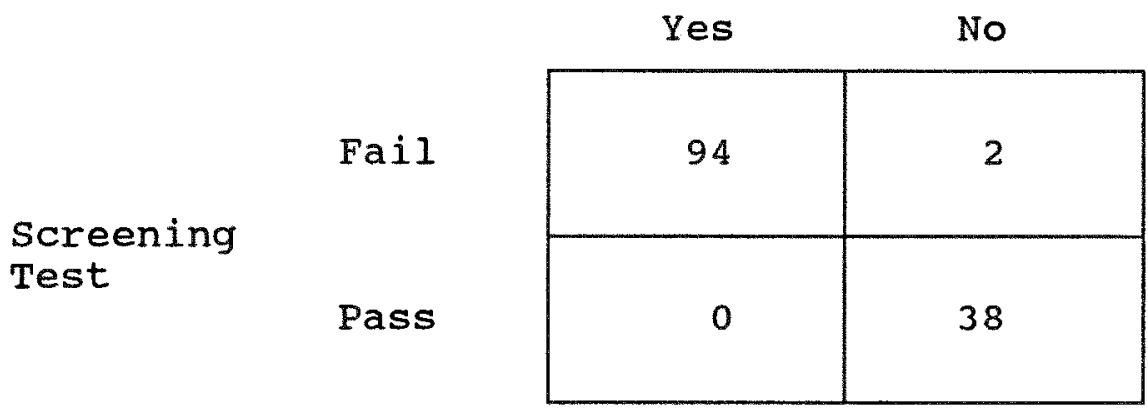

Sensitivity: $100 \%$

Specificity: $\quad 95 \%$ 
Decision Rule for age range 4-0 to 4-5: Refer child if fails two or more items or if fails items LN6, LN7, or LN9.

Table 10

Crosstabulation of Test Items LN6, LN7, LN9, and LN11 with Qualification for DCPS Programs for Language Impaired and EMH With Use of The Decision Rule

Age: $4-0$ to $4-5$

$$
\text { Qualify }
$$

\begin{tabular}{|c|c|c|}
\hline & Yes & No \\
\hline Fail & 98 & 0 \\
\hline Pass & 0 & 35 \\
\hline
\end{tabular}

Sensitivity: $100 \%$

Specificity: $100 \%$ 
Decision Rule for age range 4-6 to 4-11: Refer child if fails two or more items or if fails items LN6, LN7, or LN9.

Table 11

Crosstabulation of Test Items LN6, LN7, LN9, and LN11 with Qualification for DCPS Programs for Language Impaired and EMH With Use of The Decision Rule

Age: $4-6$ to $4-11$

$$
\text { Qualify }
$$

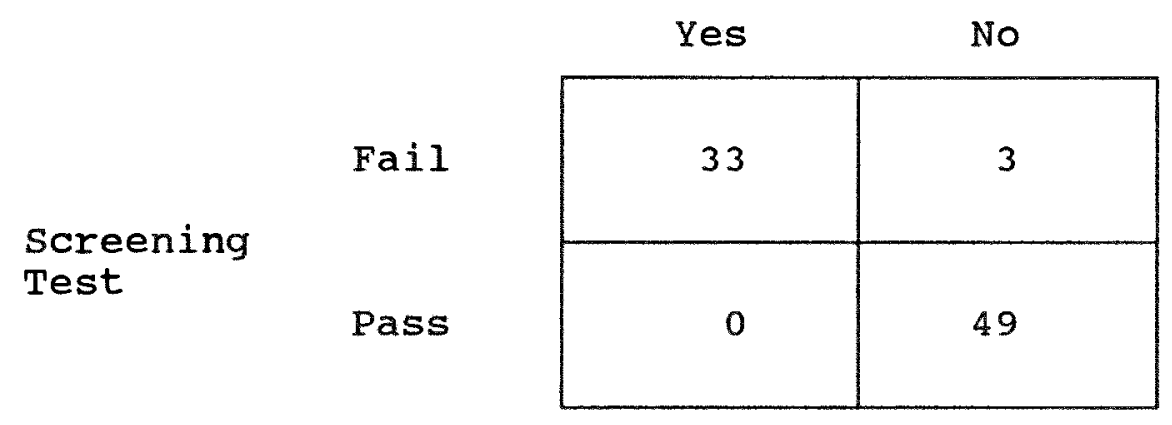

Sensitivity: $100 \%$

Specificity: $\quad 94 \%$ 
Decision Rule for age range 5-0 to 5-5: Refer child if fails one or more items.

Table 12

Crosstabulation of Test Items LN6, LN7, LN9, and LN11 with Qualification for DCPS Programs for Lanquage Impaired and EMH With Use of The Decision Rule

Age: $5-0$ to 5-5

$$
\text { Qualify }
$$

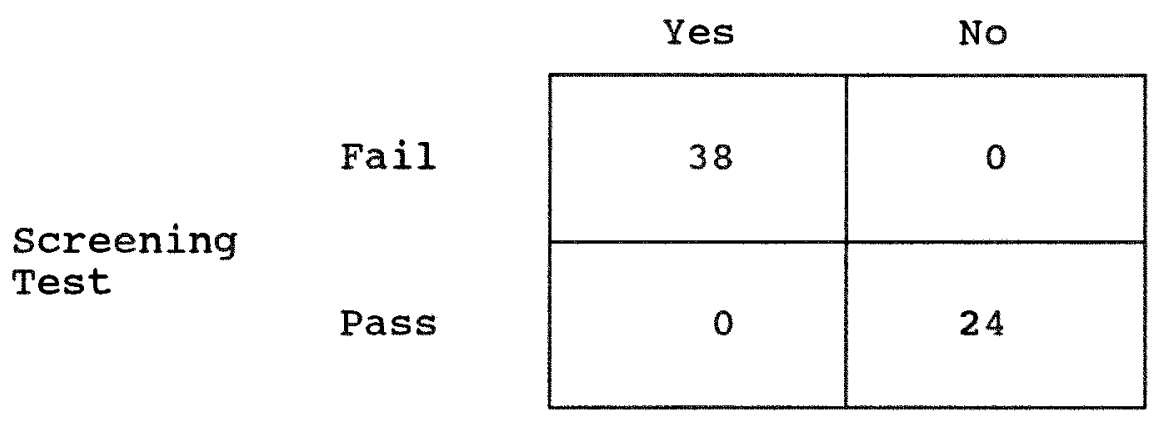

Sensitivity: $100 \%$

Specificity: $100 \%$ 
Decision Rule for age range 5-6 to 5-11: Refer child if fails one or more items.

Table 13

Crosstabulation of Test Items LN6, LN7, LN9, and LN11 with Qualification for DCPS Programs for Language Impaired and EMH With Use of The Decision Rule

Age: $5-6$ to $5-11$

$$
\text { Qualify }
$$

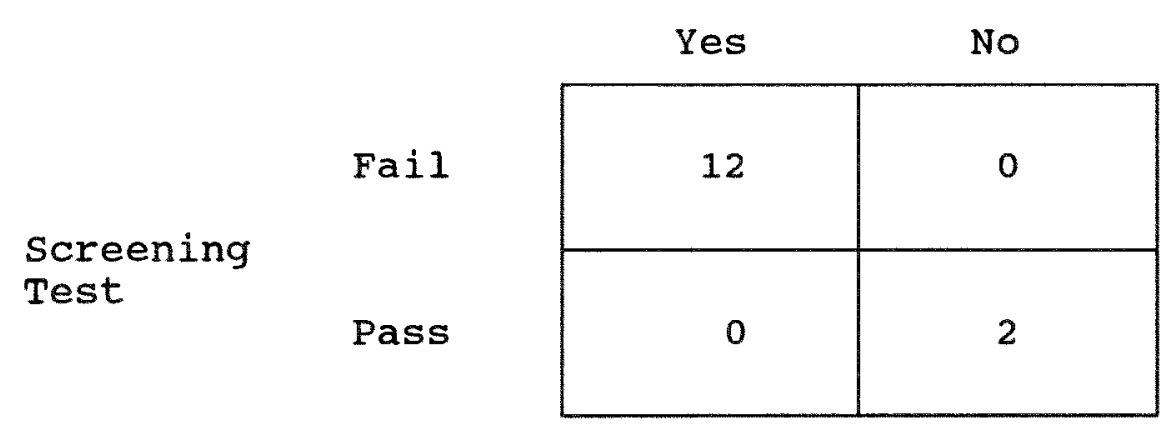

Sensitivity: $100 \%$

Specificity: $100 \%$ 
Table 14

Hit Rate for New Screening Test If Decision Rules Were Used With The sample of 500 Head start Children

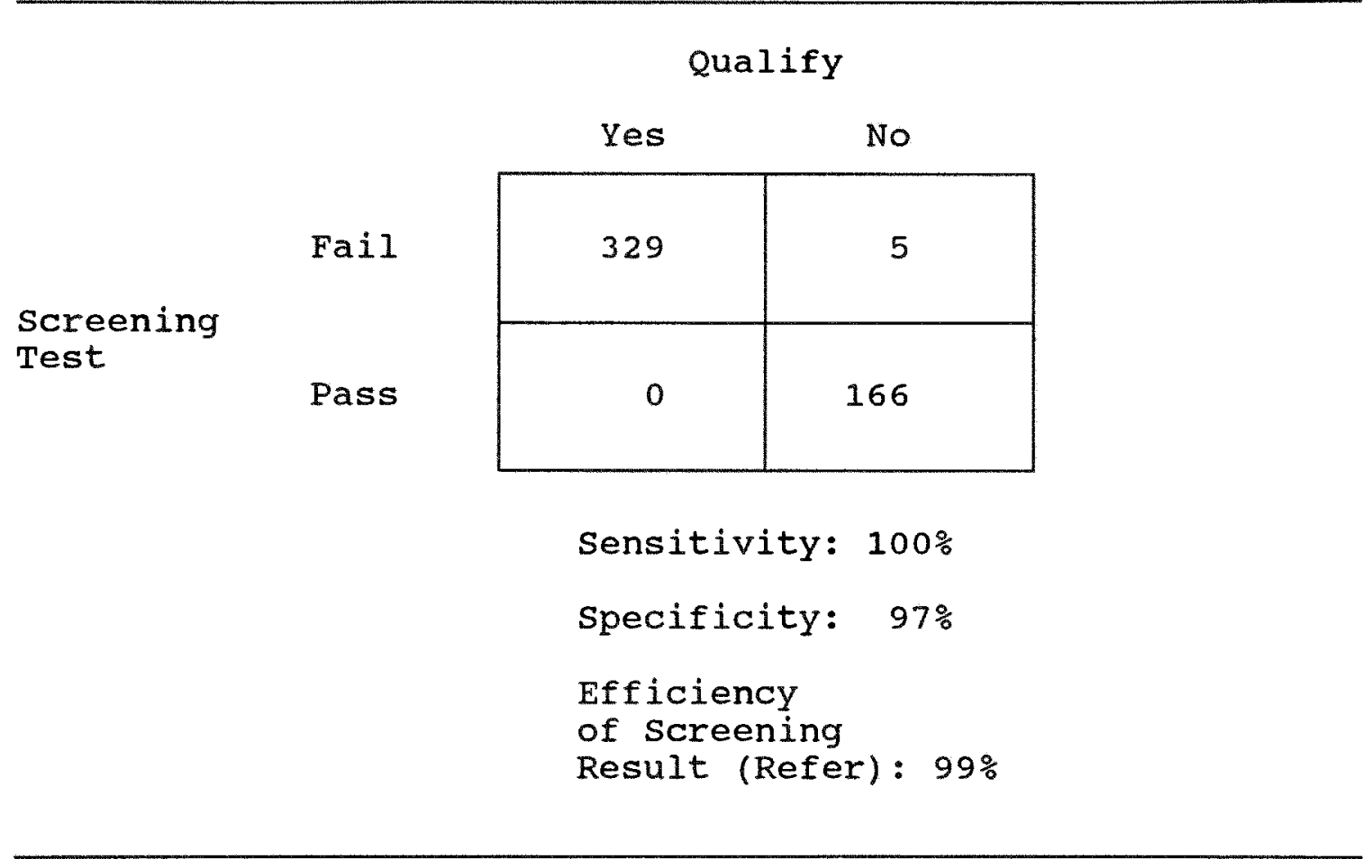

The reliability of this new screening instrument was examined through the test-retest and inter-rater reliability procedures using a random sample of 40 children $(n=40)$ who were enrolled in the Dade County Head Start program. A two week interval between the test and the retest was used. The raters were graduate assistants from the University of Miami who were majoring in an educational or mental health related field. A total of three raters were used to establish inter-rater reliability. 
The characteristics of the sample for the test-retest and the inter-rater reliability procedures were: sex (53\% male, $47 \%$ female), Ethnicity ( $55 \%$ African-American, 20\% Hispanic, 20\% Haitian, 5\% White), age (30\% 3 years, $50 \% 4$ years, $20 \% 5$ years). Table 15 summarizes the results of these two procedures.

Table 15

Test-retest and Inter-rater Reliability Results for New Screening Test $n=40$

\begin{tabular}{|c|c|c|c|c|}
\hline & $\begin{array}{l}\text { Test-Retest } \\
\text { Correlation }\end{array}$ & Examiners & Examiners & Examiners \\
\hline Item & Coefficient & $1+2$ & $1+3$ & $2+3$ \\
\hline
\end{tabular}

\begin{tabular}{lrrrr}
\hline 1 & .85 & .99 & .81 & .81 \\
2 & .85 & .88 & .99 & .88 \\
3 & 1.00 & .99 & .99 & .99 \\
4 & 1.00 & .79 & .99 & .79 \\
Total & 1.00 & .94 & .94 & .99 \\
\hline
\end{tabular}

The test-retest coefficients ranged from .85 to 1.00 , representing an acceptable level of reliability for each item. The inter-rater reliability coefficients ranged from .79 to .99 , indicating an acceptable level of reliability for the accuracy and consistency of the individual screeners. 
The validity of the new screening instrument was accomplished by using a double sample technique incorporating the two previously described samples of 600 randomly selected children enrolled in the Dade County Head Start Program. Each of the children in the two samples were put through the same evaluation procedure to obtain the classification or hit rate information for the new screening test. Figure 5 illustrates this procedure. 
Figure 5

Evaluation Procedure for Validation of Screening Decisions

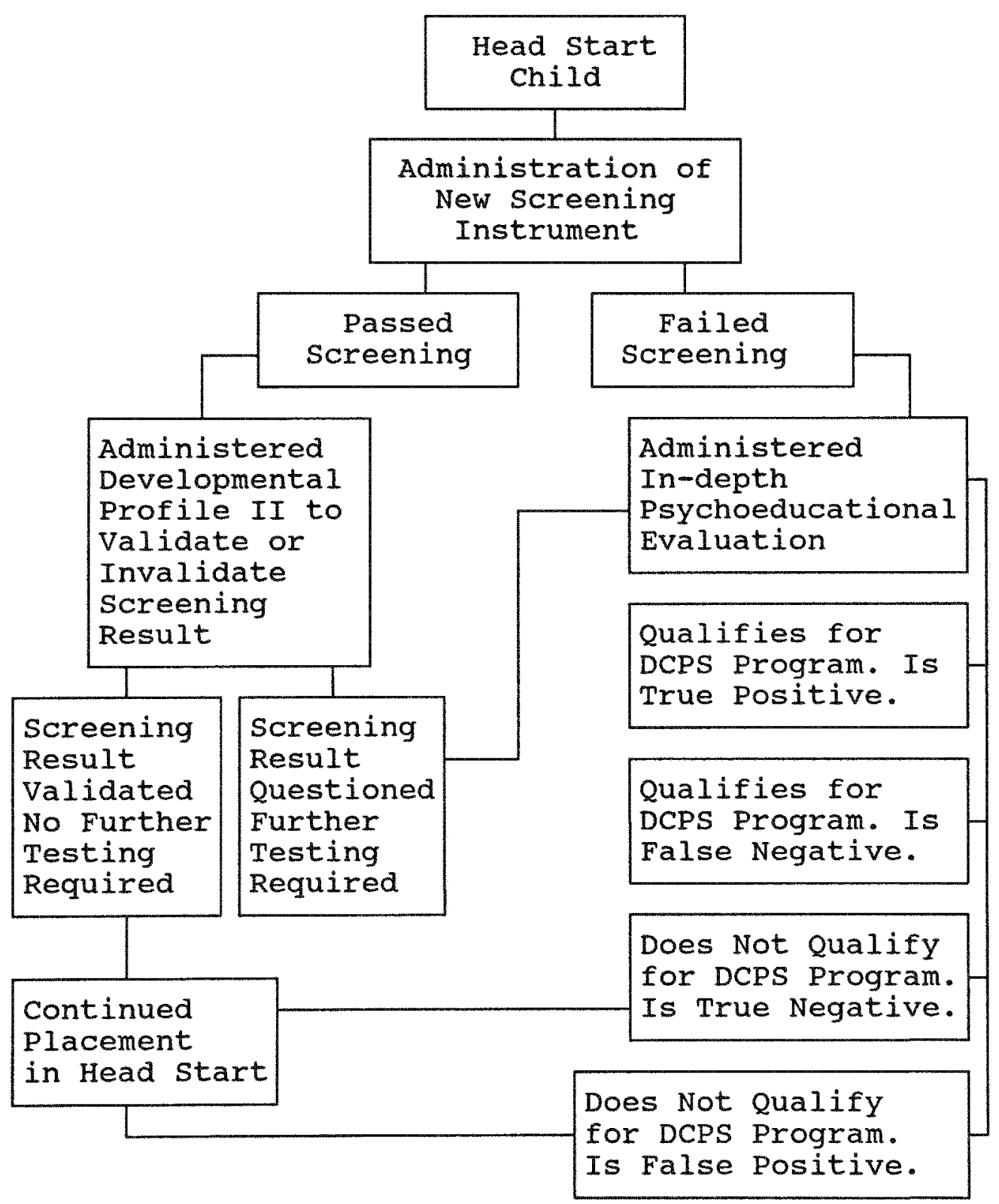


The administration of the new screening instrument yielded a decision of pass (no further evaluation recommended) or fail (further evaluation is recommended). The children in the sample who earned a decision of pass were then administered a widely used popular standardized developmental inventory, the Developmental Profile II (DP II)( see Appendix G for description) to confirm or deny the result of the new screening instrument. The manual states that "the Developmental Profile II offers five developmental age scores ... and is equally valid for use with ... Black and White children from all social classes." (Alpern, Boll, \& Shearer, 1980, p.37). The manual also states that the DP II can be used to "determine eligibility for receiving special education and/or related services..." (p. 1). The DP II may be administered in the following ways: a) an interview with parents, b) an interview and direct testing of the child, or c) self-interview completed by the teacher. If the results of the DP II indicated that further testing was needed, an in-depth evaluation was then conducted. If the result of the DP II indicated no need for further testing, the child's passing score on the new screening instrument was considered to be validated.

Although the DP II standardization group is disimilar to the population found in the Dade County Head Start program, the fact that the instrument 
was administered by a combination of teacher interview and direct testing of the child alleviated this limitation. If any child displayed difficulties in any of the developmental areas measured by the DP II then the child was administered a comprehensive evaluation.

The children whose score indicated failure on the new screening test were administered in-depth psychoeducational evaluations which included a minimum of one test for intelligence, a test for developmental skill levels, and tests for language skills. Tests selected from the following pool were used to accomplish the evaluation (see Appendix $G$ for descriptions of tests):

1) Tests of Intelligence
A) Differential Abilities Scale (DAS)
B) Leiter International Performance Scale (LIPS) (Arthur Adaptation)
C) Merrill-Palmer Scales of Mental Tests
D) Stanford-Binet IV
E) Wechsler Preschool and Primary Scale of Intelligence (WPPSI)
F) Wechsler Preschool and Primary Scale of Intelligence - Revised (WPPSI-R)

2) Tests of Developmental Skills

A) Developmental Profile II (DPII) 
B) Learning Accomplishment Profile - Diagnostic (LAP-D)

3) Tests of Language
A) Expressive One Word Picture Vocabulary Test (EOWPVT)
B) Peabody Picture Vocabulary Test - Revised (PPVT-R)
C) Preschool Language Scale (PLS)
4) Test of Adaptive Behavior
A) Scales of Independent Behavior (SIB)

Following the evaluation the Dade County Public School criteria for placement were applied to the results. The child was either found eligible or ineligible for acceptance into a DCPS program for the language impaired or for the educable mentally handicapped. In this manner the new screening test's decision was validated or not validated.

The screenings and the administration of the Developmental Profile II were conducted by trained personnel provided by the University of Miami Mailman Center for Child Development. These screeners were graduate students who were pursuing degrees in an educational or a mental health related field.

The in-depth psychoeducational evaluations were conducted utilizing a team approach. School Psychology interns from Florida International 
University, who also assisted during the screenings, provided the testing of intelligence and developmental skill levels. The interns also administered the adaptive behavior inventory to the parent or guardian of the child. Speech/Language Pathologists from the Hearing and Speech Center of Florida provided the testing in the area of language.

Bilingual personnel were utilized for the screenings with the children whose ethnic background was either Hispanic or Haitian. Bilingual examiners were used when an in-depth psychoeducational evaluation was performed for the Hispanic children. A Creole translator assisted the examiners of Haitian children.

\section{Materials}

The four items from the LAP-D were assembled into a booklet to be used at screenings. Item LN6 includes the following common objects which are provided with the LAP-D: spoon, cup, pencil, book, and scissors. The pictures provided with the LAP-D for items LN9 and LN11 were included in the booklet. Item LN7, which is comprised of questions, does not require a stimulus for the child. Therefore, for LN7 the questions list from the LAP-D was placed in the booklet. When booklets were not available, the complete LAP-D kit was used and only the four items which constituted the 
screening instrument were administered. When Hispanic and Haitian children were tested bilingual personnel used Spanish and Creole versions of the new screening instrument. 


\section{CHAPTER III}

\section{Results}

\section{Hit Rate Validity Data}

The screenings and evaluations of the randomly selected children for each sample were accomplished from September thru May during the school years of $1990-1991$ and 1991 - 1992. Sample One data was collected from September 1990 thru May 1991. Sample Two data was collected from September 1991 thru May 1992. Each child was evaluated within a month of receiving the screening.

The hit rate results for the new screening instrument with each sample can be seen in Tables 16 and 20 . Sensitivity, specificity, and efficiency of screening result (refer) scores are listed along with other hit rate scores. Tables 17 thru 19 and 21 thru 23 provide a description of the characteristics of the children who were categorized as true positives and false positives.

For Sample One the sensitivity and specificity scores were $100 \%$ and $98 \%$ respectively. The sensitivity score means that none of the children who passed the screening test were eventually identified as language impaired or educable mentally handicapped. The specificity score means that only a small percentage of the children screened $(2 \%)$ who did not qualify for 


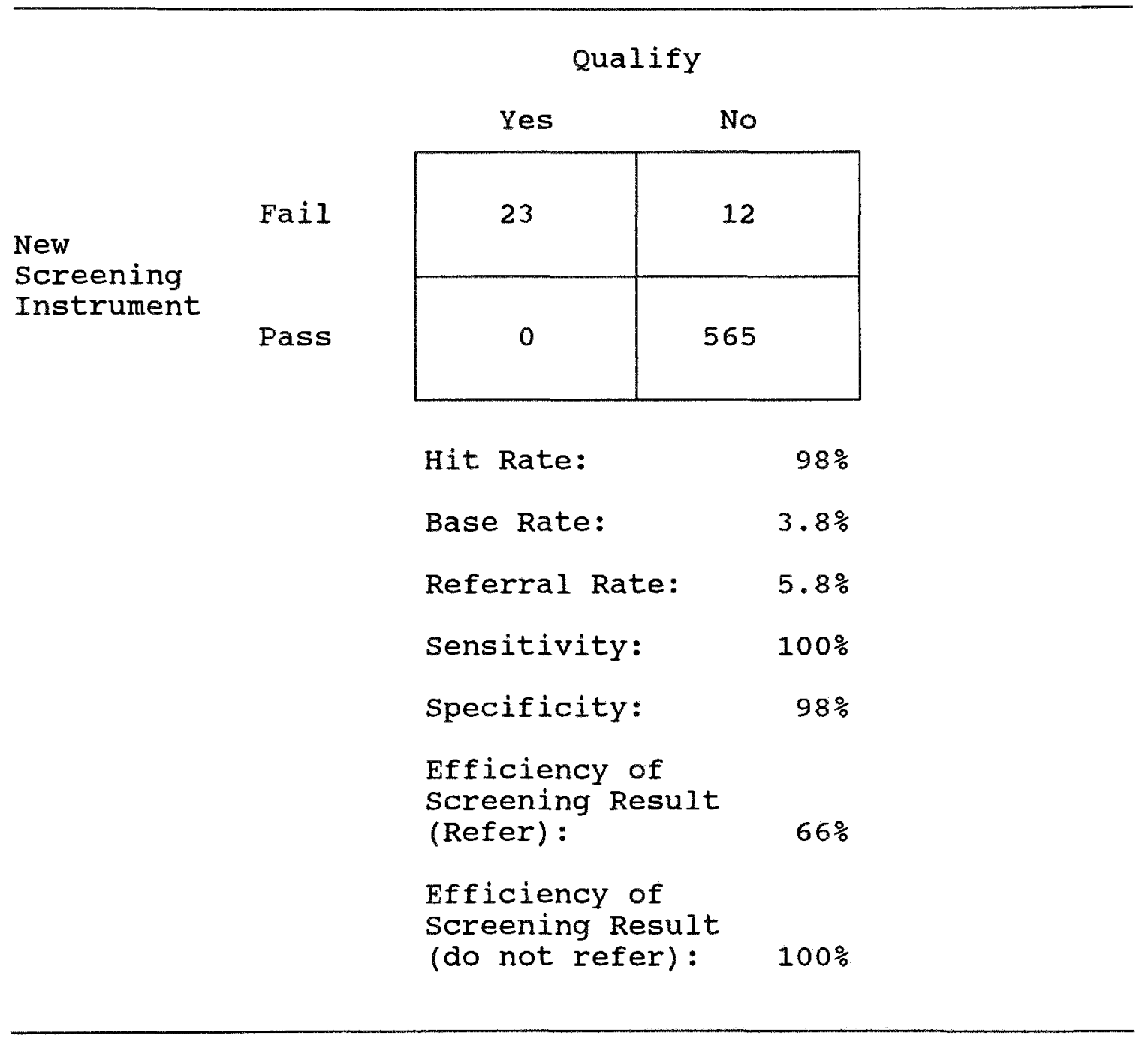

Note: Of the twenty three true positives six were EMH and seventeen were language impaired. 
Dade County Public school services failed the screening test.

The efficiency of screening result (refer) score of $66 \%$ means that once a child fails the screening test and is referred for testing there is a $66 \%$ chance of that child requiring exceptional student services.

Tables 17 thru 19 illustrate, for Sample One, how the screening test positively identified children, regardless of their ethnicity, in similar ethnic proportions as could be expected from the total Head Start population. Thus, the screening test did not discriminate along ethnic lines.

Table 17

Characteristics of True Positives for Sample one

\begin{tabular}{lrr|rrr|rrr}
\hline Ethnicity & $\#$ & $\%$ & Age & $\#$ & $\%$ & Sex & $\#$ & $\%$ \\
\hline African American & 11 & $48 \%$ & 3 & 5 & $22 \%$ & Male & 13 & $57 \%$ \\
Hispanic & 5 & $22 \%$ & 4 & 10 & $43 \%$ & Female & 10 & $43 \%$ \\
Haitian & 6 & $26 \%$ & 5 & 8 & $35 \%$ & & & \\
White & 1 & $4 \%$ & & & & & \\
\hline
\end{tabular}


Table 18

Characteristics of False Positives for Sample one

\begin{tabular}{|c|c|c|c|c|c|c|c|c|}
\hline Ethnicity & $\#$ & $\%$ & Age & $\#$ & $\%$ & Sex & $\#$ & $\%$ \\
\hline African American & 5 & $42 \%$ & 3 & 5 & $42 \%$ & Male & 7 & $60 \%$ \\
\hline Hispanic & 3 & $25 \%$ & 4 & 6 & $50 \%$ & Female & 5 & $40 \%$ \\
\hline Haitian & 4 & $33 \%$ & 5 & 1 & $8 \%$ & & & \\
\hline White & 0 & $0 \%$ & & & & & & \\
\hline
\end{tabular}

Table 19

Characteristics of Children Categorized as Positive (Refer

For Testing) for sample one

\begin{tabular}{|c|c|c|c|c|c|c|c|c|}
\hline Ethnicity & $\#$ & $\%$ & Age & $\#$ & $\%$ & Sex & $\#$ & $\%$ \\
\hline African American & 16 & $46 \%$ & 3 & 10 & $29 \%$ & Male & 20 & $54 \%$ \\
\hline Hispanic & 8 & $23 \%$ & 4 & 16 & $46 \%$ & Female & 15 & $46 \%$ \\
\hline Haitian & 10 & $28 \%$ & 5 & 9 & $25 \%$ & & & \\
\hline White & 1 & $3 \%$ & & & & & & \\
\hline
\end{tabular}


New

Screening

Instrument
Qualify

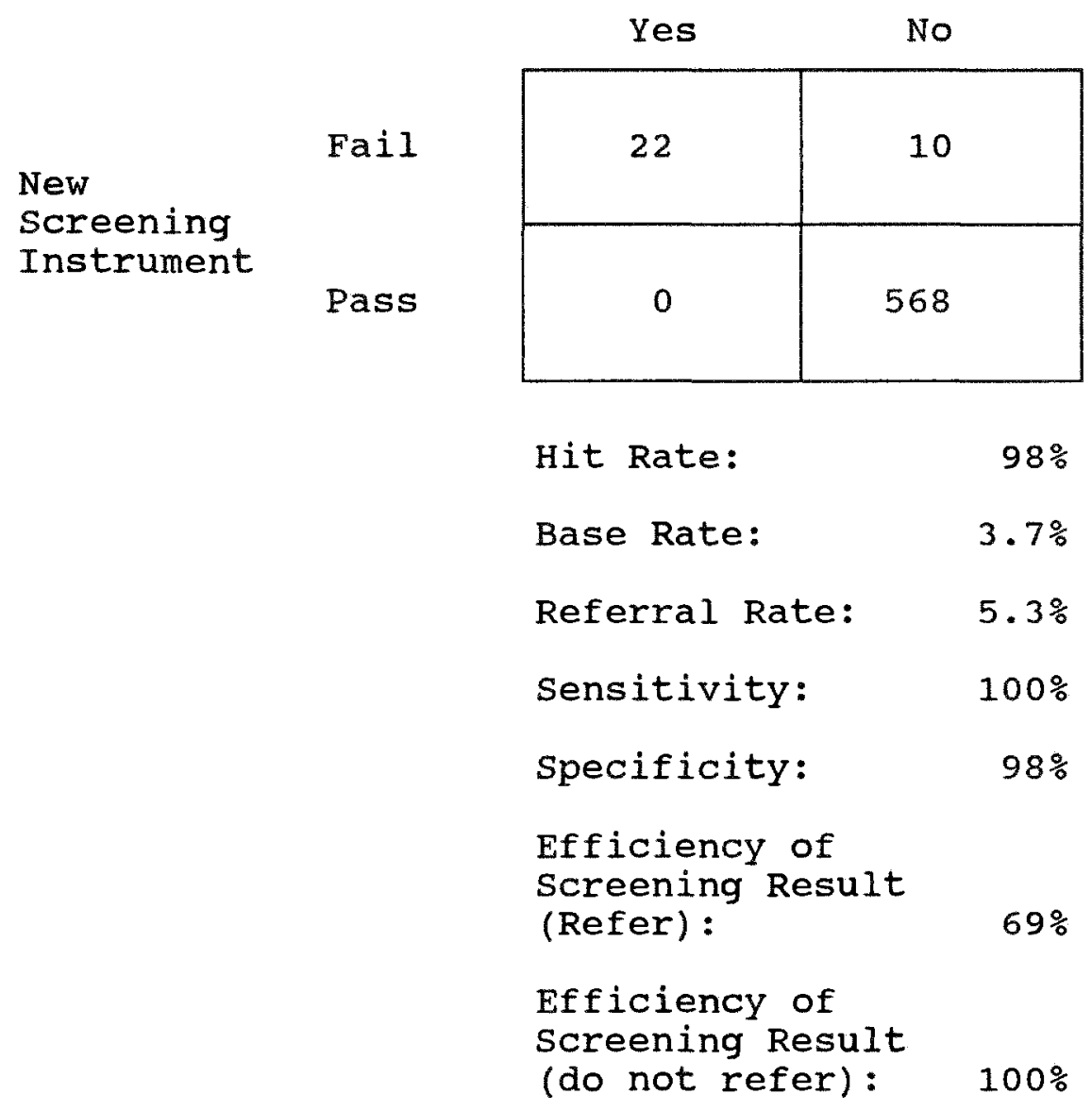

Note: Of the twenty two true positives seven were EMH and fifteen were language impaired.

For Sample Two the sensitivity and specificity scores were $100 \%$ and $98 \%$ respectively. These scores are exactly the same as for Sample One. The significance of each score is also the same, i.e. the sensitivity score 
means that none of the children who passed the screening test were eventually identified as language impaired or educable mentally handicapped and the specificity score means that only a small percentage of the children screened (2\%) who did not qualify for Dade County Public school services failed the screening test.

The efficiency of screening result (refer) score of $69 \%$ means that once a child fails the screening test and is referred for testing there is a $69 \%$ chance of that child requiring exceptional student services. This score for Sample Two was similar to the score obtained for Sample One (66\%).

Tables 21 thru 23 illustrate, for Sample Two, how the screening test positively identified children for testing, regardless of their ethnicity, in similar ethnic proportions as in the Head Start population. Thus, once again, the screening test did not discriminate along ethnic lines. 
Table 21

Characteristics of True Positives for Sample Two

\begin{tabular}{lrr|rrr|rrr}
\hline Ethnicity & $\#$ & $\%$ & Age & $\#$ & $\%$ & Sex & $\#$ & $\%$ \\
\hline African American & 11 & $50 \%$ & 3 & 5 & $23 \%$ & Male & 13 & $59 \%$ \\
Hispanic & 5 & $23 \%$ & 4 & 10 & $45 \%$ & Female & 9 & $41 \%$ \\
Haitian & 5 & $23 \%$ & 5 & 7 & $32 \%$ & & & \\
White & 1 & $4 \%$ & & & & & & \\
\hline
\end{tabular}

Table 22

Characteristics of False Positives for Sample Two

\begin{tabular}{lrr|rrr|lll}
\hline Ethnicity & $\#$ & $\%$ & Age & $\#$ & $\%$ & Sex & $\#$ & $\%$ \\
\hline African American & 5 & $50 \%$ & 3 & 4 & $40 \%$ & Male & 6 & $60 \%$ \\
Hispanic & 3 & $30 \%$ & 4 & 5 & $50 \%$ & Female & 4 & $40 \%$ \\
Haitian & 2 & $20 \%$ & 5 & 1 & $10 \%$ & & & \\
White & 0 & $0 \%$ & & & & & & \\
\hline
\end{tabular}


Table 23

Characteristics of Children Categorized as Positive (Refer

For Testing) for Sample Two

\begin{tabular}{lrr|rrr|lll}
\hline Ethnicity & \multirow{2}{*}{$*$} & \multirow{2}{*}{ Age } & $\#$ & $\%$ & Sex & $\#$ & $\%$ \\
\hline African American & 16 & $50 \%$ & 3 & 9 & $28 \%$ & Male & 19 & $59 \%$ \\
Hispanic & 8 & $25 \%$ & 4 & 15 & $47 \%$ & Female & 13 & $41 \%$ \\
Haitian & 7 & $22 \%$ & 5 & 8 & $25 \%$ & & & \\
White & 1 & $3 \%$ & & & & & \\
\hline
\end{tabular}

These results show that the screening instrument is a valid and reliable predictor of the language impaired and educable mentally handicapped categories as defined by DCPS for the Head Start population in Dade County.

For both samples, the data suggests that the screening instrument becomes a better predictor with increasing age of the child (see Tables 24 and 25). In Sample One, 50\% of the three year old children who failed the screening test qualified for placement in a language impaired or EMH program as compared to $63 \%$ of the four year olds, and $89 \%$ of the five year olds. In Sample Two, $56 \%$ of the three year old failures qualified compared with $67 \%$ of the four year olds and $88 \%$ of the five year olds. 
Table 24

Percentage of Children Categorized as True Positives for Each Age Group for sample one

\begin{tabular}{c|c|c}
\hline Age & $\begin{array}{c}\text { Total Referred } \\
\text { for Testing }\end{array}$ & $\begin{array}{c}\text { Total True } \\
\text { Positives }\end{array}$ \\
\hline 3 & 10 & 5 or $50 \%$ \\
4 & 16 & 10 or $63 \%$ \\
9 & 8 or $89 \%$ \\
\hline
\end{tabular}

Table 25

Percentage of Children Categorized as True Positives for Each Age Group for Sample Two

\begin{tabular}{c|c|c}
\hline Age & $\begin{array}{c}\text { Total Referred } \\
\text { for Testing }\end{array}$ & $\begin{array}{r}\text { Total True } \\
\text { Positives }\end{array}$ \\
\hline 3 & 9 & 5 or $56 \%$ \\
5 & 15 & 10 or $67 \%$ \\
8 & 7 or $88 \%$ \\
\hline
\end{tabular}

The screening instrument yielded similar base rate scores for both samples The Base Rate for sample one was 3.8\% (2.8\% language impaired and $1 \% \mathrm{EMH})$. This Base Rate result is interpreted as meaning that for a Dade County Head Start population of 4,000 children it can be predicted 
that 112 would be identified as language impaired $(4,000 \times .028)$ and 40 would be identified as educable mentally handicapped $(4,000 \times .01)$. The Base Rate for Sample Two was 3.7\% (2.5\% language impaired and $1.2 \%$ $\mathrm{EMH}$ ). This Base Rate result is interpreted as meaning that for a Dade County Head Start population of 4,000 children it can be expected that 100 would be identified as language impaired $(4,000 \times .025)$ and 48 would be identified as educable mentally handicapped $(4,000 \times .012)$. These base rate scores were similar to the base rate scores achieved by the previously administered screening test reported in Appendix B (Denver $=3.5 \%$, DIAL $=3 \%$, Dallas $=2.5 \%$, and Brigance $=3.5 \%$ ). These similar base rates indicate a consistency in the amount of language impaired and educable mentally handicapped children actually present in the Dade County Head Start program. This means that we can be certain of the percentage of language impaired and EMH children (as defined by DCPS) that are in the local Head Start program. A study by Stewart, Hester, and Taylor (1986) found a similar base rate for the prevalence of language disorders in an urban preschool Head Start population. In their study a base rate of $2.6 \%$ was obtained.

The null hypotheses were tested by using the chi square, a 
nonparametric test of significance. The Fisher's Exact Test (one tail) was computed when the cell counts were less than twenty. This procedure was used to show whether the new test was more accurate than the previously utilized commercial screening tests. Tables 26 through 37 display the results of this procedure. The sensitivity counts from each of the four commercial screening tests were compared to the sensitivity counts of the new screening test. The specificity counts of only two of the commercial screening tests (Developmental Inventories for the Assessment of Learning-Revised and the Brigance Early Screen) were compared to the specificity counts of the new screening test because the specificity counts of the other two commercial tests (Denver Developmental Screening Test-Revised and Dallas Preschool Screening Test) yielded a score of $100 \%$.

Table 26 displays the results of the chi square procedure comparing the new test's sensitivity count (for Sample One) with the sensitivity count of the DDST-R. The result of the chi square and the Fisher's Exact Test indicates that there was a significant difference between the new test's ability to identify the target population when compared to the DDST-R. This result means that the new test is significantly better at identifying the target population children than the DDST-R. 
Table 26

Chi Square for New Test and Denver Developmental screening

Test - Revised (DDST-R) with sample one for sensitivity

Test

New Test DDST-R

Validity

Result

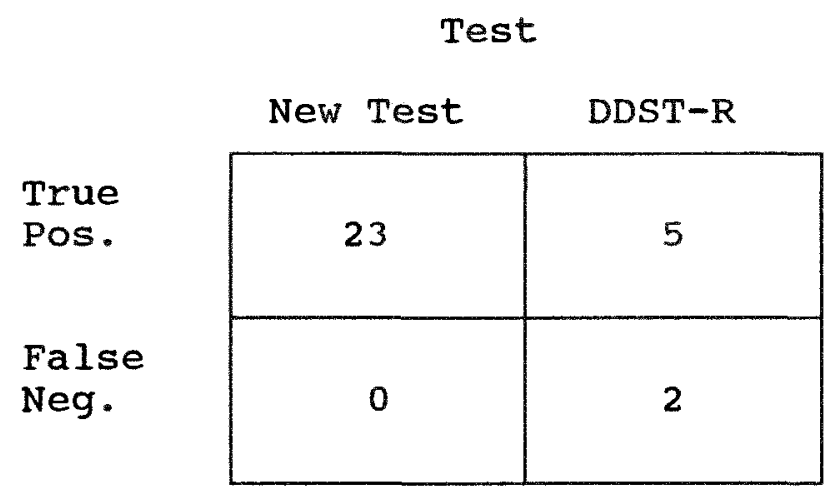

Note: Pearson Value $=7.04$, Degrees of Freedom $=1$, significant at the .008 level

Note:Fisher's Exact Test significant at the .048 level 
Table 27

Chi Square for New Test and Denver Developmental Screening Test - Revised (DDST-R) With Sample Two for sensitivity

Test

New Test DDST-R

Validity

Result

\begin{tabular}{|c|c|}
\hline 22 & 5 \\
\hline 0 & 2 \\
\hline
\end{tabular}

Note: Pearson Value $=6.75$, Degrees of Freedom $=1$, Significant at the .009 level

Note:Fisher's Exact Test significant at the .05 level

Table 27 displays the results of the chi square procedure comparing the new test's sensitivity count (for Sample Two) with the sensitivity count of the DDST-R. The result of the chi square and the Fisher's Exact Test indicates that there was a significant difference between the new test's ability to identify the target population when compared to the DDST-R. This result means that the new test is significantly better at identifying the target population children than the DDST-R. 
Table 28

Chi Square for New Test and Developmental Indicators for the Assessment of Learning-Revised (DIAL-R) with Sample one for Sensitivity

Test

Validity

Result

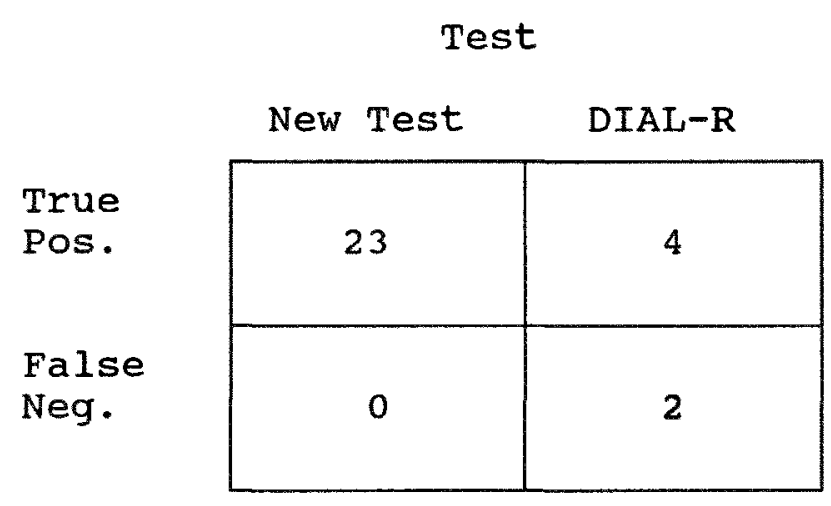

Note: Pearson Value $=8.23$, Degrees of Freedom $=1$, significant at the .004 level

Note: Fisher's Exact Test significant at the .036 level

Table 28 displays the results of the chi square procedure comparing the new test's sensitivity count (for Sample One) with the sensitivity count of the DIAL-R. The result of the chi square and the Fisher's Exact Test indicates that there was a significant difference between the new test's ability to identify the target population when compared to the DIAL-R. This result means that the new test is significantly better at identifying the target population children than the DIAL-R. 
Table 29

Chi Square for New Test and Developmental Indicators for the Assessment of Learning-Revised (DIAL-R) With Sample Two for Sensitivity

Test

Validity

Result

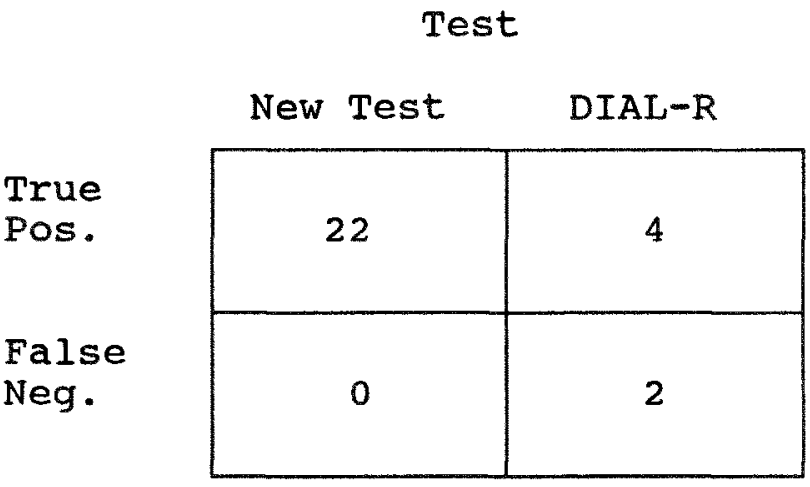

Note: Pearson Value $=7.897$, Degrees of Freedom $=1$, Significant at the .005 level

Note: Fisher's Exact Test significant at the .04 level

Table 29 displays the results of the chi square procedure comparing the new test's sensitivity count (for Sample Two) with the sensitivity count of the DIAL-R. The result of the chi square and the Fisher's Exact Test indicates that there was a significant difference between the new test's ability to identify the target population when compared to the DIAL-R. This result means that the new test is significantly better at identifying the target population children than the DIAL-R. 
Table 30

Chi Square for New Test and Developmental Indicators for the Assessment of Learning-R (DIAL-R) With Sample one for Specificity

Ralidity

Result

\begin{tabular}{ll|c|c|} 
& & New Test & DIAL-R \\
\cline { 2 - 3 } & $\begin{array}{l}\text { False } \\
\text { Pos. }\end{array}$ & 12 & 22 \\
Validity & $\begin{array}{l}\text { True } \\
\text { Result }\end{array}$ & 565 & 172 \\
\cline { 3 - 4 } & &
\end{tabular}

Note: Pearson Value $=29.536$, Degrees of Freedom $=1$, Significant at the .001 level

Table 30 displays the results of the chi square procedure comparing the new test's specificity count (for Sample One) with the specificity count of the DIAL-R. The result of the chi square indicates that there is a significant difference between the new test's ability to select out the children who are not in the target population when compared to the DIAL-R. 
Table 31

Chi Square for New Test and Developmental Indicators for the Assessment of Learning-R (DIAL-R) With Sample Two for

specificity

idity

Result

Test

New Test DIAL-R

\begin{tabular}{|c|c|c|c|}
\hline \multirow{2}{*}{$\begin{array}{l}\text { Validity } \\
\text { Result }\end{array}$} & $\begin{array}{l}\text { False } \\
\text { Pos. }\end{array}$ & 10 & 22 \\
\hline & $\begin{array}{l}\text { True } \\
\text { Neg. }\end{array}$ & 568 & 172 \\
\hline
\end{tabular}

Note: Pearson Value $=23.76$, Degrees of Freedom $=1$, Significant at the .001 level

Table 31 displays the results of the chi square procedure comparing the new test's specificity count (for Sample Two) with the specificity count of the DIAL-R. The result of the chi square indicates that there is a significant difference between the new test's ability to select out the children who are not in the target population when compared to the DIAL-R. 
Table 32

Chi Square for New Test and Dallas Preschool Screening Test With sample one for Sensitivity

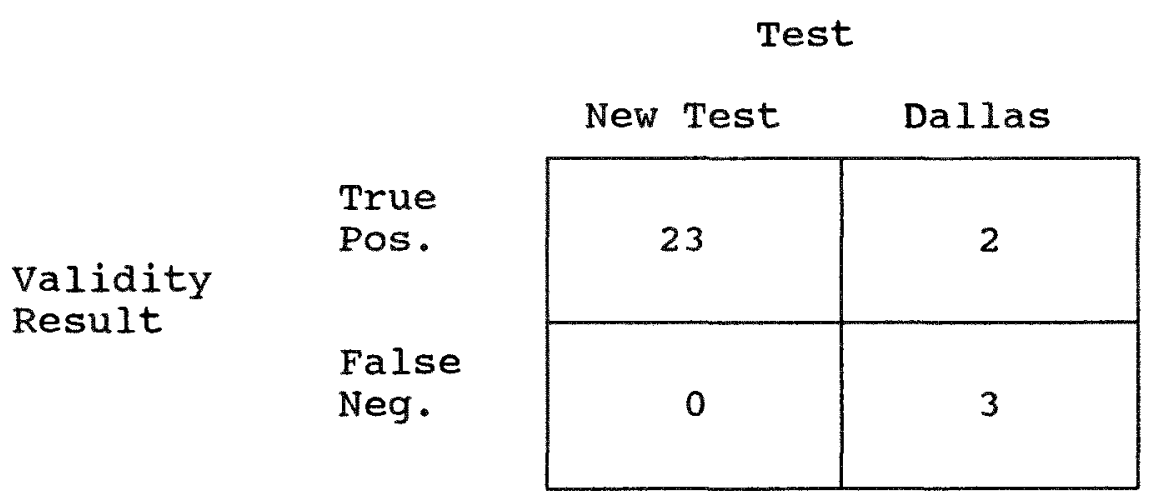

Note: Pearson Value $=15.456$, Degrees of Freedom $=1$, Significant at the .00008 level

Note: Fisher's Exact Test significant at the .003 level

Table 32 displays the results of the chi square procedure comparing the new test's sensitivity count (for Sample One) with the sensitivity count of the Dallas. The result of the chi square and the Fisher's Exact Test indicates that there was a significant difference between the new test's ability to identify the target population when compared to the Dallas. This result means that the new test is significantly better at identifying the target population children than the Dallas. 
Table 33

Chi Square for New Test and Dallas Preschool Screening Test With Sample Two for Sensitivity

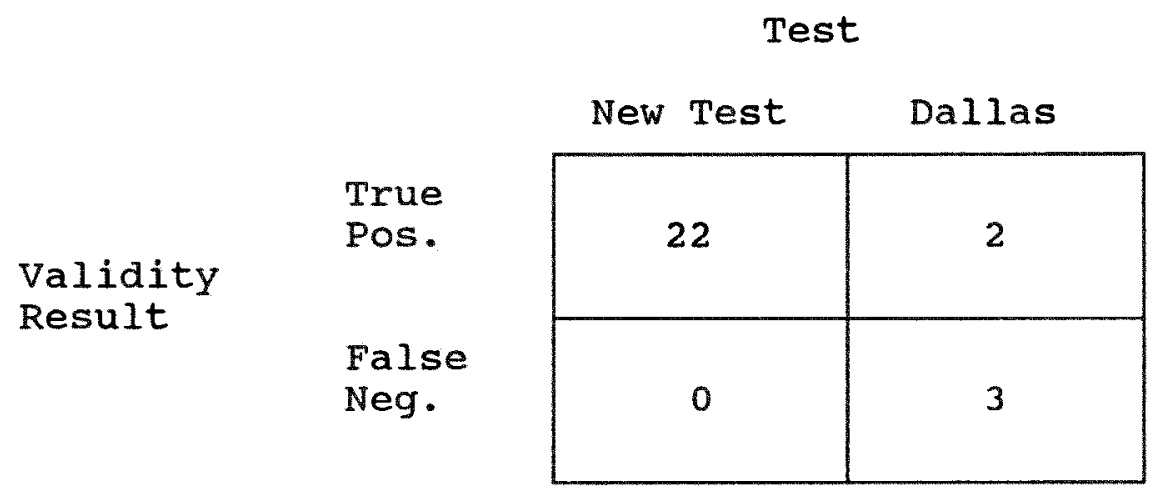

Note: Pearson Value $=14.85$, Degrees of Freedom $=1$, Significant at the .00012 level

Note:Fisher's Exact Test significant at the .003 level

Table 33 displays the results of the chi square procedure comparing the new test's sensitivity count (for Sample Two) with the sensitivity count of the Dallas. The result of the chi square and the Fisher's Exact Test indicates that there was a significant difference between the new test's ability to identify the target population when compared to the Dallas. This result means that the new test is significantly better at identifying the target population children than the Dallas. 
Table 34

Chi Square for New Test and Brigance Early Screen With Sample One for sensitivity

Test

Validity

Result

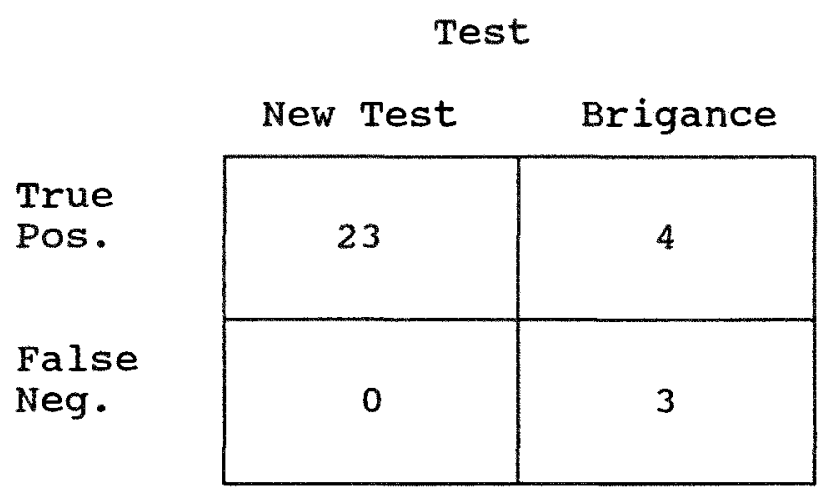

Note: Pearson Value $=10.95$, Degrees of Freedom $=1$,

Significant at the .00093 level

Note:Fisher's Exact Test significant at the .0086 level

Table 34 displays the results of the chi square procedure comparing the new test's sensitivity count (for Sample One) with the sensitivity count of the Brigance. The result of the chi square and the Fisher's Exact Test indicates that there was a significant difference between the new test's ability to identify the target population when compared to the Brigance. This result means that the new test is significantly better at identifying the target population children than the Brigance. 
Table 35

Chi Square for New Test and Brigance Early Screen With Sample Two for sensitivity

\section{Test}

Validity

Result

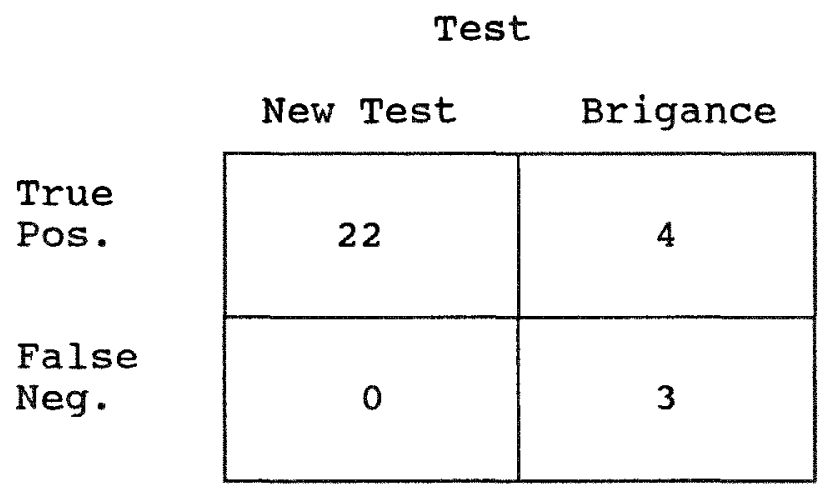

Note: Pearson Value $=10.51$, Degrees of Freedom $=1$, Significant at the .001 level

Note: Fisher's Exact Test significant at the .0096 level

Table 35 displays the results of the chi square procedure comparing the new test's sensitivity count (for Sample Two) with the sensitivity count of the Brigance. The result of the chi square and the Fisher's Exact Test indicates that there was a significant difference between the new test's ability to identify the target population when compared to the Brigance. This result means that the new test is significantly better at identifying the target population children than the Brigance. 
Table 36

Chi Square for New Test and Brigance Early Screen with Sample one for specificity

Validity

Result

\begin{tabular}{|c|c|c|}
\hline & \multicolumn{2}{|c|}{ Test } \\
\hline & New Test & Brigance \\
\hline $\begin{array}{l}\text { False } \\
\text { Pos. }\end{array}$ & 12 & 12 \\
\hline $\begin{array}{l}\text { True } \\
\text { Neg. }\end{array}$ & 565 & 181 \\
\hline
\end{tabular}

Note: Pearson Value $=8.2$, Degrees of Freedom $=1$, significant at the .004 level

Table 36 displays the results of the chi square procedure comparing the new test's specificity count (for Sample One) with the specificity count of the Brigance. The result of the chi square indicates that there is a significant difference between the new test's ability to select out the children who are not in the target population when compared to the Brigance. 
Table 37

Chi Square for New Test and Brigance Early Screen With Sample Two for specificity

Validity

Result

Test

New Test Brigance

\begin{tabular}{|c|c|}
\hline 10 & 12 \\
\hline 568 & 181 \\
\hline
\end{tabular}

Note: Pearson Value $=10.5$, Degrees of Freedom $=1$, Significant at the .0012 level

Table 37 displays the results of the chi square procedure comparing the new test's specificity count (for Sample Two) with the specificity count of the Brigance. The result of the chi square indicates that there is a significant difference between the new test's ability to select out the children who are not in the target population when compared to the Brigance. 


\section{CHAPTER IV}

\section{Discussion}

\section{Summary}

This study investigated the accuracy of a newly constructed screening instrument in identifying children, three to five years of age, in the Dade County Head Start Program, who qualify for placement into an exceptional student program for the language impaired or educable mentally handicapped (EMH) in the Dade County Public School (DCPS) system. Previously used commercial screening instruments were demonstrated to be unsatisfactory for this purpose.

The new screening instrument was constructed by utilizing existing test items from the Learning Accomplishment Profile - Diagnostic (LAP-D), an assessment tool designed to estimate the developmental level of young children in the following areas: fine $\&$ gross motor, cognitive, language, and self-help. The new instrument consisted of four items from the Language Naming subtest of the LAP-D: LN6 (names use of three common objects), LN7 (names three common objects by use), LN9 (names ten pictures of common objects), and LN11 (names eight actions in pictures). These items had been identified as being highly predictive of whether a child qualified 
for DCPS programs in the categories of language impaired or EMH through a detailed crosstabulation process. This process consisted of examining the test protocols of 500 previously evaluated Head Start children by crosstabulating each child's performance (pass or fail) with his or her ultimate qualification for special services (qualify or not qualify for language impaired or EMH placement) based upon a comprehensive psychoeducational assessment.

The new screening instrument was demonstrated to be both reliable and valid for the classification purposes for which it was designed. The reliability of the screening instrument was shown by test-retest coefficients ranging from .85 to 1.00 and interrater reliability coefficients ranging from .79 to 1.00 using a random sample of Head Start children.

The new screening instrument was validated using a double sample technique as recommended by Lichtenstein \& Ireton (1984). Two samples, each consisting of 600 randomly sampled children from the Dade County Head Start program, were utilized for the validation procedure. Each child was administered the screening instrument and then processed through a psychoeducational evaluation procedure in order to obtain the hit rate data. The double sample hit rate data demonstrated consistency in assigning 
children to the hit rate categories. The sensitivity and specificity scores for each of the samples was $100 \%$ and $98 \%$ respectively with Chi square values also indicating a significant difference. Therefore, the null hypotheses were rejected, i.e. null hypothesis one: there is no significant difference between the sensitivity scores of the new screening instrument and the sensitivity scores of the previously used commercial screening tests for the identification of language impaired and educable mentally handicapped Head Start children for Dade County Public School programs; and null hypothesis two: there is no significant difference between the specificity scores of the new screening instrument and the specificity scores of the previously used commercial screening tests for the identification of language impaired and educable mentally handicapped Head Start children for Dade County Public School programs.

Further, the new screening instrument was characterized by features which lent themselves to validity and reliability. The instrument consisted of uniform materials and precise instructions as to how it was to be administered, scored, and interpreted. The establishment of local decision rules by using data from the same population on which the screening instrument was to be used ensured a fairness in the process and enhanced the 
ability to conduct direct comparisons between samples.

The acceptability of the screening instrument to other professionals and administrators was not a factor since the LAP-D is a highly reputable instrument which is widely used throughout the United States. As previously indicated, the Dade County Public School System not only uses the LAP-D during the assessment of potentially handicapped children to obtain developmental skill age levels, but also uses the LAP-D as the basis for writing a child's IEP (Individual Educational Program). The study was successful because of the clear definitions of: a) population to be screened, b) population to be identified, c) criteria to determine who will be referred for a comprehensive assessment, and d) criteria for determining who is eligible for intervention services. The DCPS eligibility criteria places strict parameters upon the comprehensive evaluation step of the district's early intervention process. These DCPS guidelines for services have defined the categories or constructs to the point that make a high level of prediction possible.

Implications for Practice

The development of the new screening instrument has two important implications. The first implication relates to the high degree of accuracy of 
the new instrument. The instrument's capability of accurately identifying all Dade County Head Start children who will qualify as language impaired or EMH insures that these children will receive the special services they require.

The second implication relates in two ways to the efficiency of the new instrument. First, the new instrument takes approximately half the time to administer as does the previously used procedure. This allows for a more cost-effective screening program. Since the DCPS screening program screens 4,000 Head Start children each school year, the screening period can be cut from eight months to four months. Second, the capability of the instrument to select out those children who do not have special needs means that children will not go on for an unnecessary psychoeducational evaluation. This represents another saving of time and personnel utilization for DCPS.

\section{Areas for Future Research}

Future research related to this study may focus on a number of areas. First, other localities or school districts that may be starting a preschool screening program or that may be interested in improving the efficiency of their current screening program may want to consider a similar type of 
process for developing an instrument. The new instrument developed in this study was successful because it was targeted for a particular population. Before developing a local screening test, school districts and preschool screening programs must take into consideration the characteristics of their own population and the children they are interested in identifying when formulating goals and objectives.

Second, research should focus on the monitoring of the continual effectiveness of this new instrument. The possibility exists that the nature of the Head Start population may change, in ethnic make-up, possibly resulting in the predictive power of the four items used for the test being reduced. Therefore, each year, the sensitivity and specificity of the new instrument should be evaluated. In the event that the instrument is found to lose its predictive ability to a significant extent, there would need to be a reexamination of the items passed and failed during the comprehensive evaluation step.

Third, the long-term predictive validity of the new instrument could be evaluated. This would involve following over time children who had been given the screening instrument to determine if their status (i.e. true positive, false positive, true negative, false negative) held up as the children 
progressed through school.

$\underline{\text { Limitations }}$

The limitations of this study are related to what made this study successful. A target population was identified and clearly defined, and an instrument was constructed for this target population based on their actual responses on an assessment instrument. Therefore, use of this new screening instrument should be limited to the children in the Dade County Head Start program who are being considered for possible placement in the DCPS for language impaired or educable mentally handicapped services.

This study focused on children with substantial language problems and mild cognitive problems. In this population, identification can occur at an early point in time. However, for young children with lesser degrees of difficulties (e.g., mild problems in language areas), early identification is more difficult. The existing literature focuses on the necessity to utilize such means as spontaneous language sampling (Allen, 1989) and more comprehensive language screening tests (Sommers, 1989) in early identification. However, these methods require highly trained professionals for administration and interpretation. This would put a great deal of pressure on a mass preschool screening program, such as the one that exists in 
DCPS, in terms of cost and time efficiency.

Lichtenstein and Ireton (1991), following a review of the early identification literature, state that although there are limits on prediction when it is applied to the relationship between developmental assessment and future development, there can be expected to be a stronger relationship between preschool screening and in-depth developmental assessment. Although, this new screening instrument was able to predict which children would be eligible for language impaired and educable mentally handicapped placement as defined by DCPS system, this does not preclude the possibility that some of the children who passed the screening will encounter school difficulties in the future.

Finally, the demonstrated effectiveness of the new instrument is limited to identifying Head Start children who will be found eligible for language impaired or educable mentally handicapped placement. No evidence was presented to extend the usefulness of the instrument to other categories of exceptional student education. 


\section{Conclusions and Recommendations}

The results of this study lead to a number of conclusions and recommendations concerning the DCPS preschool screening program and preschool screenings in general. First, the goals of screening and the population to be screened must be clearly defined. These definitions, in turn, shape specific plans about overall screening procedures including the choice of screening instruments, decision rules, and the need for conducting comprehensive evaluations of children. In this study the population to be screened was clearly defined as the children enrolled in the Dade County Head Start program and the task was clearly defined as identifying language impaired and educable mentally handicapped children based upon the Dade County Public School system's procedural guidelines. This clarity contributed to the development of a screening instrument that accurately referred children for a complete psychoeducational evaluation.

Second, three essential elements in screening must be determined for ensuring that valid decisions are made in an efficient manner: a) the base rate, b) the decision rules or process, and c) the accuracy of the outcomes. The screening planner should be aware of the expected frequency of the specific disabilities that occur in the targeted population, should have a 
thorough understanding of the screening decision rules and the comprehensive evaluation criteria, and should have a system in place that evaluates the screening results. This study: a) established the base rate for the target population as being, on average, $3.3 \%$; b) established decision rules that were easy to follow and were directly related to the evaluation criteria; and, c) provided validity results for the new screening instrument by using the hit rate model.

Consequently, it is recommended that the new screening instrument be used with the Dade County Head Start program and all the private preschool and day care centers in Dade County with similar populations because of it's accuracy and cost-effectiveness. Other early intervention programs, such as preschools and day care centers with different types of populations than the one used in this study (e.g., different ethnic and social economic status), are encouraged to follow similar procedures as used in this study to develop a valid instrument for screening their children. If this is not possible, a screening planner should select an instrument best suited for the purpose of the screening, know the instrument's limitations, and be prepared to supplement or substitute for the instrument when it becomes necessary.

Third, cost-effectiveness must be considered. "The screening process 
must be sufficiently thorough to produce valid results, yet brief enough not to be prohibitive in cost." (Lichtenstein \& Ireton, 1991, p. 507). It must be efficient in terms of both time and personnel. In relation to time, the new screening instrument cut in half the time required to screen each child. In relation to personnel, because the instrument did not require professionals to administer, score, or interpret the results, paraprofessionals could be utilized, thereby reducing the cost.

Other conclusions relate to preschool screening in general. Preschool screening should be offered according to a schedule that allows children to proceed expeditiously from screening to follow-up assessment. Screening should be available to young children (early three year olds) and offered thereafter on a periodic or continuous basis because: a) the rate of skill development varies from child to child and b) following some school experience and the effects of maturation more qualified decisions about development can be made.

Preschool screening is an important part of an early child development evaluation process within a comprehensive educational system. It is imperative that the screening process meet the needs and match the population on which it is being used. The new screening instrument 
developed in this study accomplishes and fulfills these requirements. 


\section{APPENDIX A}

\section{Definition of Terms}

Base Rate - The prevalence of the problem to be identified.

In this study it is the amount of children in the

Head Start population who are truly language impaired or educable mentally handicapped. A numerical figure calculated by a formula. This formula yields an estimate of the existing problem that the screening instrument wants to identify.

(Lichtenstein \& Ireton, 1984)

Classification method - Validity of screening instrument is measured by "actual" status of child as determined by some criterion measure. Also known as "hit-rate" model. (Lichtenstein \& Ireton, 1984)

\section{Efficiency of screening result (refer) - Accurate screening} outcome. Is calculated by a formula. This formula yields a figure that is converted to a percentage. This percentage indicates the probability that a decision of "refer" will be accurate in identifying a target group child. (Lichtenstein \& Ireton, 1984) 
Efficiency of screening result (do not refer) - Accurate

screening outcome. Is calculated by a formula. This formula

yields a figure that is converted to a percentage. This

percentage indicates the probability that a decision of

"do not refer" will be accurate in correctly identifying

a child who is not within the target group.

(Lichtenstein \& Ireton, 1984)

False negative or under-referral - Not referred by the screening procedure for testing but in need of service.

(Lichtenstein \& Ireton, 1984)

False positive or over-referral - Referred by the screening procedure for testing but not in need of services.

(Lichtenstein \& Ireton, 1984)

FDLRS/South - Florida Diagnostic and Learning Resources

System/South, one of 18 centers in the State of Florida that supply support services to parents and teachers of children with disabilities. Funding is through Federal, State, and local means. 
Hit Rate - The proportion of accurate screening decisions out of the total number of screening decisions. Originally proposed by Meehl \& Rosen (1955), it has influenced the work of a number of researchers (Barnes, 1982; Lichtenstein, 1981; and Satz \& Fletcher, 1979). Calculated by a formula.

This formula yields a figure which converts to a percentage. This percentage is an index of a screening instrument's accuracy. Should be as close to one or $100 \%$ as possible. (Lichtenstein \& Ireton, 1984)

Language Impaired - Abnormal processing or production of form, function, or content in the language system. (Special Programs and Procedures for Exceptional Students, 1991)

Negative - Child is low risk and not referred for testing. (Lichtenstein \& Ireton, 1984)

Positive - Child is regarded as high risk and will be referred for further testing. (Lichtenstein \& Ireton, 1984) Referral Rate - The total number of children referred for testing by a particular screening instrument. Calculated by a formula which yields a figure. This figure converts 
to a percentage. This percentage should be higher than the

base rate and will thus index the possibility that all of the target group children would have been identified.

\section{(Lichtenstein \& Ireton, 1984)}

Speech Impaired - Disorders of articulation, fluency, or voice which interferes with communication. (Special Programs and Procedures for Exceptional Students, 1991)

Sensitivity - A screening measure's capacity for identifying those children with special problems. Calculated by a formula which yields a figure. This figure converts to a percentage which indexes the true positives. This percentage should be as close to one or $100 \%$ as possible. (Lichtenstein \& Ireton, 1984)

Specificity - A screening procedure's accuracy in selecting out those children who do not have special needs.

Calculated by a formula which yields a figure. This figure converts to a percentage which indexes the true negatives. Should be as close to one or $100 \%$ as possible, but typically $70 \%$ or above. (Lichtenstein \& Ireton, 1984) 
True negative - Not referred by the screening procedure for testing and not in need of services. (Lichtenstein \& Ireton, 1984) True positive - Referred by the screening procedure for testing and in need of service. (Lichtenstein \& Ireton, 1984) 


\section{APPENDIX B}

The following is a description and a listing of the "hit rate" data recorded for each of the four commercial screening tests used in the past by DCPS with the Dade County Head Start population. The sources for the descriptions were the test manuals and Southworth, Burr, \& Cox (1981).

\section{Denver Developmental Screening Test - Revised (DDST-R)}

Authors: William K. Frankenburg and Josiah B. Dodds

Date: 1981

Purpose: To identify significant motor, social, and/or language problems through the use of a series of developmental tasks

Age Range: 1 month to 6 years

Time to Administer: 10 to 20 minutes

Description: The DDST-R consists of 105 items that are arranged according to the areas of Personal-Social, Fine Motor-Adaptive, Language, and Gross Motor. On the test form an age range of expected performance is shown for each of the items. Tasks are administered according to the child's age. These tasks are scored on the form as Pass, Fail, or Questionable and yield a profile of the child's performance. Final results for each sector are categorized as "normal", "abnormal", or "questionable". The 
Test was developed at the University of Colorado Medical Center.

Norms, Reliability, Validity: The normative sample consisted of 1036 children living in Denver, Colorado, between the ages of 2 weeks and 6.4 years. Of the total tested, 543 were male and 493 were female. The ethnic make-up of the sample was $82 \%$ White, $11 \%$ Hispanic, and $7 \%$ Black. The occupation of the subjects' fathers were $17.5 \%$ Professional, 17\% Managerial, $11.4 \%$ Salesman, 36.1\% Craftsman, and 18\% Unskilled. TestRetest reliability was conducted using 20 children and one examiner. The manual states that "for each child the percent of items performed the same way one week later ranged from $90 \%$ to $100 \% "$ (p.62). Two hundred thirtysix children were administered the DDST-R and the Stanford-Binet or the Revised Bayley Scale of Infant Tests. Validity results were $73 \%$ true positives, $92 \%$ true negatives, $7.2 \%$ false positives, and $2.95 \%$ false negatives.

Critique: a) for the 3-5 year range the items are not relevant to school functioning, b) normative sample is not similar to that of Dade County Head Start population, c) use of the DDST-R with the Head Start program in Dade County has produced too many false negatives (see Table B-2 section B and sensitivity figure). 
The following table is a description of the characteristics of the children used to obtain the Hit Rate data for the Denver Developmental Screening Test-Revised. These children were randomly selected from the Dade County Head Start program.

Table B-1

Characteristics of Sample for Hit Rate Validity of DDST-R

\begin{tabular}{|c|c|c|c|c|c|}
\hline Ethnicity & $\%$ & Age & $\%$ & Sex & $\%$ \\
\hline African American & $51 \%$ & Three & $33.3 \%$ & Male & $51 \%$ \\
\hline Hispanic & $25 \%$ & Four & $33.3 \%$ & Female & $49 \%$ \\
\hline Haitian & $22 \%$ & Five & $33.3 \%$ & & \\
\hline White & $2 \%$ & & & & \\
\hline
\end{tabular}


Table $B-2$

Hit Rate for DDST-R with Dade county Head start Program

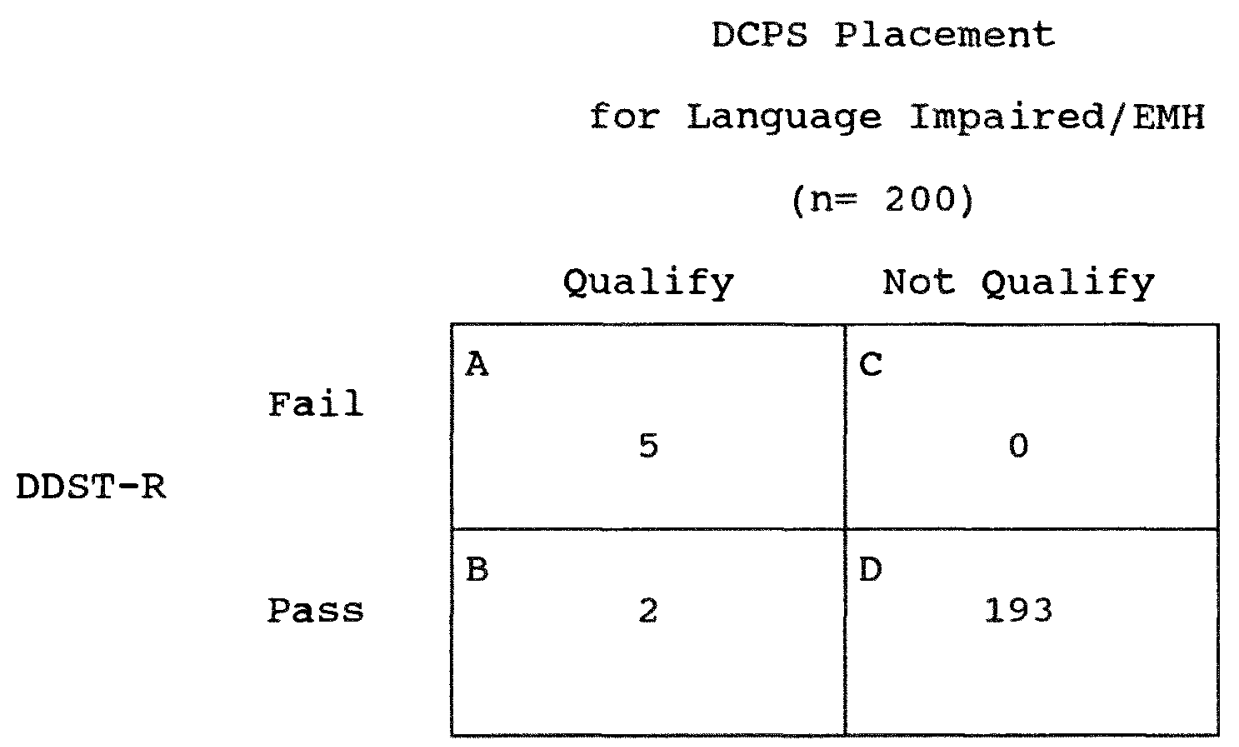

Note:Data obtained from screenings and evaluations of the Dade

County Head Start Program by DCPS in 1987. The children were randomly

selected and following the screening each child was administered a

psychoeducational evaluation in order to determine validity.

Note: Of these two false negatives both qualified for language

impaired.

Note: Of the seven children who qualified for services two were for EMH and five were for language impaired.

Note:Base rate $=2.5 \%$ language impaired and $1 \% \mathrm{EMH}$ 
Hit Rate:

Base Rate:

Referral Rate:

Sensitivity:

Specificity:

Efficiency of screening result (refer)

Efficiency of screening result (do not refer)

$$
\frac{A+D}{A+B+C+D}=\frac{5+193}{5+2+0+193}=.99=99 \%
$$

$$
\frac{A+B}{A+B+C+D}=\frac{5+2}{5+2+0+193}=.035=3.5 \%
$$

$$
\frac{A+C}{A+B+C+D}=\frac{5+0}{5+2+0+193}=.025=2.5 \%
$$

$$
\frac{A}{A+B}=\frac{5}{5+2}=.714=71.4 \%
$$

$$
\frac{D}{C+D}=\frac{191}{0+193}=1=100 \%
$$

$$
\frac{A}{A+C}=\frac{5}{5+0}=1=100 \%
$$$$
\frac{D}{B+D}=\frac{193}{2+193}=.989=99 \%
$$

Analysis: Specificity score is perfect meaning that every child who failed the screening was identified. However, the sensitivity score was .71 which indicates that there is a $71 \%$ probability that this screening instrument will identify the target population (language impaired and EMH children). This sensitivity score is too low. Although all the children that failed the screening qualified for DCPS services, two children were overlooked or misidentified as not at-risk. These two children would not have received the services that they needed. 


\section{Developmental Indicators for the Assessment of Learning-R (DIAL-R)}

Authors: Carol Mardell-Czudnowski and Dorothea Goldenberg

\section{Date: 1983}

Purpose: To identify children in need of follow-up services because of learning problems.

Age Range: 2 to 6 years

Time to Administer: 20 to 30 minutes per child

Description: DIAL-R is a multidimension screening test that requires a station approach. Three stations are set up to screen for the following areas of functioning: Motor (Fine \& Gross), Concept, and Communication. The scale is administered by a professional or trained paraprofessional. The test includes 24 items plus 8 additional behavioral items. Results can be reported using cutoff points for total scores or area scores for different percentile scores for all-white or all non-white populations. The total score is used to classify a child as belonging to one of three groups: "potential problem", "ok", or "potential gifted", based on performances of 1.5 or more standard deviations below or above the mean. A national stratified subsample of 1,861 children, adjusted to match the 1980 census (73\% white and $27 \%$ nonwhite), was used to establish explicit cutoff points for screening 
decisions.

Norms, Reliability, Validity: The latent-trait method was used to evaluate item characteristics based on a sample of 2447 children (ages 2-0 to 5-11), of whom 1089 were nonwhite children. The sample was stratified on the basis of chronological age, sex ( $51 \%$ male \& $49 \%$ female), ethnicity ( $56 \%$ white \& 44\% nonwhite), geographic region (4 regions), and size of community ( $>50,000-52 \%$ and $<50,000-48 \%$ ). Internal consistency reliabilities reported by age levels vary widely across area, and range from .41 to .88 (the median reliability for the three areas combined was approximately .74). The median reliability for the total score was approximately .86 . Test-retest reliabilities based on one study; $(N=65$, with a variable interval for retests); were .76 (Motor),.895 (Concepts), .77 (Language), and .87 (Total). No data are presented on interrater reliability. Critique: a) administration time is too long for efficient screening purposes, b) requires too many screeners for a screening, c) there is no hit rate information, c) normative sample is not compatible with Dade County Head Start Program, d) a study by Jacob, Snider, and Wilson (1988) on the validation of the DIAL-R found that although it is useful in identifying children in need of services "a screening program that incorporates locally 
validated decision-to-refer rules and multiple cutoffs is likely to maximize the usefulness of DIAL-R results for identifying children with special education needs" (p. 295), e)hit Rate for DIAL-R with the Dade County Head Start Program shows to many false positives and some false negatives (see Table B-4 sections B and C, and sensitivity, specificity, and efficiency of outcome (refer) figures).

The following table is a description of the characteristics of the children used to obtain the Hit Rate data for the Developmental Indicators for the Assessment of Learning-Revised. These children were randomly selected from the Dade County Head Start program.

Table B-3

Characteristics of Sample for Hit Rate Validity of DIAL-R

\begin{tabular}{lc|cc|c}
\hline Ethnicity & $\%$ & Age & Sex $\%$ \\
\hline African American & $48 \%$ & Three & $33.3 \%$ & Male 50.5\% \\
Hispanic & $28 \%$ & Four & $33.3 \%$ & Female 49.5\% \\
Haitian & $23 \%$ & Five & $33.3 \%$ & \\
White & $1 \%$ & & & \\
\hline
\end{tabular}




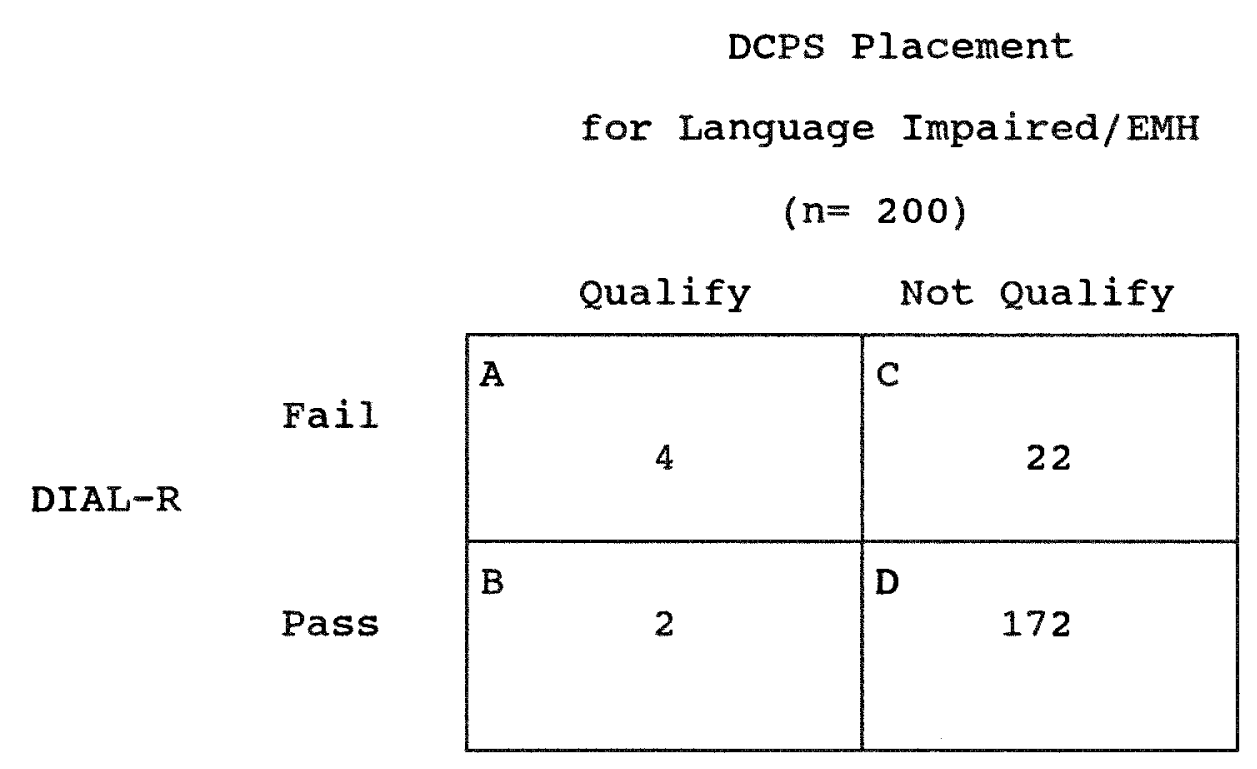

Note:Data obtained from screenings and evaluations of Dade County Head Start by DCPS in 1988 . The children were randomly selected and following the screening each child was administered a psychoeducational evaluation in order to determine validity. Note: Of these two false negatives both qualified for language impaired.

Note: Of the six who qualified for services three were for EMH and three were for language impaired.

Note: Base rate $=1.5 \%$ language impaired and $1.5 \% \mathrm{EMH}$. 
Hit Rate:

$$
\frac{A+D}{A+B+C+D}=\frac{4+172}{4+2+22+172}=.88=88 \%
$$

Base Rate:

$$
\frac{A+B}{A+B+C+D}=\frac{4+2}{4+2+22+172}=.03=
$$

Referral Rate:

$$
\frac{A+C}{A+B+C+D}=\frac{4+22}{4+2+22+172}=.13=13 \%
$$

Sensitivity:

$$
\frac{A}{A+B}=\frac{4}{4+2}=.666=66.6 \%
$$

Specificity:

$$
\frac{D}{C+D}=\frac{172}{22+172}=.886=88.6 \%
$$

Efficiency of screening result

$$
\frac{A}{A+C}=\frac{4}{4+22}=.153=15.3 \%
$$
(refer)

Efficiency of screening result (do not refer)

$$
\frac{D}{B+D}=\frac{172}{2+172}=.988=98.8 \%
$$

Analysis: Sensitivity and specificity scores are too low. Twenty-two children were false positive and two children were false negative. There is only a $66.6 \%$ probability of identifying the target child and an $88.6 \%$ probability of the test instrument accurately selecting out the language impaired or EMH child. 


\section{Dallas Preschool Screening Test}

Authors: Robert R. Percival and Suzanne Poxon

Date: 1972

Purpose: To identify learning disabilities of young children.

Age Range: 3 to 6 years

Time to Administer: 15 minutes

Description: The test screens six areas: Auditory, Language, Motor, Visual, Psychological, and Articulation. Developmental age levels are given for each item, ranging from 3 to 6 years. A profile sheet summarizes the information.

Norms, Reliability, Validity: The standardization of the Dallas involved approximately 3,000 children. A random sample of 3, 4, and 5 year olds in the Richardson School District, a suburb of Dallas, Texas, was used. This district is described as being "above average in education, social, and financial status" (p. 11). Approximately 100 black children were evaluated with no significant difference in any of the means as compared with the total sample group. A kindergarten class of Mexican-Americans was tested using a Spanish translation. The only significantly different scores were in the area of language where the Hispanic children scored below the 
expected norm. Test-retest information was obtained by testing 23 pupils in a two week interval. This procedure yielded correlation figures which ranged from .77 to .95 in the various areas. A validity study was conducted using the Columbia Mental Maturity Test. This study yielded correlation coefficients of .59 for 4 year olds and .68 for 3 year olds. Other test correlations with the Dallas were: PPVT (.46), Detroit Motor Subtest (.56), Draw A Man (.59). Expected scores were obtained by testing 60 children in each age category.

Critique: a) normative sample is not compatible with Dade County Head Start Program, b) hit rate data is not available, c) hit rate for Dallas with the Dade County Head Start Program shows false negatives (see Table B-6 section $\mathrm{B}$ and sensitivity figure). 
The following table is a description of the characteristics of the children used to obtain the Hit Rate data for the Dallas Preschool Screening Test. These children were randomly selected from the Dade County Head Start program.

Table B-5

Characteristics of Sample for Hit Rate Validity of Dallas

\begin{tabular}{lc|cc|c}
\hline Ethnicity & $\%$ & Age & Sex $\%$ \\
\hline African American & $52 \%$ & Three & $33.3 \%$ & Male $50 \%$ \\
Hispanic & $24 \%$ & Four & $33.3 \%$ & Female 50\% \\
Haitian & $23 \%$ & Five & $33.3 \%$ & \\
White & $1 \%$ & & & \\
\hline
\end{tabular}


Table $B-6$

Hit Rate for Dallas with Dade County Head start Program

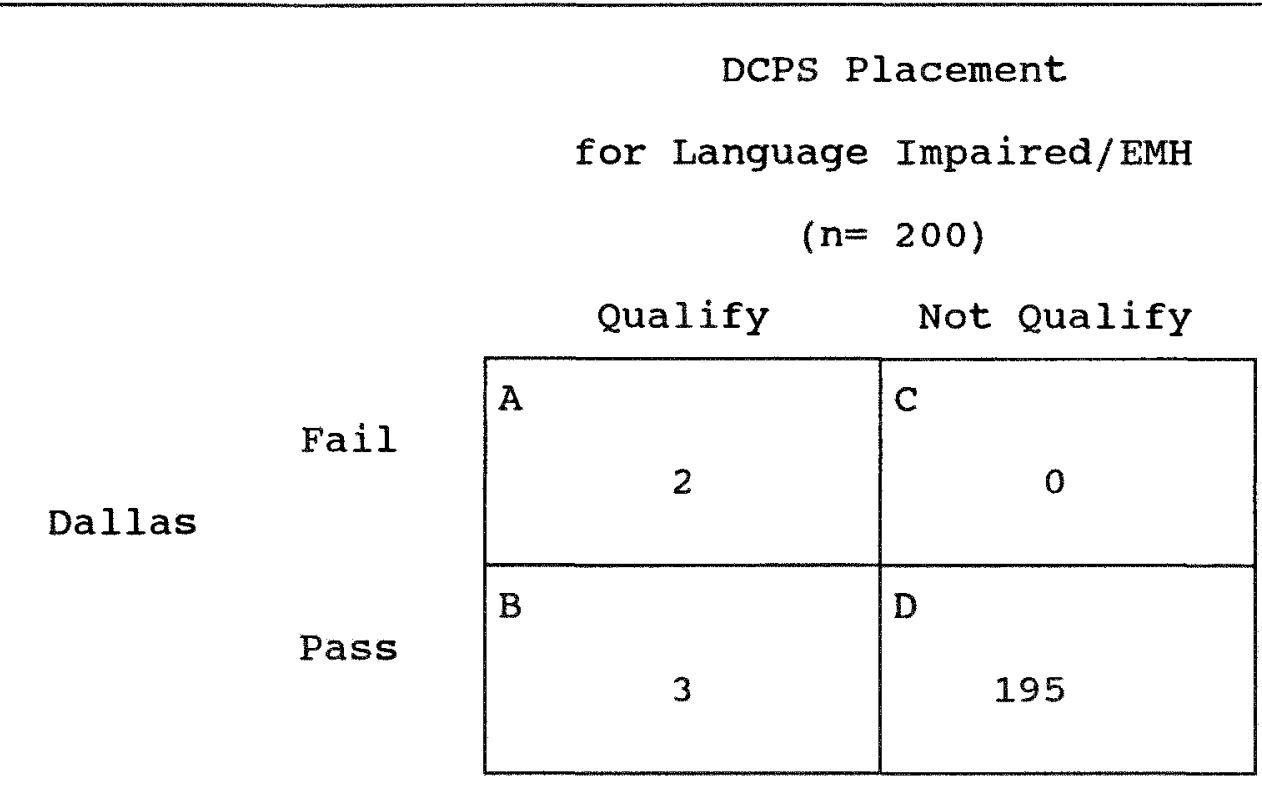

Note:Data obtained from screenings and evaluations of Dade County

Head Start Program by DCPS in 1989. The children were randomly

selected and following the screening each child was administered a psychoeducational evaluation in order to determine validity.

Note:Of these three false negatives, all three qualified for language impaired.

Note:Of the five children who qualified for services one was for EMH and four were for language impaired.

$\underline{\text { Note }}:$ Base rate $=2 \%$ language impaired and $.5 \% \mathrm{EMH}$ 
Hit Rate:

$$
\frac{A+D}{A+B+C+D}=\frac{2+195}{2+3+0+195}=.985=98.5 \%
$$

Base Rate:

$$
\frac{A+B}{A+B+C+D}=\frac{2+3}{2+3+0+195}=.025=2.5 \%
$$

Referral Rate:

$$
\frac{A+C}{A+B+C+D}=\frac{2+0}{2+3+0+195}=.01=1 \%
$$

Sensitivity:

$$
\frac{A}{A+B}=\frac{2}{2+3}=.4=40 \%
$$

Specificity:

$$
\frac{D}{C+D}=\frac{195}{0+195}=1=100 \%
$$

Efficiency of screening result (refer)

$$
\frac{A}{A+C}=\frac{2}{2+0}=1=100 \%
$$

Efficiency of screening result $\frac{D}{B+D}=\frac{195}{3+195}=.984=98.4 \%$ (do not refer)

Analysis: The specificity score is perfect indicating that this instrument is not referring children unnecessarily. However, the sensitivity score is .40 meaning that there is only a $40 \%$ probability that this test is identifying the target population. 


\section{Brigance Preschool Screen (BPS)}

Author: Albert H. Brigance

Date: 1985

Purpose: To provide a sampling of a child's learning, development, and skills in a broad range of areas. The areas sampled are language, motor, numbers, body awareness, and visual discrimination.

Age Range: 3 and 4 year olds

Time to Administer: 10 to 12 minutes

Description: The Brigance Preschool Screen is a criterion referenced test. The BPS is made up of a three year old screen and a four year old screen. There are 11 skills assessed with versions of the Brigance. Each individual skill has a maximum score (either 6,9 , or 10 depending on the skill). The highest possible total score is 100 . A cutoff score of 60 is recommended by the author. Any child scoring below this cutoff score should be referred for further evaluation. The author also recommends that a local cutoff score be established.

Norms, Reliability, Validity: The manual eludes to history, field testing, and critiquing; however, there is no mention of reliability or validity data. There is a description of how educators from 12 states were asked to 
evaluate the content validity. There is no mention of construct, criterionrelated validity, test-retest reliability, or internal constancy.

Also, there is no information on hit rate.

Critique: a) no normative sample information, b) no hit rate data, c) hit rate for Brigance with Dade County Head Start Program shows too many false positives and some false negatives (see Table B-8 sections B and C, sensitivity and efficiency of screening outcome "refer" figures).

The following table is a description of the characteristics of the children used to obtain the Hit Rate data for the Brigance Early Screen. These children were randomly selected from the Dade County Head Start program.

Table B-7

Characteristics of Sample for Hit Rate Validity of Brigance

\begin{tabular}{lc|cc|c}
\hline & $\%$ & Age & Sex $\%$ \\
Ethnicity & & Three & $33.3 \%$ & Male $52 \%$ \\
African American & $50 \%$ & Four & $33.3 \%$ & Female $48 \%$ \\
Hispanic & $25 \%$ & Five & $33.3 \%$ & \\
Haitian & $24 \%$ & & & \\
White & $1 \%$ & & & \\
\hline
\end{tabular}


Table $B-8$

Hit Rate for Brigance with Dade County Head start Program

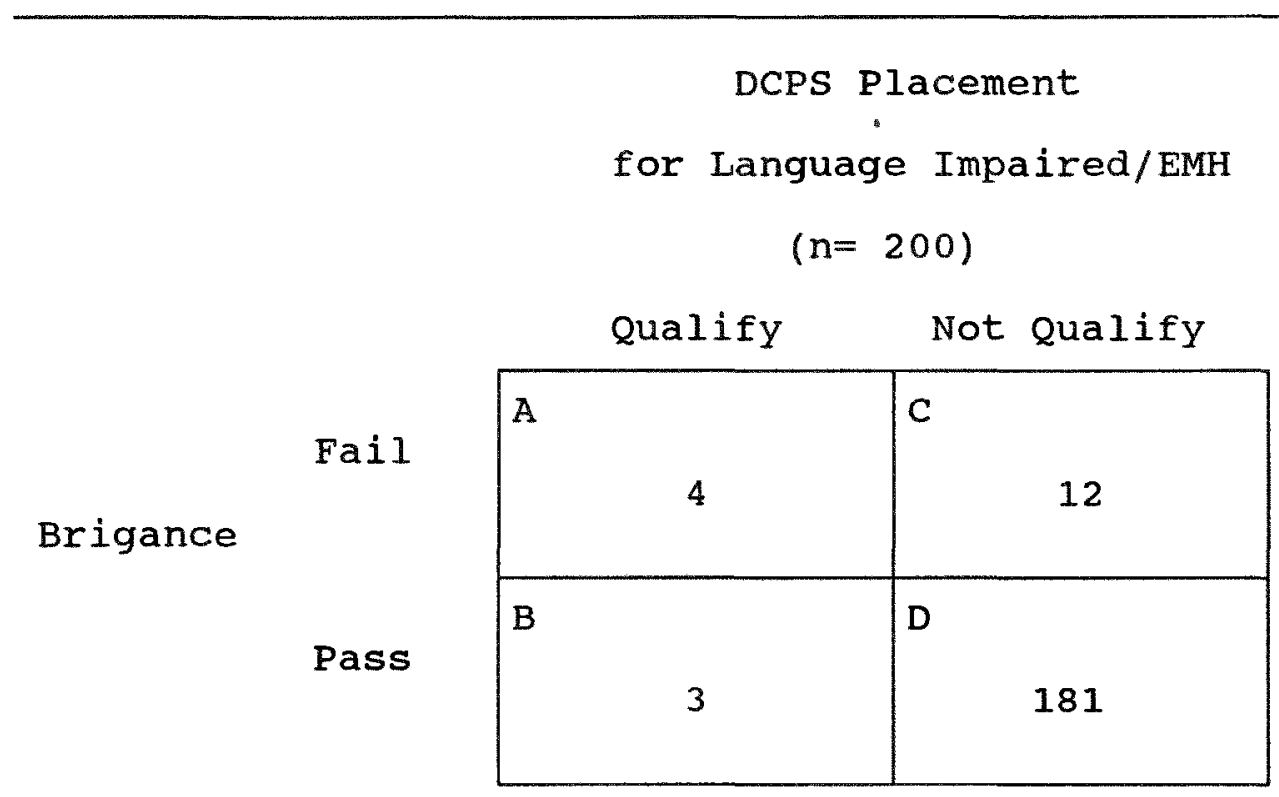

Note:Data obtained from screenings and evaluations of Dade County Head Start Program by DCPS in 1990.

Note:Randomly selected for screening and evaluation.

Note: Of these three false negatives all three qualified for language impaired.

Note:Of the seven who qualified for services two were for EMH and five were for language impaired.

Note: Base rate $=2.5 \%$ language impaired and $1 \% \mathrm{EMH}$ 
Hit Rate:

Base Rate:

Referral Rate:

Sensitivity:

Specificity:

Efficiency of screening result (refer)

Efficiency of screening result (do not refer)
$\frac{A+D}{A+B+C+D}=\frac{4+181}{4+3+12+181}=.925=92.5 \%$ $\frac{A+B}{A+B+C+D}=\frac{4+3}{4+3+12+181}=.035=3.5 \%$ $\frac{A+C}{A+B+C+D}=\frac{4+12}{4+3+12+181}=.08=8 \%$ $\frac{A}{A+B}=\frac{4}{4+3}=.57=57 \%$ $\frac{D}{C+D}=\frac{181}{12+181}=.937=93.7 \%$ $\frac{A}{A+C}=\frac{4}{4+12}=.25=25 \%$ $\frac{D}{B+D}=\frac{181}{3+181}=.98=98 \%$

Analysis: Sensitivity and Specificity scores are too low. Twelve children were false positive and three children were false negative. There is only a $57 \%$ probability of identifying the target child and an $93.7 \%$ probability of the test instrument accurately selecting out the language impaired or EMH child. 


\section{APPENDIX C}

The following is a compressed version of the Dade County Public

Schools procedural guidelines for the two handicapping conditions considered in this study.

\section{Language Impaired}

A. Children below age 5 .

1. There is a significant difference between language performance and other developmental behaviors.

Significant difference is defined as greater than one standard deviation or $30 \%$ or more difference between language age scores and other developmental behavior scores (e.g., mental age, fine motor, gross motor, self-help, adaptive behavior).

or

2. There is a significant difference between receptive and expressive language abilities. Significant difference is defined as $30 \%$ or more difference between receptive language age scores and expressive language are scores. 
B. Children age 5

1. There is a significant difference between language performance and nonverbal performance. Significant difference is defined as two or more standard deviations.

or

2. There is a significant difference between receptive and expressive language scores.

Significant difference is defined as two or more standard deviations.

or

3. Two or more, but not all, components of the language system are rated moderately, or severely impaired on a language severity rating scale.

II. Educable Mentally Handicapped - Children of all ages A. The measured level of general intellectual functioning is two or more standard deviations below the mean and generally falls between two and three 
standard deviations below the mean. The standard error of measurement may be considered in individual cases. The profile of intellectual functioning shows consistent subaverage performance in a majority of the areas evaluated.

and

B. The assessed level of adaptive behavior is below that of other students of the same age and socio-cultural group. and

C. The demonstrated level of performance in academic, preacademic, or developmental achievement is subaverage. 


\section{APPENDIX D}

The following is a description of the commercial instruments that were examined for item predictability as to whether a Head Start child qualified or not for Language Impaired or EMH placement into the DCPS Preschool Program.

Expressive One-Word Picture Vocabulary Test (EOWPVT)

Author: Morrison F. Gardner

Date: 1979

Purpose: To obtain an estimate of a child's expressive verbal intelligence by means of one-word expressive picture vocabulary.

Age Range: 2 to 12 years

Time to Administer: 10 to 15 minutes

Description: In this test the child demonstrates his/her ability to understand and use words by naming pictures of single objects. There are 112 test plates, one picture to a page. The child names each picture as the examiner turns the pages of a flip book. Testing is started with the plate at the child's chronological age; instructions are given for establishing a basal age and a ceiling age so that all items do not have to be presented. The raw score may be converted to mental age, deviation IQ, stanine, and percentile rank by 
reference to tables in the manual. The 32-page manual also includes a discussion of research background, test development, and statistical development.

Norms, Reliability, Validity: Standardization was accomplished with a sample of 1,607 children in the San Francisco Bay area. The age range of the sample was 2 years to 11 years 11 months. In the sample the percentage of males was 47.5 and the percentage of females was 52.5 . The "racialcultural composition of the sample was: Whites (81.6\%), Blacks (11.5\%), Hispanics $(5.2 \%)$, and Other (1.7\%). These children attended public, private, and parochial schools. Split-half reliability coefficients were computed for each age group and ranged from .87 to .96 with a median reliability of .94 . Concurrent validity was obtained by correlating IQ scores from the EOWPVT with those from the Peabody Picture Vocabulary Test (PPVT) and the Columbia Mental Maturity Scale (CMMS). Correlations with the PPVT ranged from .67 to .78 , with a median of .70 . Correlations with the CMMS, ranged from .29 to .59 , with a median of .39 .

\section{Learning Accomplishment Profile - Diagnostic (LAP-D):}

Authors: David Wilson Le May; Patricia M. Griffin; Anne R. Sanford; and 
The Chapel Hill Training-Outreach Project, Chapel Hill, North Carolina.

The LAP-D was produced from funding by the Office of Child

Development and the Bureau of Education for the Handicapped, Department of Health, Education, and Welfare.

Date: 1977

Purpose: To evaluate the child's level of skill before entering an instructional program, evaluate the child's exit skills following an instructional program, and validate the effectiveness of an instructional program.

Age Range: 3 months to 72 months

Time to Administer: 45 minutes to one hour

Description: The LAP-D is a developmental skill diagnostic assessment instrument based on the task analysis model. In this type of model, skill development is considered a continuum, moving upward from fundamental behaviors, to complex and learned behaviors. It was made available to the public in 1977. The LAP-D measures the child's developmental skill level in five areas (each area has two subscales except Self-Help which has five). The five areas and subscales with examples of tasks for children between the ages of three years and five years are: 
1)Fine Motor
A)Manipulation - string beads, complete puzzles (six \& eight piece)
B)Writing - copy circle, trace diamond

2)Cognitive
A)Matching - match colors, patterns, and pictures
B)Counting - count by rote (1-3), recite numbers (1-10)

3)Language/Cognitive
A)Naming - Name three common objects, name pictures
B)Comprehension - point to pictures named, point to numbers named

4)Gross Motor
A)Body Movement - Jump, balance, run, skip
B)Object Movement - catch, kick, throw a ball

5)Self-Help
A)Eating
B)Dressing
C)Toileting
D)Grooming
E)Self-Direction

The LAP-D items in each subscale are task-analytically arranged in an 
ascending order of difficulty. Each task is listed with a corresponding developmental age (e.g. Item: Names six body parts -30 months). The tasks and task-developmental age associations were obtained from and based on cumulative research findings in the area of early childhood development by Cattell (1950), Gesell (1940), Griffin (1975), Hammill (1974), Illg and Ames (1955), Lillie (1975), and Sanford (1970). A developmental age score for each subscale is arrived at by computing a basal ( 3 items correct in a row) and a ceiling ( 3 out of 5 items incorrect). The total number of items incorrect is subtracted from the total number of correct items. The number computed by this mathematical process is considered the total number of items successfully completed in the subscale. This total number is then converted to a developmental age score, for each subscale, by using a developmental profile scoring sheet.

Norms, Reliability, Validity: The reliability of the LAP-D was accomplished with the test-retest procedure. Correlation coefficients ranged from .82 to .98 . Inter-rater reliability coefficients were obtained by using three examiners and ranged from .76 to .98 . Validity data is not listed in the manual. 
Leiter International Performance Scale (LIPS) (Arthur Adaptation):

Author: Grace Arthur

Date: 1980

Purpose: To measure nonverbal intelligence

Age Range: 3 thru 7.99 years

Time to Administer: 30 minutes

Description: The Leiter is a point scale which yields a mental age and an I.Q. It does not require verbalization on the part of the examiner or respondent and it does not have time limits. The Leiter contains sixty items. The materials consist of a wooden response frame with an adjustable card holder. All tests are administered by attaching the appropriate picture card to the frame. Directions are pantomimed. The child chooses the matching blocks and inserts them into the frame in an appropriate slot. The types of tasks range from matching of colors and forms to completion of patterns, analogous designs, classification of objects.

Norms, Reliability, Validity: The test was standardized on 289 children. These children were all from "middle class" America. No validity or reliability data is available in the manual. 


\section{Merrill-Palmer Scale of Mental Tests}

Author: Rachel Stutsman

Date: 1931

Purpose: To measure intellectual ability in young children

Age Range: 24 months to 63 months

Time to Administer: One hour

Description: The Merrill-Palmer is comprised of 93 items organized in order of difficulty. It yields a mental age and an I.Q. score. The Merrill-Palmer uses mostly non-verbal tasks to measure mental ability. Speed of performance is emphasized on some of the items. The MerrillPalmer is organized into six month intervals from 18 to 71 months. Motor ability plays an important part in the test. Most of the verbal tasks require one word responses. An example of some of the items are: throwing a ball, cutting with scissors, putting puzzles together, matching colors, counting blocks, copying a star, buttoning buttons, completing a peg board. The mental-age score arrived at is computed into the I.Q.

Norms, Reliability, Validity: The standardization sample included 300 males and 300 females aged one year six months to six years six months who were tested in 1931. Sample characteristics are not available in the 
manual. The manual does not report reliability coefficients.

\section{Peabody Picture Vocabulary Test-Revised (PPVT-R)}

Author: Lloyd and Leota M. Dunn

Date: 1981

Purpose: To measure a child's receptive vocabulary

Age Range: 2 years 6 months to 18 years

Time to Administer: 10 to 20 minutes

Description: The PPVT-R consists of a booklet with 150 test plates each with four numbered pictures. The examiner says the stimulus word and the child responds by pointing to, giving the number of, or otherwise indicating the picture best illustrating the word. Raw scores convert to a standard score, percentile rank, stanine, and an age equivalent.

Norms, Reliability, Validity: The PPVT-R, for ages $21 / 2$ through 18 years, was standardized on 4,200 children based on the population data of the 1970 census. At the early childhood level, the sample was divided into nine 6-month age groups. The sampling included half males and half females. Geographic representation included the four regions of Northeast, South, North Central, and West. Ethnic representation is said to reflect the 
1970 census data and is listed in the manual as: White (85.4\%), Black (9.6\%), Hispanic (3.8\%), and Other (1.2\%). Extensive reliability and validity data are listed in the manual. Split-half reliability coefficients are listed for each age group. No predictive validity is available; however correlations with individual intelligence tests and achievement tests are listed in table form.

\section{Preschool Language Scale (PLS)}

Authors: Ira Zimmerman, Violette Steiner, and Roberta Evatt

Date: 1969

Purpose: The PLS was designed to measure the language ability of children ages two thru six. It evaluate's developmental progress, maturational lag, and strengths and deficiencies in the language skills of young children.

Age Range: 1-6 to 6-11 years

Time to Administer: 30 minutes

Description: The PLS has two scales: Auditory Comprehension and Verbal Ability. The Auditory Comprehension scale is comprised of nonverbal responses such as pointing to a picture which the examiner has named, knowing body parts, following directions, comparing size, distinguishing 
prepositions, grouping objects, recognizing colors, differentiating texture, and distinguishing weight differences. This scale is comprised of forty items. The second scale is Verbal Ability. In this scale the child is required to respond, name, or explain. This scale includes such items as naming animals, pronouncing sounds correctly, naming opposites, repeating digits, repeating sentences, counting, and conversing in sentences.

Norms, Reliability, Validity: None are reported in the manual. 


\section{APPENDIX E}

The Tables E-1 thru E-12 show the results of the crosstabulation process which led to the identification of the four items from the Learning Accomplishment Profile -Diagnostic that formed the new screening test.

Table E-1

Crosstabulation of Test Item LN6 with Qualification for

DCPS Programs for Language Impaired and EMH

Age: 3

Test

Item

LN6

\begin{tabular}{|c|c|c|}
\hline & \multicolumn{2}{|c|}{ qualify } \\
\hline & Yes & No \\
\hline Fail & 138 & 11 \\
\hline Pass & 10 & 47 \\
\hline
\end{tabular}

Sensitivity: $93 \%$

Specificity: $81 \%$ 
Table $E-2$

Crosstabulation of Test Item LN6 with Qualification for DCPS Programs for Lanquage Impaired and EMH

Age: 4

Test

Item

LN6

\begin{tabular}{|c|c|c|}
\hline & & \\
\hline & Yes & No \\
\hline Fail & 105 & 5 \\
\hline Pass & 26 & 82 \\
\hline & Sensi & $80 \%$ \\
\hline & Speci & $94 \%$ \\
\hline
\end{tabular}


Table E-3

Crosstabulation of Test Item LNG with Qualification for DCPS Programs for Lanquage Impaired and EMH

Age: 5

Test

Item

LN6

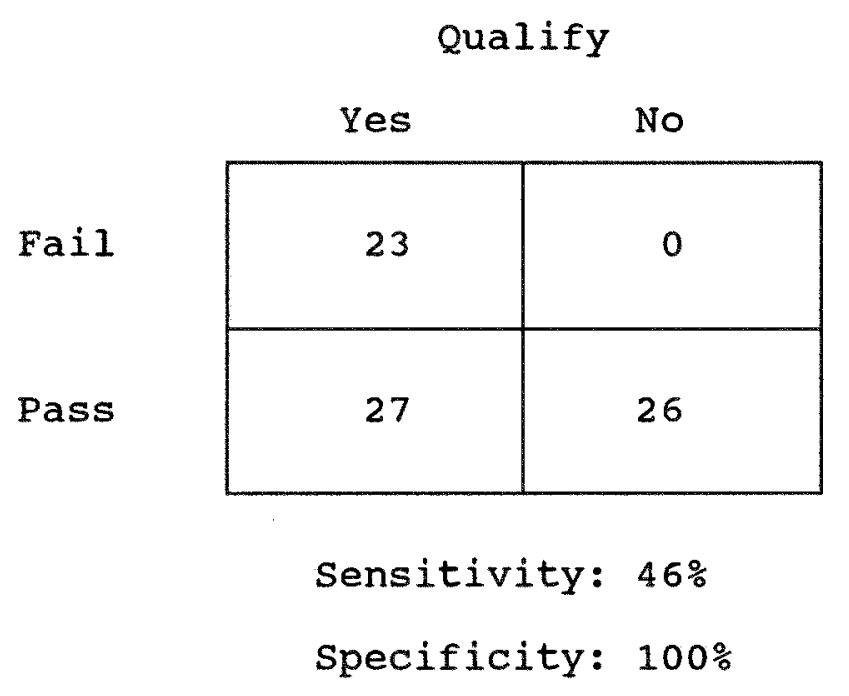


Table E-4

Crosstabulation of Test Item LN7 with Qualification for DCPS Programs for Language Impaired and EMH

Age: 3

Test

Item

LN7

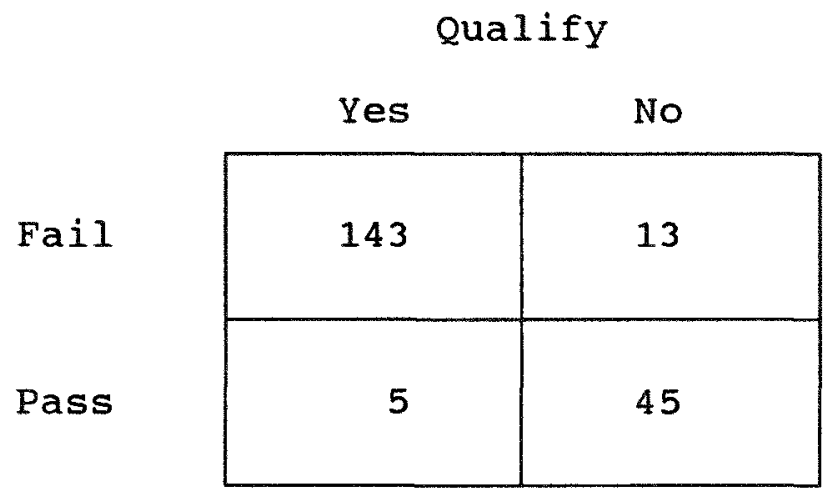

Sensitivity: $97 \%$

Specificity: $78 \%$ 
Table $E-5$

Crosstabulation of Test Item LN7 with Qualification for

DCPS Programs for Language Impaired and EMH

Age: 4

Qualify

\begin{tabular}{|c|c|c|c|}
\hline & & Yes & No \\
\hline \multirow{2}{*}{$\begin{array}{l}\text { Test } \\
\text { Item } \\
\text { LN7 }\end{array}$} & Fail & 116 & 10 \\
\hline & Pass & 15 & 77 \\
\hline
\end{tabular}

Sensitivity: $89 \%$

Specificity: $89 \%$ 
Table E-6

Crosstabulation of Test Item IN7 with oualification for

DCPS Programs for Lanquage Impaired and EMH

Age: 5

Qualify

\begin{tabular}{|c|c|c|c|}
\hline & & Yes & No \\
\hline \multirow{2}{*}{$\begin{array}{l}\text { Test } \\
\text { Item } \\
\text { LN7 }\end{array}$} & Fail & 31 & 0 \\
\hline & Pass & 19 & 26 \\
\hline
\end{tabular}

Sensitivity: $62 \%$

Specificity: $100 \%$ 
Table E-7

Crosstabulation of Test Item LN9 with Qualification for

DCPS Programs for Language Impaired and EMH

Age: 3

Test

Item

LN9

\begin{tabular}{|c|c|c|}
\hline & \multicolumn{2}{|c|}{ Qualify } \\
\hline & Yes & No \\
\hline Fail & 120 & 0 \\
\hline Pass & 28 & 58 \\
\hline
\end{tabular}

Sensitivity: $81 \%$

Specificity: $100 \%$ 
Table E-8

Crosstabulation of Test Item LN9 with Qualification for DCPS Programs for Lanquage Impaired and EMH

Age: 4

Test

Item

LN9

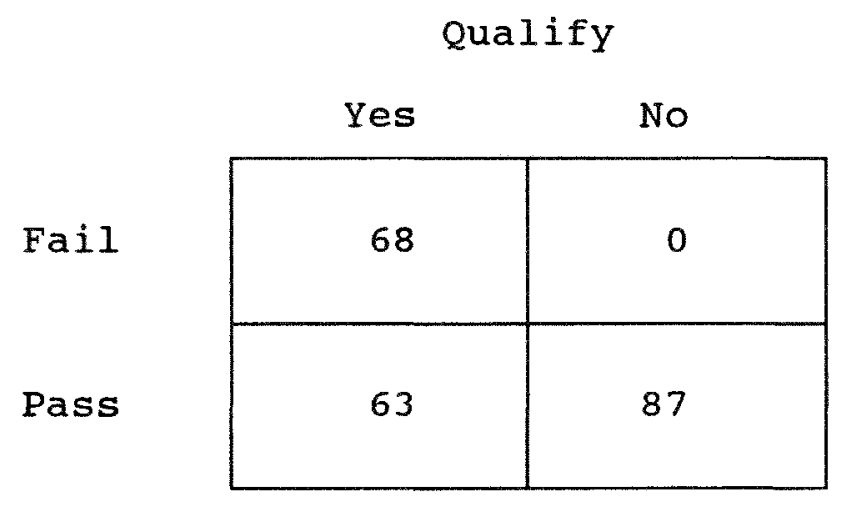

Sensitivity: $52 \%$

Specificity: $100 \%$ 
Table E-9

Crosstabulation of Test Item LN9 with Qualification for DCPS Programs for Language Impaired and EMH

Age: 5

Test

Item

LN9

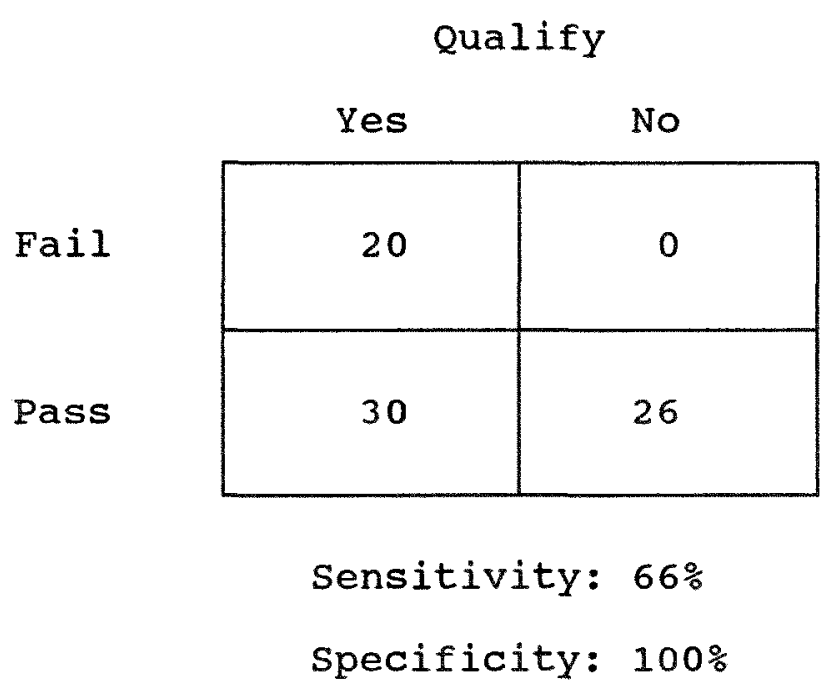


Table E-10

Crosstabulation of Test Item LN11 with Qualification for DCPS Programs for Language Impaired and EMH

Age: 3

Item

LN11

\begin{tabular}{l|r|r|}
\multicolumn{2}{c}{ Qualify } \\
\multicolumn{1}{c}{ Yes } & No \\
\cline { 2 - 3 } Fail & 145 & 33 \\
Pass & 3 & 25 \\
\cline { 2 - 3 } & & \\
\hline
\end{tabular}

Sensitivity: $98 \%$

Specificity: $43 \%$ 
Table E-11

Crosstabulation of Test Item LN11 with Qualification for DCPS Programs for Language Impaired and EMH

Age: 4

Test

Item

LN11

\begin{tabular}{|c|c|c|}
\hline & & \\
\hline & Yes & No \\
\hline Fail & 127 & 13 \\
\hline Pass & 4 & 74 \\
\hline & Sens & $97 \%$ \\
\hline & Spec & $85 \%$ \\
\hline
\end{tabular}


Table E-12

Crosstabulation of Test Item IN11 with Qualification for DCPS Programs for Language Impaired and EMH

Age: 5

Test

Item

LN 11

\begin{tabular}{|c|c|c|}
\hline & \multicolumn{2}{|c|}{ Qualify } \\
\hline \multirow[b]{2}{*}{ Fail } & Yes & No \\
\hline & 49 & 0 \\
\hline \multirow[t]{3}{*}{ Pass } & 1 & 26 \\
\hline & Sensitivity: & $98 \%$ \\
\hline & Specificity: & $100 \%$ \\
\hline
\end{tabular}




\section{APPENDIX F}

The Tables F-1 thru F-24 show the results of the crosstabulation process which led to the decision rules for the screening test (refer or do not refer) for each of the six age ranges (3-0 to $3-5,3-6$ to $3-11,4-0$ to $4-5,4-6$ to 4 $11,5-0$ to $5-5$, and 5-6 to 5-11).

Table $\mathrm{F}-1$

Crosstabulation of Test Item LN6 with Qualification for DCPS Programs for Language Impaired and EMH

Age: $3-0$ to $3-5$

Qualify

\begin{tabular}{|c|c|c|c|}
\hline \multirow{3}{*}{$\begin{array}{l}\text { Test } \\
\text { Item } \\
\text { LN6 }\end{array}$} & \multirow[b]{2}{*}{ Fail } & Yes & No \\
\hline & & 52 & 2 \\
\hline & Pass & 2 & 16 \\
\hline
\end{tabular}

Sensitivity: $96 \%$

Specificity: $89 \%$

Note: Of the two false negatives each failed items LN7, LN9, and LN11.

Note: of the two false positives each passed all of the other items. 
Table F-2

Crosstabulation of Test Item LN6 with Qualification for

DCPS Programs for Language Impaired and EMH

Age: $3-6$ to $3-11$

Test

Item

LN6

\begin{tabular}{l|c|c|} 
& Fail & 96 \\
Pass & 8 & 31 \\
\hline
\end{tabular}

Qualify

Sensitivity: $91 \%$

Specificity: $78 \%$

Note: of the eight false negatives seven failed items LN7, LN9, and LN11. The other one failed items LN7 and LN11.

Note: of the nine false positives five also failed item LN11. one failed item LN7 and LN11. One also failed item LN7. Two did not fail any other item. 
Table $\mathrm{F}-3$

Crosstabulation of Test Item LN6 with Qualification for

DCPS Programs for Lanquage Impaired and EMH

Age: $4-0$ to $4-5$

Test

Item

LN6

$$
\text { qualify }
$$

\begin{tabular}{l|c|c|}
\multicolumn{1}{c}{ Yes } & \multicolumn{1}{c|}{ No } \\
\cline { 2 - 3 } & Fail & 2 \\
Pass & 26 & 33 \\
\hline
\end{tabular}

Sensitivity: $73 \%$

Specificity: $94 \%$

Note: Of the twenty-six false negatives twenty-two failed items LN7 and LN11. Two failed items LN7, LN9, and LN11 and two failed items LN9 and LN11.

Note: Of the two false positives all passed each of the other items. 
Table $F-4$

Crosstabulation of Test Item LNG with Qualification for DCPS Programs for Lanquage Impaired and EMH

Age: $4-6$ to $4-11$

Test

Item

LN6

Fail

Qualify

\begin{tabular}{|c|c|c|c|}
\hline \multirow{3}{*}{$\begin{array}{l}\text { Test } \\
\text { Item } \\
\text { LN6 }\end{array}$} & \multirow[b]{2}{*}{ Fail } & Yes & No \\
\hline & & 33 & 3 \\
\hline & Pass & 0 & 49 \\
\hline
\end{tabular}

Sensitivity: $100 \%$

Specificity: $94 \%$

Note: Of the three false positives one failed items LN7 and LN11. Two also failed item LN7. 
Table F-5

Crosstabulation of Test Item LN6 with Qualification for

DCPS Programs for Language Impaired and EMH

Age: $5-0$ to $5-5$

Qualify

Test

Item

LN6

\begin{tabular}{c|c|c|}
\multicolumn{1}{c}{ Fail } & \multicolumn{1}{c}{ Yes } & \multicolumn{1}{c}{ No } \\
\cline { 2 - 3 } & 20 & 0 \\
Pass & 18 & 24 \\
\hline
\end{tabular}

Sensitivity: $53 \%$

Specificity: $100 \%$

Note: Of the eighteen false negatives three failed item LN7. Ten failed item LN11. Three failed items LN9 and LN11 and two failed items LN7 and LN11. 
Table $F-6$

Crosstabulation of Test Item LN6 with Qualification for DCPS Programs for Language Impaired and EMH

Age: $5-6$ to $5-11$

Qualify

Test

Item

LN6

\begin{tabular}{l|l|l|}
\multicolumn{1}{l}{ Yes } & \multicolumn{1}{c}{ No } \\
\cline { 2 - 3 } Fail & 3 & 0 \\
& & \\
\hline & & \\
\hline & 9 & 2 \\
& & \\
\hline
\end{tabular}

Sensitivity: $25 \%$

Specificity: $100 \%$

Note: Of the nine false negatives six failed item LN11. The other three failed items LN7, LN9, and LN11. 
Table F-7

Crosstabulation of Test Item LN7 with Qualification for DCPS Programs for Language Impaired and EMH

Age: $3-0$ to $3-5$

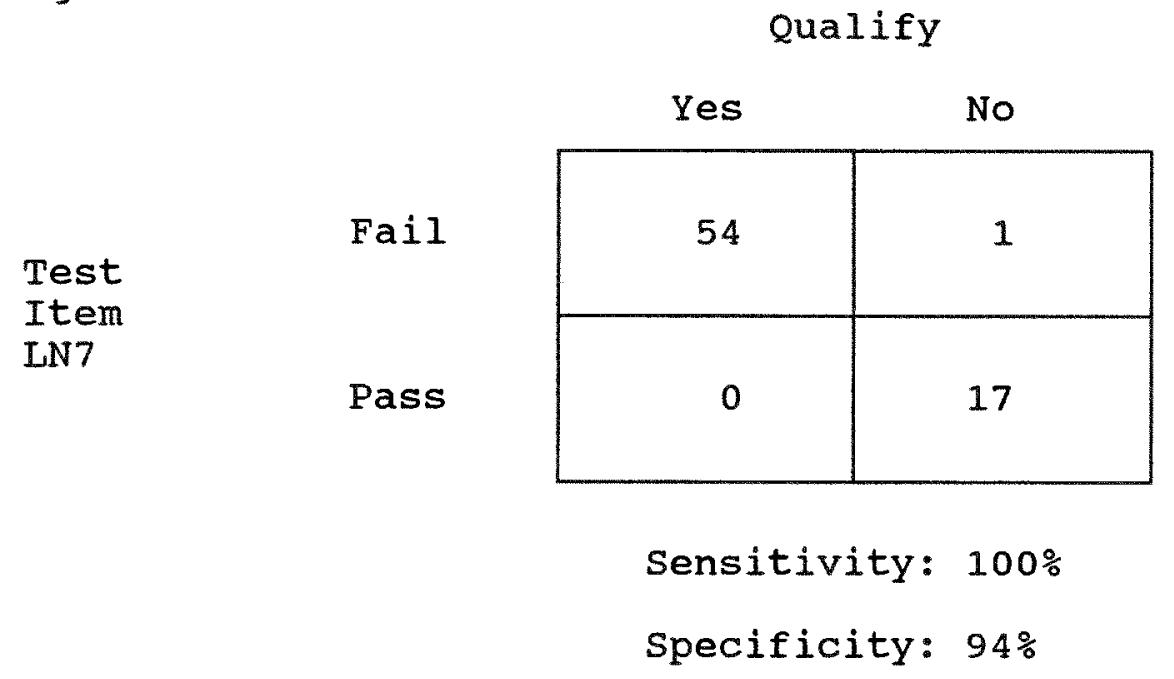

Note: Of the false positive only item LN11 was failed. 
Table $\mathrm{F}-8$

Crosstabulation of Test Item LN7 with Qualification for DCPS Programs for Language Impaired and EMH

Age: $3-6$ to $3-11$

Qualify

Test

Item

LN7

Qualify
Yes
\begin{tabular}{|c|c|}
\hline 89 & 12 \\
\hline 5 & 28 \\
\hline
\end{tabular}

Sensitivity: $95 \%$

Specificity: $70 \%$

Note: Of the five false negatives four failed items LN6, LN9, and LN11. The other one failed items LN6 and LN11. Note: of the twelve false positives one failed items LN6 and LN11. Ten also failed item LN11. One also failed only item LN6. 
Table $F-9$

Crosstabulation of Test Item LN7 with Qualification for DCPS Programs for Lanquage Impaired and EMH

Age: $4-0$ to $4-5$

Test

Item

LN7

Qualify

\begin{tabular}{|c|c|c|}
\hline & Yes & No \\
\hline Fail & 89 & 1 \\
\hline Pass & 9 & 34 \\
\hline
\end{tabular}

Sensitivity: $91 \%$

Specificity: $97 \%$

Note: of the nine false negatives three failed items LN6, LN9, and LN11. Three failed items LN6 and LN11. Two failed items LN9 and LN11. One also failed item LN6. Note: The false positive also failed item LN11. 
Table F-10

Crosstabulation of Test Item LN7 with Qualification for

DCPS Programs for Lanquage Impaired and EMH

Age: $4-6$ to $4-11$

Test

Item

LN7

Qualify

\begin{tabular}{ll|c|c|}
\multicolumn{1}{c}{} & \multicolumn{1}{c}{ Yes } & No \\
\cline { 2 - 3 } & Fail & 27 & 9 \\
Test & & & \\
In7 & Pass & 6 & 43 \\
& & & \\
& &
\end{tabular}

Sensitivity: $82 \%$

Specificity: $83 \%$

Note: Of the six false negatives three failed items LN6, LN9, and LN11. Three failed items LN6 and LN11.

Note: of the nine false positives two failed items LN6 and LN11. One also failed item LN11. Six failed only item LN7. 
Table $F-11$

Crosstabulation of Test Item LN7 with Qualification for

DCPS Programs for Lanquage Impaired and EMH

Age: $5-0$ to $5-5$

Test

Item

LN7

\begin{tabular}{|c|c|c|}
\hline & \multicolumn{2}{|c|}{ Qualify } \\
\hline & Yes & No \\
\hline Fail & 25 & 0 \\
\hline Pass & 13 & 24 \\
\hline
\end{tabular}

Sensitivity: $66 \%$

Specificity: $100 \%$

Note: of the thirteen false negatives three failed items LN9 and LN11. The other ten failed item LN11. 
Table $F-12$

Crosstabulation of Test Item LN7 with Qualification for DCPS Programs for Language Impaired and EMH

Age: $5-6$ to $5-11$

Test

Item

LN7

Qualify
Yes
\begin{tabular}{|c|c|}
\hline 6 & No \\
\hline 6 & 2 \\
\hline
\end{tabular}

Sensitivity: $50 \%$

Specificity: $100 \%$

Note: Of the six false negatives all six failed item LN11. 
Table $F-13$

Crosstabulation of Test Item LN9 with Qualification for

DCPS Programs for Language Impaired and EMH

Age: $3-0$ to $3-5$

Test

Item

LN9

\begin{tabular}{|c|c|c|}
\hline & \multicolumn{2}{|c|}{ Qualify } \\
\hline & Yes & No \\
\hline Fail & 47 & 0 \\
\hline Pass & 7 & 18 \\
\hline
\end{tabular}

Sensitivity: $87 \%$

Specificity: $100 \%$

Note: of the seven false negatives all seven also failed items LN6, LN7, and LN11. 
Table $\mathrm{F}-14$

Crosstabulation of Test Item LN9 with Qualification for

DCPS Programs for Lanquage Impaired and EMH

Age: $3-6$ to $3-11$

$$
\text { Qualify }
$$

\begin{tabular}{|c|c|c|c|}
\hline \multirow{3}{*}{$\begin{array}{l}\text { Test } \\
\text { Item } \\
\text { LN9 }\end{array}$} & \multirow[b]{2}{*}{ Fail } & Yes & No \\
\hline & & 73 & 0 \\
\hline & Pass & 21 & 40 \\
\hline
\end{tabular}

Sensitivity: $78 \%$

Specificity: $100 \%$

Note: Of the twenty-one false negatives eleven failed items LN6, LN7, and LN11. Eight failed items LN6 and LN11 and two failed items LN7 and LN11. 
Table F-15

Crosstabulation of Test Item LN9 with Qualification for

DCPS Programs for Language Impaired and EMH

Age: $4-0$ to $4-5$

Test

Item

LN9

\begin{tabular}{l|c|c|}
\multicolumn{1}{c|}{ Yes } & \multicolumn{1}{c|}{ No } \\
\cline { 2 - 3 } Fail & 50 & 0 \\
\hline \multirow{3}{*}{ Pass } & 48 & 35 \\
\hline
\end{tabular}

Sensitivity: $51 \%$

Specificity: $100 \%$

Note: of the forty-eight false negatives twenty-two failed items LN7 and LN11. Nineteen failed items LN6, LN7, and LN11. Three failed items LN6 and LN11. Three failed LN6 and LN7 and one failed LN6. 
Table F-16

Crosstabulation of Test Item LN9 with Qualification for DCPS Programs for Language Impaired and EMH

Age: $4-6$ to $4-11$

\begin{tabular}{|c|c|c|c|}
\hline & & Yes & No \\
\hline \multirow{2}{*}{$\begin{array}{l}\text { Test } \\
\text { Item } \\
\text { LN9 }\end{array}$} & Fail & 18 & 0 \\
\hline & Pass & 15 & 52 \\
\hline
\end{tabular}

Sensitivity: $55 \%$

Specificity: $100 \%$

Note: of the fifteen false negatives twelve failed items LN6, LN7, and LN11. Three failed items LN6 and LN11. 
Table $\mathrm{F}-17$

Crosstabulation of Test Item LN9 with Qualification for

DCPS Programs for Language Impaired and EMH

Age: $5-0$ to $5-5$

\begin{tabular}{|c|c|c|c|}
\hline & & & \\
\hline & & Yes & No \\
\hline Test & Fail & 14 & 0 \\
\hline & Pass & 24 & 24 \\
\hline
\end{tabular}

Sensitivity: $37 \%$

Specificity: $100 \%$

Note: of the twenty-four false negatives nine failed items LN6, LN7, and LN11. Two failed items LN7 and LN11. Three failed item LN7 and ten failed item LN11. 
Table F-18

Crosstabulation of Test Item LN9 with Qualification for

DCPS Programs for Language Impaired and EMH

Age: $5-5$ to 5-11

Qualify

\begin{tabular}{|c|c|c|c|}
\hline & & Yes & No \\
\hline \multirow{2}{*}{$\begin{array}{l}\text { Test } \\
\text { Item } \\
\text { LN9 }\end{array}$} & Fail & 6 & 0 \\
\hline & Pass & 6 & 2 \\
\hline
\end{tabular}

Sensitivity: $50 \%$

Specificity: $100 \%$

Note: Of the six false negatives all six failed LN11. 
Table F-19

Crosstabulation of Test Item LN11 with Qualification for DCPS Programs for Lanquage Impaired and EMH

Age: $3-0$ to $3-5$

Qualify

Test

Item

LN11

\begin{tabular}{|c|c|c|}
\hline & & \\
\hline & Yes & No \\
\hline Fail & 54 & 15 \\
\hline Pass & 0 & 3 \\
\hline & Sens & $100 \%$ \\
\hline & Spec & $20 \%$ \\
\hline
\end{tabular}

Note: The large number of false positives which produced such a low specificity score is due to the developmental level of this item (48 months). This item is to difficult for a child in this age range. Therefore, this item should not be included in the decision rule for this age range. 
Table $\mathbf{F}-20$

Crosstabulation of Test Item LN11 with Qualification for DCPS Programs for Language Impaired and EMH

Age: $3-6$ to $3-11$

Qualify

Test

Fail

Item

LN11

\begin{tabular}{l|r|r|}
\multicolumn{1}{c}{ Yes } & \multicolumn{1}{c|}{ No } \\
\cline { 2 - 3 } Fail & 91 & 18 \\
Pass & 3 & 22 \\
\hline
\end{tabular}

Sensitivity: $97 \%$

Specificity: $55 \%$

Note: Of the three false negatives all three failed items LN6 and IN7.

Note: The large number of false positives which produced such a low specificity score is due to the developmental level of this item (48 months). This item is to difficult for a child in this age range. Therefore, this item should not be used in the decision rule for this age range. 
Table $\mathrm{F}-21$

Crosstabulation of Test Item LN11 with Qualification for DCPS Programs for Language Impaired and EMH

Age: $4-0$ to $4-5$

Test

Item

LN 11

Qualify

\begin{tabular}{|c|c|c|}
\hline & Yes & No \\
\hline Fail & 94 & 5 \\
\hline Pass & 4 & 30 \\
\hline
\end{tabular}

Sensitivity: $96 \%$

Specificity: $86 \%$

Note: of the four false negatives three failed items LN6 and LN7. The other one failed item LN6.

Note: of the five false positives one failed LN7. Four did not fail any other item. 
Table $F-22$

Crosstabulation of Test Item LN11 with Qualification for DCPS Programs for Lanquage Impaired and EMH

Age: $4-6$ to $4-11$

Test

Item

LN11

\begin{tabular}{l|c|c|}
\multicolumn{2}{c}{ Qualify } \\
Yes & No \\
\cline { 2 - 3 } Fail & 33 & 8 \\
Pass & 0 & 44 \\
\hline
\end{tabular}

Sensitivity: $100 \%$

Specificity: $85 \%$

Note:This item is an excellent predictor of qualification for this age group. The sensitivity score is $100 \%$ which means that no children who passed the item qualified for services. The specificity score is $86 \%$ which means that the item is reasonably accurate in selecting out the children who do not need services.

Note: of the eight false positives one failed items LN6 and LN7. Three failed item LN7. Four did not fail any other item. 
Table $F-23$

Crosstabulation of Test Item LN11 with Qualification for DCPS Programs for Lanquage Impaired and EMH

Age: $5-0$ to $5-5$

Item

LN11

Qualify
Xes
\begin{tabular}{|c|c|}
\hline 37 & 0 \\
\hline 1 & 24 \\
\hline
\end{tabular}

Sensitivity: $97 \%$

Specificity: $100 \%$

Note:The one false negative failed only item LN7. 
Table $\mathrm{F}-24$

Crosstabulation of Test Item LN11 with oualification for DCPS Programs for Lanquage Impaired and EMH

Age: $5-6$ to $5-11$

Test

Item

LN11

\begin{tabular}{|c|c|c|}
\hline & \multicolumn{2}{|c|}{ Qualify } \\
\hline & Yes & No \\
\hline Fail & 12 & 0 \\
\hline Pass & 0 & 2 \\
\hline
\end{tabular}

Sensitivity: $100 \%$

Specificity: $100 \%$

Note: Although this item has scores of $100 \%$ it is too perfect of a predictor for qualification for services for this age group. The specificity score of $100 \%$ could mean that a child was overlooked for services. It is desirable in a screening instrument to have some false positives so that a level of confidence exists such that a child is not erroneously identified as not needing special services. 


\section{APPENDIX G}

The following is a description of the tests that were used for the in-depth psychoeducational evaluation. Generally, one or two intelligence tests, one developmental test, one to three language tests, and one adaptive behavior test constituted the complete evaluation.

\section{Tests of Intelligence}

\section{Differential Abilities Scale (DAS):}

Author: Colin D. Elliott

Date: 1990

Purpose: Measure cognitive and achievement levels of young children.

Age Range: $21 / 2$ thru 7 years

Time to Administer: 25 to 65 minutes

Description: The preschool level of the cognitive battery of the DAS is organized into a set of core subtests that yield a GCA (General Conceptual Ability). A set of diagnostic subtests provide additional information of specific abilities. The DAS is comprised of two levels: 1) 2-6 to 3-5 and 2) 3-6 to 5-11. Level One includes the following Core Subtests (Block Building, Verbal Comprehension, Picture Similarities, Naming Vocabulary) 
and the following Diagnostic Subtests (Recall of Digits, Recognition of Pictures). Level Two includes the following Core Subtests (Verbal Comprehension, Naming Vocabulary, Picture Similarities, Pattern Construction, Copying, Early Number Concepts) and Diagnostic Subtests (Block Building, Matching Letter-Like Forms, Recall of Objects, Recall of Digits, Recognition of Pictures). Raw scores are converted to $\mathrm{T}$ scores and percentiles. Subtest $T$ scores are summed and converted to normalized standard scores.

Norms, Reliability, Validity: The DAS was standardized using 1,175 children. Each age group was evenly divided between males and females. Four ethnic categories were used: White, Black, Hispanic, and Other. The sample was stratified according to four regions: Northeast, North Central, South, and West. Internal reliability coefficients range from .66 to .98 . Standard errors of measurement for the GCA range from 4.39 to 4.73 for the various age groups. Test-retest reliability coefficients range from .38 to .90 for the subtests and GCA. Inter-rater reliability coefficients ranged from .74 to .98 . Validity studies with other tests are listed in the manual. The DAS correlated .81 with the WPPSI-R and .77 with the Standford-Binet IV. 
Leiter International Performance Scale (LIPS)(Arthur Adaptation): (see

Appendix D)

Merrill-Palmer Scales of Mental Tests: (see Appendix D)

Stanford-Binet IV:

Authors: Robert L. Thorndike, Elizabeth P. Hagen, Jerome M. Sattler

Date: 1986

Purpose: Measure intelligence

Age Range: 2 thru adult

Time to Administer: one hour

Description: The Stanford-Binet IV contains four designated areas: Verbal Reasoning, Abstract/Visual Reasoning, Quantitative Reasoning, and ShortTerm Memory. These four areas are measured by the use of fifteen subtests. Only eight of the subtests are administered to preschoolers: Vocabulary, Comprehension, Absurdities, Pattern Analysis, Copying, Quantitative, Bead Memory, and Memory for Sentences. Raw scores are converted to three types of standard scores: standard age scores for the subtests, Area Scores, and a Composite Score.

Norms, Reliability, Validity: The standardization sample consisted of 5,013 individuals in 17 age groups. The sample was selected based on the 
1980 census data. Stratification variables included geographic region, community size, ethnic group, age, gender, and socioeconomic status.

Internal consistency reliabilities for the composite score range from .95 to .99 for the 17 different age groups. Reliability coefficients for the various subtests range from .66 to .96 . The technical manual includes test-retest data along with validity data.

Wechsler Preschool and Primary Scales of Intelligence (WPPSI):

Author: David Wechsler

Date: 1967

Purpose: Measure intelligence of young children

Age Range: 4 to $61 / 2$ years

Time to Administer: 45 minutes to one hour

Description: The WPPSI contains eleven subtests: Information, Vocabulary, Arithmetic, Similarities, Comprehension, Picture Completion, Mazes, Block Design, Sentences, Animal House, and Geometric Design. It uses a deviation IQ which has a mean of 100 and a standard deviation of 15 for three types of IQ's: Verbal, Performance, and Full Scale. Raw scores for each subtest are converted to scaled scores.

Norms, Reliability, Validity: The WPPSI was standardized on 1200 
children. The selection of children was based on the U.S. census data for 1960. Internal consistency reliabilities for each of the three IQ's range from .91 to .96 . Subtest reliabilities range from .77 to .87 . Standard errors of measurement for the three IQ's are: Full Scale (2.88), Verbal (3.57), and Performance (3.85). Test-retest reliability for the three scales are: Full Scale (.91), Verbal (.86), and Performance (.89). Validity data is limited in the manual.

Wechsler Preschool and Primary Scales of Intelligence-Revised (WPPSI-R):

Author: David Wechsler

Date: 1989

Purpose: Measure intelligence of young children

Age Range: 3 thru 7 years

Time to Administer: 45 to 60 minutes

Description: The WPPSI-R contains twelve subtests (6 verbal and 6 performance). The WPPSI-R is organized similarly to the WPPSI.

Norms, Reliability, Validity: The WPPSI-R was standardized on 1700 children with an equal number of males and females. Four major geographical regions are represented: Northeast, North Central, South, and 
West. Ethnic groups (White, Black, Hispanic, and Others) are included on a percentage basis similar to what is reported in the 1986 census survey. Internal consistency reliabilities for each of the three IQs range from .85 to .97. Subtest reliabilities range from .54 to .90 . Standard errors of measurement for the three IQs range from 2.81 to 4.98 . Test-retest reliability for the three scales are: Full Scale (.91), Verbal (.89), and Performance (.87). Validity data, reported in the manual, correlates the WPPSI-R with the WPPSI. Coefficients between the three scales are Full Scale (.87), Verbal (.82), and Performance (.82). The validity correlation reported between the WPPSI-R and the Stanford-Binet IV is .74, while that between the WPPSI-R and the McCarthy Scales of Children's Abilities is .81 .

\section{Tests of Development}

\section{Developmental Profile II (DPII):}

Authors: Gerald Alpern, Thomas Boll, and Marsha Shearer

Date: 1980

Purpose: Estimate developmental level of children

Age Range: Birth to 9 years 
Time to Administer: 20 to 30 minutes

Description: The Developmental Profile II includes five scales: Physical Skills, Self-Help, Social, Academic, and Communication. The DP II can be used to determine eligibility for receiving special education and/or related services, as a planning tool to develop IEP's, a measure of a child's progress, and as a method of evaluating an entire educational program. The DP II can be administered either through direct observation of the child or from a third party interview. The administration involves determining if the child does or does not have skills listed in each scale. The child receives credit in months for each developmental skill passed in an area. These passes are added and this total corresponds to the developmental age score for the scale.

Norms, Reliability, Validity: The standardization subjects $(3,008)$ were from Indiana and Washington. The sample characteristics are: Males (1527), Females (1481), Whites (2525), Blacks (424), Other (54). Racial data was available on only 3003 of the 3008 subjects. Reliability and Validity information in the manual refers to the correspondence of the test results and reports from parents and teachers and performance of the child. A reliability study is reported in the manual using Head Start teachers for 
both test-retest and interrater reliability information. The conclusions from these reliability studies is that the "...Developmental Profile generates scores with extremely high scorer, reporter, and test-retest reliability." (Alpern, Boll, \& Shearer, 1980, p.36). The validity study reported in the manual was based on 100 children ( 88 whites and 12 Blacks) with age ranges from 3 months to 12 years. The manual reports a high percentage of agreement between mother's reporting of child's developmental level and the child's actual performance on the DP II.

Learning Accomplishment Profile-Diagnostic (LAP-D): (see Appendix D)

\section{Tests of Language}

Expressive One-Word Picture Vocabulary Test (EOWPVT): (see Appendix D)

Peabody Picture Vocabulary Test-Revised (PPVT-R): (see Appendix D) Preschool Language Scale (PLS) (PLS): (see Appendix D) 


\section{Test of Adaptive Behavior}

\section{Scales of Independent Behavior (SIB):}

Authors: Robert H. Bruininks, Richard W. Woodcock, Richard F.

Weatherman, Bradley K. Hill

Date: 1984

Purpose: Measure functional independence and adaptive behavior of children and adults.

Age Range: Infants to adults

Time to Administer: 20 to 30 minutes

Description: The SIB consists of four adaptive behavior skill clusters encompassing fourteen subscales. The four clusters are: Motor Skills, Social Interaction and Communication Skills, Personal Living Skills, and Community Living Skills. These four clusters are combined to form the Broad Independence Scale. The SIB also has a problem behavior scale that yields four maladaptive indexes. The SIB is administered to a third party who knows the examinee well, such as a parent or teacher. An easel is used during administration and the informant is shown possible responses to items on the easel pages. The SIB yields age equivalents, percentile ranks, standard scores, and normal curve equivalents. 
Norms, Reliability, Validity: A sample of 1,764 individuals was used for standardization. The sample was stratified according to sex, community size, geographic location, socioeconomic status, and race. Internal consistency estimates range from .64 to .95 . Test-retest coefficients range from .78 to .91 and inter-rater reliability estimates from .74 to .86 . 
Adelman, H. S. (1982). Identifying learning problems at an early age: A critical appraisal. Journal of Clinical Child Psychology, 11, 255-261.

Allen, D. A. (1989). Developmental language disorders in preschool children: Clinical subtypes and syndromes. School Psychology Review, $\underline{18}, 442-451$.

Alpern, G., Boll, T., \& Shearer, M. (1980). Developmental Profile II. Aspen, Colorado: Psychological Development Publishers. American Psychiatric Association. (1985). Standards for educational and psychological testing (2nd ed.). Washington, DC: Author. Arthur, G. (1952). Arthur adaptation of the Leiter International Performance Scale. Los Angeles, California: Western Psychological Services.

Barnes, K. E. (1982). Preschool screening. Springfield, Illinois: Charles C. Thomas.

Bracken, B. A. (1987). Limitations of preschool instruments and standards for minimal levels of technical adequacy. Journal of Psychoeducational Assessment, 4, 313-326. 
Bruiniks, R. H., Woodcock, R. W., Weatherman, R. F., \& Hill, B. K., (1984). Scales of Independent Behavior. Allen, Texas: DLM Teaching Resources, Inc.

Brigance, A. H. (1985). Brigance Preschool Screen. North Billerica, Massachusetts: Curriculum Associates.

Castro, G., \& Mastropieri, M. A. (1986). The efficiency of early intervention programs for handicapped children: a meta-analysis. Exceptional Children, 52, 417-424.

Cantwell, D. P. \& Baker, L. (1987). Developmental speech and language disorders. New York, New York: The Guilford Press.

Cattell, P. (1950). Measurement of intelligence of infants and young children. New York, New York: The Psychological Corporation.

Dade County Public Schools. (1991). Special programs and procedures for exceptional students. Miami, FL: Author.

Dunn, L. M., \& Dunn, L. M. (1981). Peabody Picture Vocabulary Test. Circle Pines, Minnesota: American Guidance Service.

Edmiaston, R. K., \& Mowder, B. A. (1985). Early intervention for handicapped children: Efficacy issues and data for school psychologists. Psychology in the Schools, 22, 171-178. 
Elliott, C. D. (1990). Differential Abilities Scale. New York, New York: Harcourt Brace Jovanovich, Inc.

Fewell, R. R., \& Oelwein, P. L. (1991). Effective early intervention:

Results from the model preschool program for children with down syndrome and other developmental delays. Topics in Early Childhood Special Education, 11(1), 56-68.

Frankenburg, W. K., \& Dodds, J. B. (1981). Denver Developmental

Screening Test-Revised. Denver, Colorado: University of Colorado Medical Center.

Funk and Wagnall (1965). Standard dictionary. Britannica World Language Edition. Chicago: Encyclopedia Britannica, Inc., Vol. II.

Gardner, M. F. (1979). Expressive One-Word Picture Vocabulary Test. Novato, California: Academic Therapy Publications.

Gesell, A.L. (1940). The first five years of life: A guide to the study of the preschool child. New York, New York: Harper.

Glaros, A. G., \& Kline, R. B. (1988). Understanding the accuracy of tests with cutting scores: The sensitivity, specificity, and predictive value model. Journal of Clinical Psychology, 44, 1013-1023. 
Griffin, P. M., \& Sanford, A. R. (1975). Learning Accomplishment Profile for Infants. Lewisville, North Carolina: Kaplan Press.

Hammill, D. D. (1974). Evaluating children for instructional purposes. In Jones, R. L., (ED.), Special education in transition. Boston, Massachusetts: Allyn.

Harrison, P.L. (1992). Planning and Evaluating Preschool Screening and Assessment Programs. Child Assessment News, 2(3), 7-12.

IIg, F. L., \& Ames, L. B. (1955). The Gesell Institute's child behavior from birth to ten. New York, New York: Harper.

Ittenbach, R.F., Harrison, P.L., \& Deck, M.D. (1989). Issues in preschool screening. Alabama A.C.D. Journal, 15(2), 37-44.

Jacob, S., Snider , K. P., \& Wilson, J. F. (1988). Validity of the DIAL-R for identifying children with special education needs and predicting early reading achievement. Journal of Psychoeducational Assessment, $\underline{6}$, 289-297.

Lazar, I., \& Darlington, R. (1982). Lasting effects of early education: A report from the consortium for longitudinal studies. Monographs of the Society for Research in Child Development, 47(2-3), Serial No. 195. 
Le May, D. W., Griffin, P. M., \& Sanford, A. R. (1977). Learning Accomplishment Profile Diagnostic Edition. Chapel Hill, North Carolina: Chapel Hill Training Outreach Project.

Lichtenstein, R. (1979). Classificational methods for the psychometric evaluation of screening procedures. Paper presented at the Society for Research in Child Development, San Francisco, California.

Lichtenstein, R. (1981). Comparative validity of two preschool screening tests: Correlational and classificational approaches. Journal of Learning Disabilities, 14, 68-73.

Lichtenstein, R. \& Ireton, H. (1984). Preschool screening. Philadelphia, Pennsylvania: Grune \& Stratton, Inc.

Lichtenstein, R., \& Ireton, H. (1991). Preschool screening for development and educational problems. In B. Bracken (Ed.), The psychoeducational assessment of preschool children, (2nd ed.). 486-513. Needham Heights, Massachusetts: Allyn \& Bacon.

Lillie, D. L. (1975). Early childhood education. Chicago, Illinois: Science Research Associates. 
Mardell-Czudnowski, C., \& Goldenberg, D. (1983). Developmental Indicators for the Assessment of Learning-Revised. Circle Pines, Minnesota: American Guidance Services.

McNulty, B. A., Smith, D. B., \& Soper, E. W. (1983). Appendix to effectiveness of early special education for handicapped children. Report commissioned by the Colorado General Assembly: Colorado State Publications Depository and Distribution Center.

Meehl, P. E. \& Rosen, A. (1955). Antecedent probability and the efficiency of psychometric signs, patterns, or cutting scores. Psychological Bulletin, 52, 194-216.

Meisels, S. J., Harbin, G., \& Modigliani, K. (1988). Formulating optimal state early childhood intervention policies. Exceptional Children, $\underline{55}$, 159-165.

Percival, R. R., \& Poxon, S. (1972). Dallas Preschool Screening Test. Dallas, Texas: Dallas Educational Services.

Salvia, J., \& Ysseldyke, J. E. (1977). Assessment in special and remedial education. Boston, Massachusetts: Houghton Mifflin.

Sanford, A. R. (1970). The Learning Accomplishment Profile. WinstonSalem, North Carolina: Kaplan Press. 
Satz, P., \& Fletcher, J.M. (1979). Early screening tests: Some uses and abuses. Journal of Learning Disabilities, 12, 65-69.

Scott, K., \& Hogan, A. (1982). Methods for the identification of high-risk and handicapped infants. In C. Ramey, \& P. Trohanis (Eds.), Finding and educating high risk and handicapped infants, 213-242. Baltimore, Maryland: University Park Press.

Sommers, R. K. (1989). Language Assessment: Issues in the use and interpretations of tests and measures. School Psychology Review, 18, $452-462$.

Southworth, L. E., Burr, R. L., \& Cox, A. E. (1981). Screening and evaluating the young child: A handbook of instruments to use from infancy to six years. Springfield, Illinois: Charles C. Thomas.

Stewart, J. M., Hester, E. J., \& Taylor, O. L. (1986). Prevalence of language, speech, and hearing disorders in an urban preschool black population. Journal of Childhood Communication Disorders, 2, 107-123. Stutsman, R. (1931). Merrill-Palmer Scale of Mental Tests. Los Angeles, California: Stoelting Publishers. 
Suen, H. K., Mardell -Czudnowski, C., \& Gollenberg, D. S. (1989). Classification reliability of the DIAL - R preschool screening test. Educational and Psychological Measurement, 49, 673-680.

Thorndike, R. L., Hagen, E. P., \& Sattler, J. M. (1986). $\underline{\text { Stanford-Binet }}$ IV. Chicago, Illinois: The Riverside Publishing Company.

Thurman, S. K., \& Widerstrom, A. H. (1985). Young children with special needs: A developmental and ecological approach. Boston, Massachusetts: Allyn and Bacon.

Wechsler, D. (1967). Wechsler Preschool and Primary Scales of Intelligence-Revised. New York, New York: Harcourt Brace Jovanovich, Inc.

Wechsler, D. (1989). Wechsler Preschool and Primary Scales of Intelligence-Revised. New York, New York: Harcourt Brace Jovanovich, Inc.

Wilson, B. J., \& Reichmuth, Sr. M. (1985). Early-screening programs: When is predictive accuracy sufficient? Learning Disabilities Quarterly, $\underline{8}, 182-188$. 
Ysseldyke, J. E., \& O'Sullivan, P. J. (1987). Predicting preschool screening referral rates from district demographic data. Journal of School Psychology, 25, 119-29.

Zimmerman, I., Steiner, V., \& Evatt, R. (1969). Preschool Language Scale. New York, New York: Harcourt Brace Jovanovich, Inc. 


\section{Bibliography}

Allen, D. V., \& Bliss, L. S. (1987). Concurrent validity of two language screening tests. Journal of Communication Disorders, 20, 305-317.

Anastasi, A. (1988). Psychological testing. New York, New York:

Macmillan.

Barnes, K. E. (1978). The Jansky Predictive Index. In W.K.

Frankenburg (Ed.), Proceedings of the second international conference on developmental screening. Denver, Colorado: University of Colorado.

Barnett, D. W., Faust, J., \& Sarmir, M. A. (1988). A validity study of two preschool screening instruments: The LAP-D and DIAL-R. Contemporary Educational Psychology, 13, 26-32.

Buck, A., \& Gart, J. (1966). Comparison of a screening test and a reference test in epidemiological studies. American Journal of Epidemiology, $\underline{83}$, 586-592.

Burr, R. L., Cox, A. E., \& Southworth, L. E. (1980). Screening and evaluating the young child. Springfield, Illinois: Charles C. Thomas. 
Byrne, J.M., Smith, D. J., \& Backman, J. E. (1987). Cognitive impairment in preschoolers: Identification using the Personality Inventory for Children-Revised. Journal of Abnormal Psychology, 15, 239-246.

Carnine, D. W., \& Kameenui, E. J. (1990). The general education initiative and children with special needs: A false dilemma in the face of true problems. Journal of Learning Disabilities, 23, 141-144, 148.

Deiner, P. L., \& Peters D. L. (1987). The reality of early childhood: Head start and the child development associate (CDA). Topics in Early Childhood Special Education, 7(3), 1-58.

Diamond, K. E., \& Le Furgy, W. G. (1988). Screening for developmental handicaps: Outcomes from an early childhood screening program. Physical and Occupational Therapy in Pediatrics, 8 (1), 43-59.

Fletcher, J. M. (1979). Early screening tests: Some uses and abuses. Journal of Learning Disabilities, 12(1), 65-69.

Frankenburg, W. K. (1974). Selection of diseases and tests in pediatric screening. Pediatrics, 54, 612-616.

Gallagher, J. J., \& Bradley, R. H. (1972). Early identification of developmental difficulty. In I. J. Gordon (Ed.), Early childhood education. Chicago: University of Chicago Press. 291-303. 
Gesell , A.L., \& Amatruda, C.S., (1941). Developmental Diagnosis. New York, New York: Paul B. Hoeber.

Goodwin, L. D., \& Goodwin, W. L. (1991). Using generalizability theory in early childhood special education. Journal of Early Intervention, 15, 193-204.

Greenberg, B. (1987). Using microcomputers and mainframes for data analysis in the social sciences. New York, New York: Merrill.

Harrington, R. G. (1984). Preschool screening: The school psychologist's perspective. School Psychology Review, 13, 363-374.

Hasenstab, S. M. (1980). Language assessment of the preschool child with language delay. Paper presented at the Annual International Convention of The Council for Exceptional Children, Philadelphia, Pennsylvania.

Hicks, C.P. (1982). Fundamental concepts in the design of experiments. Fort Worth, Texas: Holt, Rinehart, \& Winston, Inc. Jansky, J., \& de Hirsch, K. (1972). Preventing reading failure: prediction, diagnosis, intervention. New York, New York: Harper \& Row. Johnson, H. W. (1980). Preschool test description. Springfield, Illinois: Charles C. Thomas. 
Keogh, B. K. (1983). Early identification: One component of comprehensive services for at-risk children. Topics In Childhood Special Education, $\underline{3}(3), 7-16$.

Kerlinger,F.N. (1973). Foundations of behavioral research. Fort Worth, Texas: Holt, Rinehart, \& Winston, Inc.

Kerns, G. M., \& Mallory, B. L. (1988). Consequences of categorical labeling of preschool children. Topics In Early Childhood Special Education, $8(3), 39-50$.

Lindsay, G. A., \& Wedell, K. (1982). The early identification of educationally at risk children revisited. Journal of Learning Disabilities, $15,212-217$.

McCauley, R., \& Swisher, L. (1984). Psychometric review of language and articulation tests for preschool children. Journal of Speech and Hearing Disorders, 49 , 34-41.

Meisels, S. J. (1978). Developmental screening in early childhood: A guide. Washington, D.C.: National Association for the Education of Young Children. 
Meisels, S. J. (1984). Prediction, prevention and developmental screening in the EPSDT program. In H. W. Stevenson and A. E. Siegal (Eds.). Child development research and social policy, 267-317, V1. Chicago, Illinois: University of Chicago Press.

Meisels, S. J. (1989). Can developmental screening tests identify children who are developmentally at risk, Pediatrics, $\underline{83}, 578-585$.

Mercer, C. D., Algozzine, B., \& Trifiletti, J. (1979). Early identification - An analysis of the research. Learning Disability Quarterly, 2(2), 12-24.

Miller, L. J., \& Sprong, T. A. (1986). Psychometric \& qualitative comparison of four preschool screening instruments. Journal of Learning Disabilities, 19, 480-484.

O’Sullivan P. J., \& Ysseldyke, J. E. (1987). Predicting preschool screening referral rates from district demographic data. Journal of School Psychology, 25, 119-129.

Paget, K.D., \& Nagle, R. J. (1986). A conceptual model of preschool assessment. School Psychology Review, 15, 154-65.

Salvia, J., \& Ysseldyke, J. E. (1991). Assessment, (5th ed.). Boston, Massachusetts: Houghton Mifflin. 
Sattler, J. M. (1988). Assessment of children. San Diego, California:

Jerome M. Sattler.

Satz, P., \& Fletcher, J.M. (1988). Early identification of learning disabled children: An old problem revisited. Journal of Consulting and Clinical Psychology, 56, 824-829.

Sheehan, R., \& Sites, J. (1989). Implications of P. L. 99-457 for assessment. Topics in Early Childhood Special Education, 9, 103-115. Slavin, R. E., Madden, N. A., Karweit, N. L., Dolan, L., Wasik, B. A., Shaw, A., Mainzer, K. L., \& Haxby, B. (1991). Neverstreaming: Prevention and early intervention as an alternative to special education. Journal of Learning Disabilities, 24, 373-378.

Stevenson, J. (1984). Predictive value of speech and language screening. Developmental Medicine \& Child Neurology, 26, 528-538.

Ysseldyke, J. E. (1985). Current screening and diagnostic practices for identifying young handicapped children. Early Childhood Assessment Project Research Report \#2. Minnesota University, Minneapolis. (ERIC Document Reproduction Service No. ED 269 951). 